\title{
DATOS SOBRE LA FLORA Y VEGETACIÓN DEL PARQUE NATURAL DE LOS ALCORNOCALES (CÁDIZ-MÁLAGA, ESPAÑ)
}

\author{
Andrés V. PÉREZ LATORRE, Antonio GALÁN DE MERA, Patricia NAVAS, \\ David NAVAS, Yolanda GIL y Baltasar CABEZUDO
}

RESUMEN. Datos sobre la flora y vegetación del Parque Natural de Los Alcornocales (Cádiz-Málaga, España). Se ha realizado un estudio de la flora, vegetación y paisaje vegetal del Parque Natural de Los Alcornocales, situado en las provincias de Cádiz y Málaga (SW de la Península Ibérica, Andalucía). La altitud máxima en el Parque es de $1091 \mathrm{~m}$.; la litología dominante es a base de areniscas silíceas y arcillas salvo en el NW donde predominan las calizas. Las precipitaciones son muy abundantes (entre 800 y 1400 $\mathrm{mm}$.) así como el régimen de nieblas causado por la cercanía al Estrecho de Gibraltar; se reconocen dos pisos bioclimáticos, termo y mesomediterráneo con oceanidad acusada. Como resultado se han catalogado unos 1300 taxones de plantas vasculares, destacandose en este trabajo las especies protegidas, endemismos o primeras citas para Andalucía Occidental, de entre ellas 9 son pteridófitos relícticos de gran valor fitogeográfico. Se han inventariado un total de 89 asociaciones y comunidades. Se realizan comentarios sobre sintaxones de rango superior a asociación. Se lectotipifica una subasociación y se neotipifica una asociación. Se describen como nuevos sintáxones un orden (Rhododendro pontici-Prunetalia lusitanicae), dos alianzas (Rhododendro pontici-Prunion lusitanicae y Salicion pedicellatae), 6 asociaciones, 4 subasociaciones y 6 combinaciones. Se reconocen 6 series climatófilas de las cuales es nueva una de quejigares sobre calizas (Oleo sylvestris-Querceto broteroi $S$ ), otras dos son de alcornocales sobre areniscas (Quercus suber), una de quejigares morunos en zonas más húmedas (Quercus canariensis), una de robledales en las cumbres (Quercus pyrenaica) y una de encinares sobre calizas en zonas basales (Quercus rotundifolia). Como serie mixta ligada a las condiciones de los vertisoles se desarrolla una serie de acebuchales (Olea sylvestris). Como vegetación permanente sobre calizas aparecen algarrobales (Ceratonia siliqua), sobre areniscas aparecen enebrales (Juniperus oxycedrus), en cumbres azotadas por el viento reconocemos una comunidad con quejigueta ( $Q$ uercus lusitanica) y una variante relictual edafoxerófila sobre areniscas con pino negral (Pinus pinaster). Como serie mixta ligada a las condiciones de humedad tanto ambiental como edáfica se desarrollan ojaranzales (Rhododendron ponticum) similares a las formaciones de laurisilva macaronésica. Las series edafohigrófilas del Parque son: las alisedas (Alnus glutinosa), las saucedas (Salix pedicellata), las choperas (Populus alba), las fresnedas (Fraxinus angustifolia), los adelfares (Nerium oleander), los tarajales (Tamarix africana) y los brezales edafohidrófilos (Erica ciliaris). Existen así mismo mosaicos de comunidades ligadas a corredores ecológicos, entornos humanos, rupícolas, epífitas, aerohalófilas, de medios acuáticos y salinos. Finalmente se presentan el esquema sintax onómico comentado, las tablas fitosociológicas correspondientes a las novedades y un mapa de las series de vegetación del Parque.

Palabras clave. Flora, vegetación, sintaxonomía, Los Alcornocales, Andalucía, España.

Trabajo realizado en el marco del convenio 807/031050 firmado entre la Consejería de Medio Ambiente de la Junta de Andalucía y la Universidad de Málaga (Dpto. Biología Vegetal). 
SUMMARY. Data on the flora and vegetation of the Natural Park of Los Alcornocales (Cádiz-Málaga, Spain). We have carried out a study about the flora, vegetation and landscape inthe Natural Park Los Alcornocales, located in the provinces of Cádiz and Málaga (SW of the Iberian Peninsula, Andalusia). The maximum altitude in the Park is $1091 \mathrm{~m}$.; the dominant litology is characterised by sandstones and clays, in the NW prevail the limestones. The annual rainfalls are very abundant (between 800 and $1400 \mathrm{~mm}$.) as well as the fogs regime, caused by the nearness to the Strait of Gibraltar; we have recognized two bioclimactic belts, thermo (annual mean temperature $17-18^{\circ} \mathrm{C}$ ) and mesomediterranean $\left(14-16^{\circ} \mathrm{C}\right)$ with accused oceanity. As a result, more than 1300 taxa of vascular plants have been catalogued, emphasizing in this work 77, because they are protected species, endemics or first records for western Andalusia; among them, 9 species are relictic ferns and have a great phytogeographic value. A total of 89 associations and communities have been inventoried. We have accomplished commentaries on sintaxa with a range superior to association. We lectotypified a subassociation and one association is neotypified. We describe as new sintaxa one order (Rhododendro pontici-Prunetalia lusitanicae), two alliances (Ri ododendro ponticiPrunion lusitanicae and Salicion pedicellatae), 6 associations, 8 subassociations aid 1 combination. We have recognized 6 climactic series, among them one is new and characterised by forests of Quercus brotero $i$ on calcareous soils (Oleo sylvestris-Querceto broteroi $S$ ), other two are forests of Quercus suber on sandstones, another one is characterised by Quercus canariensis in wet slopes, one of Quercus pyrenaica in the summits and one of Quercus rotundifolia on lowland calcareous soils. As a mixed serie bound to the conditions of the vertisols occurs forests ofOlea sylvestris. As permanent vegetation on calcareous solis appears Ceratonia siliqua; on sandstones appears Juniperus oxycedrus; in summits flogged by strong winds we recognize a community with Quercus lusitanica and on rocky sandstones a relictual variant with Pinus pinaster. A mixed serie bound to the environmental humidity conditions as well as to wet soils is characterized by Rhododendron ponticum, similar to the macaronesian laurisilva. The series linked to rivers in the Park are characterised by: Alnus glutinosa (permanent stream rivers on sandstones), Salix pedicellata (partially droughted rivers), Populus alba (fluvisols), Fraxinus angustifolia (riverine sandyargilic soils), Nerium oleander (totally droughted rivers), Tamarix africana (erratic or halophyll streams) and wet heaths with Erica ciliaris. Also exist communities mosaics bound to ecological corridors, human environments, rocks and cliffs, epiphytes, aerohalophylls and those tipycal of saline and aquatic environments. Finally, a commented syntaxonomic scheme, some inventories tables corresponding to the new or commented syntaxa and a map of the vegetation series of the Park are presented

Key words. Flora, vegetation, sintaxonomy, Los Alcornocales, Natural Park, Andalucía, España

\section{INTRODUCCIÓN}

Siguiendo con los trabajos básicos sobre los espacios naturales protegidos de Andalucía (Pérez Latorre et al., 1998), como paso previo y necesario para su gestión, iniciamos en el año 1998, en el marco de un convenio firmado con la Consejería de Medio Ambiente de la Junta de Andalucía, los estudios sobre cartografía de la diversidad vegetal del Parque Natural de los Alcornocales (Cádiz). Fue necesario un estudio inicial sobre las características edafológicas y climatológicas como paso previo al estudio de la flora y vegetación. Este conocimiento nos permitió un análisis de las agrupaciones de los elementos florísticos en unidades de vegetación, paso previo de una política adecuada de conser-vación de especies y hábitats. Durante el desarrollo de la base cartográfica y de inventariación, se han obtenido una serie de datos florísticos y fitosociológicos que consideramos de interés no solo para el parque sino para todo el sector Algíbico. Nuestro objetivo, en el trabajo que ahora publicamos, es dar a conocer las principales novedades fitosociológicas, las serie de vegetación en las que se incluyen y sobre todo un esquema sintaxonómico, por supuesto no definitivo, de todo el complejo de comunidades que han sido utilizadas para el estudio cartográfico. 


\section{MATERIAL Y MÉTODOS}

\section{Área de estudio}

El Parque Natural Los Alcornocales (Cádiz-Málaga, Andalucía) es la extensión de alcornoques (Quercus suber) más meridional de Europa. Al norte limita con el río Majaceite (embalse de los Hurones) y la sierra de Ubrique, al este con el valle del río Hozgarganta, al oeste con la campiña gaditana de Medina Sidonia y Jerez de la Frontera, y al sur con los arenales de Tarifa y el estrecho de Gibraltar. Las sierras más importantes que forman su orografía de $\mathrm{N}$ a S son: la sierra de las Cabras (667 m), la sierra del Aljibe (Picacho $884 \mathrm{~m}$, Montero $912 \mathrm{~m}$, Aljibe $1092 \mathrm{~m}$ ), la sierra de los Melones (Loma del Sanguinar 398 m), la sierra Blanquilla (665 m), la sierra de Montecoche (563 m), la sierra del Niño (Cruz del Romero $780 \mathrm{~m})$, la sierra de la Luna (786 m), la sierra de Ojén (Utrera $718 \mathrm{~m}$ ) y la sierra de Fates (Órganos $657 \mathrm{~m}$ ). Las sierras del Aljibe, de los Melones y de la Luna forman la divisoria hidrográfica entre los ríos que vierten al océano Atlántico y al mar Mediterráneo. El único río tributario al Atlántico es el Barbate, con varios afluentes que recorren el Parque de E a O: Rocinejo, Alberite, Celemín y Almodóvar. En cambio, desembocan en el mar Mediterráneo los ríos Hozgarganta, Guadarranque, Guadacorte, Palmones y de la Miel.

El edificio litológico de la mayor parte del territorio está constituido por las unidades alóctonas del Campo de Gibraltar, la unidad del Aljibe y al norte, la unidad Subbética. Está constituido por colinas margosas y areniscas cuarzosas del Aljibe que se orientan de $\mathrm{N}$ a S y se flexionan cerca de Tarifa formando alineaciones E-O (Chauve, 1968). El Trías subbético está muy bien representado en las arcillas y margas de los valles del Celemín y Benalup, al $\mathrm{O}$ del territorio, mientras que los afloramientos de calizas jurásicas se encuentran en la sierra de las Cabras, la Peña del Almed y el Peñón del Berrueco.
El Parque Natural disfruta de clima mediterráneo, con los máximos de lluvia durante el invierno (estacionalidad de las precipitaciones, EST, de tipo IOPV; Pérez Latorre et al., 1993; Nieto Caldera et al., 1994) y con al menos dos meses de aridez durante el verano, aunque en determinados puntos la humedad en esta estación es alta influyendo directamente sobre la vegetación. De los seis pisos bioclimáticos existentes en la Región Mediterránea (Rivas Martínez et al., 1991) solamente existen en el territorio el termo y mesomediterráneo. Dentro de los pisos bioclimáticos es posible reconocer horizontes o subpisos en virtud de cambios en las series de vegetación, faciaciones o comunidades que coinciden también con los límites de algunos bioindicadores. Son bioindicadores del piso termomediterráneo: Acanthus mollis subsp. platyphyllos, Aristolochia baetica, Arenaria emarginata, Armeria hirta, Asparagus albus, Calicotome villosa, Chamaerops humilis, Culcita macrocarpa, Diplazium caudatum, Dryopteris guanchica, Festuca arundinacea subsp. atlantigena, Osyris quadripartita, Polypodium macaronesicum, Psilotum nudum, Pteris incompleta, Rubia agostinhoi, Scrophularia laxiflora, Ulex baeticus subsp. scaber y Vandenboschia speciosa. Son bioindicadores del piso mesomediterráneo: Daphne laureola subsp. latifolia (puntualmente en el termomediterráneo), Deschampsia stricta, Helianthemum nummularium, Lotus glareosus var. villosus, Pedicularis sylvatica subsp. lusitanica, Prunus spinosa, Quercus xfontqueri y $Q$. pyrenaica.

Según la distribución de determinadas plantas dentro del piso mesomediterráneo podemos distinguir dos variantes climáticas o subpisos: mesomediterráneo cálido (It $>280$ ) y mesomediterráneo fresco $($ It $<280)$. Se puede determinar el piso mesomediterráneo cálido por la ausencia de elementos termomediterráneos genuinos y la presencia de otras plantas térmicas sensibles a las heladas: 
Myrtus communis, Olea europaea var. sylvestris, Phlomis purpurea, Pistacia lentiscus, Rhododendron ponticum y Rubia peregrina subsp. longifolia. El subpiso fresco del piso mesomediterráneo es muy puntual en las cumbres del Aljibe, de la Luna, del Castillo, del Niño y Ojén, donde se manifiesta con la aparición de comunidades de rebollos (Quercus pyrenaica) y brezales característicos ("herrizas") por encima de los 700-800 m., situadas de cara a los vientos atlánticos.

La zona de estudio, se encuentra sometida a una elevada influencia marítima. Dentro de la provincia de Cádiz, en la costa, el frío se hace menor y las heladas desaparecen, es decir, que las mínimas absolutas anuales (ma) son menos bajas y se aproximan más a las máximas absolutas anuales (Ma). Aplicando esta amplitud térmica, al irnos alejando de la costa hacia las cumbres, "ma» se va haciendo menor y aparecen las heladas aumentando la continentalidad. De acuerdo con el índice de continentalidad de Rivas Martínez et al. (1990 a), en el Parque Natural sólo distinguimos los tipos oceánico y semioceánico, que quedan reflejados en formaciones tan características como los brezales aljíbicos de influencia atlántica, la vegetación de tipo lauroide, los pastizales vivaces de elevada biomasa y los herbazales escionitrófilos de lindero de los bosques.

De los ombrotipos reconocidos en la Región Mediterránea (Rivas Martínez et al., 1991), en el territorio estudiado existen tres, subhúmedo, húmedo e hiperhúmedo (desde subhúmedo superior hasta hiperhúmedo inferior), lo que quiere decir que la precipitación es bastante alta. Ésto es debido al relieve y a la apertura de las sierras hacia el golfo de Cádiz; es decir, a los vientos húmedos de poniente. También las precipitaciones orográficas adquieren una gran importancia. Las masas de aire del Atlántico ascienden por las laderas y se enfrían por expansión, aumentando la humedad relativa del aire, provocando la saturación y condensación con nubosidad de tipo cumuliforme y se llega a formar un bosque de nieblas. Lo que aleja esta situación de un bosque tropical es la xericidad estival aunque ésta puede verse amortiguada por la formación de nieblas causadas por el viento de Levante, que si bien se origina en la baja térmica sahariana y es un viento seco, tiene un elevado poder de condensación del agua del mar.

El territorio que ocupa el Parque Natural Los Alcornocales participa de la siguiente división fitogeográfica de acuerdo con las clasificaciones de Galán de Mera y Vicente Orellana (1996), para el SO de la Península Ibérica, y Pérez Latorre et al. (1996) y Cabezudo et al. (1998) para la provincia de Cádiz y O de la de Málaga:

Reino Holártico

Región Mediterránea

Subregión Mediterránea Occidental

Superprovincia Iberomarroquí-Atlántica Provincia Tingitano-OnuboAlgarviense

Sector Aljíbico

Subsector Aljíbico [áreas silíceas sin relictos tropicales pteridofíticos] 1. Distrito Aljúbico

Subsector Algecireño [áreas silíceas con relictos tropicales pteridofíticos]

2. Distrito Algecireño Subsector Sidonense [áreas calizas y margo-yesosas]

3. Distrito Sidonense

4. Distrito Cabrerense

El distrito Cabrerense, no descrito anteriormente, comprende las sierras calizas de las Cabras, de la Sal y del Valle (Cádiz), al NO del Parque Natural. Se caracteriza especialmente por los quejigales basófilos termomediterráneos de Oleo sylvestrisQuercetum broteroi y por los lentiscares con 
madroños y algarrobos de AsparagoRhamnetum oleoidis ceratonietosum siliquae que albergan plantas que permiten diferenciar este territorio del resto del subsector Sidonense como Halimium atriplicifolium, Juniperus phoenicea, Pistacia terebinthus, Ptilostemon hispanicus, Quercus broteroi, $Q \times$ marianica, y Sanguisorba hybrida.

\section{Metodología}

Existen estudios básicos (Galán de Mera, 1993 y Pérez Latorre, 1993) sobrela flora y vegetación del Parque Natural, otros sobre aspectos de su biodiversidad (Ojeda et al., 1995, 1996), de su relación fitogeográfica con la península Tingitana (Nezadal et al., 1994; Pérez Latorre et al., 1996; Deil, 1997) o sobre su conservación mediante la Directiva Comunitaria 92/43 de "Hábitats" (Gil Jiménez et al., 1996). En éste trabajo se realiza un catálogo de la flora de interés y se profundiza en el estudio fitosociológico y sinfitosociológico de la vegetación, incidiendo en su ecología y fitogeografía y en sus relaciones con territorios norteafricanos y macaronésicos.

La flora vascular herborizada está conservada en los herbarios básicos de consulta sobre el Parque (MGC y USP), y desde la publicación de la Flora Vascular de Andalucía Occidental, se han podido denunciar nuevos e interesantes hallazgos (Galán de Mera, 1991, 1994, 1995; Galán de Mera et al., 1995 a; Sánchez García y Galán de Mera, 1997; García Murillo y Palacios, 1998; Garrido Díaz e Hidalgo Maqueda, 1998). Estas novedades son enumeradas otra vez en el capítulo de «resultados», junto a otro grupo de plantas endémicas (aljíbicas, tingitanas o tingitanoonubo-algarvienses) que constituyen rarezas en el territorio o que tienen una gran importancia fitogeográfica. Cada taxon se acompaña de su tipo biológico, corología, posición bioclimática y fitosociológica en el
Parque. En algunos casos se hacen observaciones con información adicional, como su status de conservación según el Decreto 104/1994 de la Junta de Andalucía sobre "Protección de Flora Amenazada".

Para la identificación de las especies de la Flora se han utilizado las obras "Flora Vascular de Andalucía Occidental", "Flora Iberica" y "Flora Europaea". Para la descripción de las unidades de vegetación se ha seguido el método fitosociológico de Braun-Blanquet (1979) con las matizaciones aportadas por Schuhwerk (1990), y para las nuevas propuestas nomenclaturales el Código de Nomenclatura Fitosociológica (CNF- Barkman et al., 1986). Los diferentes estadíos dinámicos de la vegetación han sido analizados, en general, según la metodología unidireccional de las series de vegetación (Rivas Martínez, 1987).

\section{RESULTADOS}

\section{Flora de interés}

\section{Andropogon distachyos $\mathrm{L}$.}

Hemicriptófito. Paleotropical, S Europa y N Africa. Termo-mesomediterráneo. Albardinales, suelos esqueléticos (Hyparrhenietalia podotrichae). Poco frecuente en la provincia de Cádiz.

\section{Armeria hirta Willd. subsp. hirta}

Hemicriptófito. Aljíbico, onubense, hispalense y tingitano. Termomediterráneo. Pastizales vivaces (Agrostion castellanae).

\section{Asphodelus roseus Humbert \& Maire}

Criptófito. Iberomarroquí-atlántico. Termomesomediterráneo. Brezales (Stauracanthenion boivinii).

\section{Asplenium billotii Schultz}

Hemicriptófito. Circummediterráneo-macaronésico. Termo-mesomediterráneo. Comunidades rupícolas terrosas. (Bartramio-Polypodion serrulati). Especie vulnerable. 
Bellis rotundifolia (Desf.) Boiss. \& Reuter

Hemicriptófito. Aljíbico, bermejense y mauritánico. Termo-mesomediterráneo. Pastizales humícolas (Stachyo lusitanicae-Cheirolophenion sempervirentis).

Biscutella lyrata L. (= Biscutella microcarpa DC.) Hemicriptófito. Aljíbico y onubense. Termomesomediterráneo. Pastizales xerófilos (Festucion elegantis).

Brachypodium sylvaticum (Hudson) Beauv. var. gaditanum (Talavera) Galán de Mera

Hemicriptófito. Aljíbico. Termomesomediterráneo. Pastizales de lindero (Origanion virentis).

Bupleurum foliosum Salzm. ex DC.

Caméfito. Aljíbico, tingitano y bermejense. Termo-mesomediterráneo.

Brezales (Stauracanthenion boivinii).

\section{Callitriche cribosa Schotsman}

Hidrófito. Oeste de la Región Mediterránea. Termo-mesomediterráneo. Comunidades acuáticas temporales (Ranunculion aquatilis). Poco frecuente en la provincia de Cádiz.

\section{Callitriche regis-jubae Schotsman}

Hidrófito. Oeste de la Región Mediterránea. Termomediterráneo. Comunidades de aguas distróficas (Ranunculion aquatilis). Poco frecuente en la provincia de Cádiz.

Carex elata All. subsp. mauritanica (Boiss. \& Reuter) Galán de Mera (= Carex acuta L. subsp. mauritanica (Boiss. \& Reuter) Asensi \& Díez Garretas)

Criptófito: helófito. Aljíbico y tingitano. Termo-mesomediterráneo. Comunidades de grandes cárices (Caricenion broteraniae).

\section{Celtis australis L.}

Mesofanerófito. Mediterráneo occidental, surasiático. Termomediterráneo. Comunidades arbustivas subrupícolas y setos (Querco-Oleion sylvestris). Especie vulnerable.

\section{Cheilanthes guanchica Bolle}

Hemicriptófito. Oeste de la Región
Mediterránea. Termo-mesomediterráneo. Fisurícola (Phagnalo-Cheilantion maderensis). Muy rara en la provincia de Cádiz.

Cistus ladanifer L. subsp. africanus Dans. (= C. ladanifer L. var. petiolatus Maire, $C$. ladanifer var. tangerinus Pau)

Microfanerófito. Bermejense, aljíbico, tingitano y rifeño. Termo-mesomediterráneo. Jarales (Ulici-Calicotomenion villosae).

Christella dentata (Forsskål) Brownsey \& Jermy

Hemicriptófito. Paleotropical y aljíbico. Termomediterráneo. Aunque en la actualidad la única población habita medios encharcados y nitrificados (Plantaginetalia majoris), la vegetación potencial corresponde a ojaranzales (PrunoLauretea azoricae). Especie en peligro.

\section{Crepis tingitana Ball}

Criptófito. Tingitano-Onubo-Algarviense. Termomediterráneo. Comunidades escionitrófilas (Geranio-Anthriscion).

\section{Culcita macrocarpa C. Presl}

Hemicriptófito. Íbero-macaronésico. Termomediterráneo. Ojaranzales higrófilos con relictos tropicales (Pruno-Lauretea azoricae). Especie en peligro.

\section{Cynara baetica (Sprengel) Pau}

Hemicriptófito. Bético y aljíbico. Termomesomediterráneo. Cardales nitrófilos (Carthametalia lanati).

\section{Cytisus tribracteolatus Webb}

Nanofanerófito. Aljíbico. Termomesomediterráneo. Vegetación de fisuras anchas (Stauracanthenion boivinii, Rumici-Dianthion lusitani).

Daphne laureola L. subsp. latifolia (Cosson) Rivas Martínez

Nanofanerófito. Suribérico-norteafricano. (Termo)-mesomediterráneo. Ojaranzales (Rhododendro-Prunetalia lusitanicae). Es destacable la ecología desviante respecto a sus preferencias típicas: bosques de pinsapos y quejigos de la montaña bética (Aceri-Quercion fagineae, Paeonio-Abietienion). 
Davallia canariensis (L.) Sm.

Hemicriptófito, Epífito. Cántabro-atlántico, tingitano-onubo-algarviense, macaronésico. Termomesomediterráneo. Comunidades epífitas y de grietas terrosas (Bartramio-Polypodion serrati).

Deschampsia stricta (Gay) Hackel

Hemicriptófito. Iberomarroquí-atlántico. Mesomediterráneo. Pastizales xerofíticos (Festucion elegantis).

Digitalis purpurea L. subsp. bocquetii Valdés

Hemicriptófito. Aljíbico. Termomesomediterráneo. Pastizales humícolas de lindero (Stachyo lusitanicae-Cheirolophenion sempervirentis).

Diplazium caudatum (Cav.) Jermy

Hemicriptófito. Aljíbico-macaronésisco. Termomediterráneo. Ojaranzales higrófilos con relictos tropicales (Rhododendro-Prunion lusitanicae).

\section{Drosophyllum lusitanicum (L.) Link}

Hemicriptófito. Iberomarroquí-atlántico. Termo-mesomediterráneo. Brezales xerófilos (Stauracanthenion boivinii). Especie vulnerable.

Dryopteris guanchica Gibby \& Jermy.

Hemicriptófito. Ibero-macaronésico. Termomediterráneo. Quejigales y ojaranzales (Quercion broteroi, Pruno-Lauretea azoricae). Especie considerada extinta en el Parque.

Erigeron karvinskianus DC.

Hemicriptófito. Neotropical (termomesomediterráneo). Muros nitrificados (Parietarietalia). No citada en la Flora de Andalucía Occidental.

Festuca baetica Hackel ex Aschers. \& Graebn.

Hemicriptófito. Bético, aljíbico y mauritánico. Termo-mesomediterráneo. Pastizales xerofíticos (Festucion elegantis).

\section{Festuca boissieri Janka}

Hemicriptófito. Aljíbico y tingitano. Termomediterráneo. Ojaranzales higrófilos (Rhododendro-Prunion lusitanicae).
Frangula alnus Miller subsp. baetica (Reverchon \& Willk.) Rivas Goday ex Devesa

Microfanerófito. Iberomarroquí-atlántico. Termo-mesomediterráneo. Ojaranzales higrófilos (Rhododendro-Prunion lusitanicae).

Fumana laevipes (L.) Spach

Caméfito. Mediterráneo. Termomesomediterráneo. Matorrales basófilos (CistoMicromerietea). No citada en la Flora de Andalucía Occidental.

Genista tridens (Cav.) DC.

Caméfito. Tingitano-onubo-algarviense. Termo-mesomediterráneo. Brezales (Stauracanthenion boivinii).

Helianthemum nummularium (L.) Miller (= H. chamaecistus Miller)

Caméfito. Eurosiberiano y mediterráneo. Mesomediterráneo. Brezales (Ericion umbellatae). No citada en la Flora de Andalucía Occidental.

\section{Holcus grandiflorus Boiss. \& Reuter}

Hemicriptófito. Aljíbico. Termomesomediterráneo. Brezales (Stauracanthenion boivinii).

Hypochaeris radicata L. subsp. platylepis (Boiss.) Jahandiez \& Maire

Hemicriptófito. Bético, aljíbico y mauritánico. Termo-mesomediterráneo. En pastizales vivaces (Molinio-Arrhenatheretea).

\section{Ilex aquifolium $\mathrm{L}$.}

Mesofanerófito. Termo-mesomediterráneo. Ojaranzales y quejigales (Rhododendro-Prunetalia spinosae, Quercion broteroi). Especie vulnerable.

Iris filifolia Boiss.

Criptófito. Aljíbico, bético y tingitano. Termomesomediterráneo. En jarales (UliciCalicotomenion).

Isoetes durieui Bory.

Criptófito. Mcditerráneo-occidental. Termomediterráneo. Comunidades efímeras de juncales enanos (Preslion cervinae). Especie vulnerable. 
Juncus $x$ donyanae Fernández-Carvajal $(=J$. rugosus Steudel $\mathrm{x} J$. striatus Schousboe ex E.H.F. Meyer)

Hemicriptófito. Tingitano-onubo-algarviense. Termomediterráneo. Juncales acidófilos (Juncion acutiflori).

\section{Juncus rugosus Steudel}

Hemicriptófito. Tingitano-onubo-algarviense. Termo-mesomediterráneo. Juncales acidófilos (Juncion acutiflori).

\section{Juniperus oxycedrus L.}

Microfanerófito. Mediterráneo. Termomesomediterráneo. Enebrales xerófilos (PinoJuniperion phoeniceae).

\section{Klasea alcalae (Cosson) J. Holub}

Hemicriptófito. Aljíbico, tingitano y rifeño. Termo-mesomediterráneo.

Brezales

(Stauracanthenion boivinii).

\section{Laurus nobilis L.}

Mesofanerófito. Mediterráneo-macaronésico. Termo-mesomediterráneo. Ojaranzales y quejigales (Rhododendro-Prunetalia spinosae, Quercion broteroi). Especie vulnerable.

\section{Leontodon tingitanus (Boiss. \& Reuter) Ball}

Hemicriptófito. Bético, aljíbico y tingitano. Termo-mesomediterráneo. Pastizales de vertisuelos interiores y con influencia marítima (GaudinioHordeion bulbosi, Crithmo-Daucion halophili).

\section{Limonium emarginatum (Willd.) O. Kuntze}

Caméfito. Aljíbico y tingitano. Termomediterráneo. Acantilados marítimos (Crithmo-Daucion halophili).

Lotus glareosus Boiss. \& Reuter var. villosus

Hemicriptófito. Iberomarroquí-atlántico. Termo-mesomediterráneo. Pastizales xerofíticos (Jasonio-Koelerietalia). No citada en la Flora de Andalucía Occidental.

\section{Narcissus cantabricus DC.}

Criptófito. Iberomarroquí-atlántico. Termomesomediterráneo. Fisurícola (Asplenietea trichomanis). No citada en la Flora de Andalucía Occidental.
Narcissus viridiflorus Schousboe

Criptófito. Aljíbico y tingitano. Termomediterráneo. Majadales (Plantaginion serrariae).

Nothobartsia aspera (Brot.) Bolliger \& Molau Caméfito. Tingitano-Onubo-Algarviense. Termo-mesomediterráneo. Brezales (Stauracanthenion boivinii).

\section{Mercurialis reverchonii Rouy}

Caméfito. Aljúbico-Tingitano.

Termomediterráneo. Herbazales nitrófilos (Origanion virentis).

\section{Origanum compactum Bentham}

Caméfito. Aljíbico, rondense y mauritánico. Termo-mesomediterráneo. Matorrales basófilos (Eryngio-Ulicion erinacei).

Phyllitis sagitatta (D.C.) Guinea \& Heywood

Hemicriptófito. Mediterráneo. Termomesomediterráneo. Comunidades rupícolas de oquedades sombrías (Asplenietalia). Especie vulnerable que se encuentra en el límite con el Parque Natural de Grazalema. Especie vulnerable.

\section{Pinus pinaster Aiton}

Mesofanerófito. SW de Europa y mediterráneo occidental. Termo-mesomediterráneo. Brezales con pinos negrales (Stauracanthenion boivinii).

\section{Polygala baetica Willk. in Willk. \& Lange}

Caméfito. Tingitano-onubo-algarviense. Mesomeditarráneo. Brezales (Stauracanthenion boivinii).

\section{Polypodium interjectum Shivas}

Hemicriptófito. Eurosiberiano y mediterráneo. Termo-mesomediterráneo. Grietas terrosas (Bartramio-Polypodion serrati).

\section{Polypodium macaronesicum Bobrov}

Epífito. Macaronésico y aljíbico. Termomediterráneo. Comunidades briopteridofíticas epífitas (Bartramio-Polypodion serrati).

\section{Prunus spinosa $\mathrm{L}$.}

Microfanerófito. Euroasiático, iberomarroquí- 
atlántico. Mesomeditarráneo. Robledales ombrófilos (Quercenion pyrenaicae).

Psilotum nudum (L.) Beauv.

Hemicriptófito.

Pantropical.

Termomediterráneo. Comunidades fisurícolas relícticas (Bartramio-Polypodion serrati). Especie en peligro.

Pteris incompleta Cav.

Hemicriptófito. Aljíbico, tingitano, ribatagano-sadense y macaronésico. Termomediterráneo. Ojaranzales higrófilos con relictos tropicales (Rhododendro-Prunion lusitanicae). Especie vulnerable.

Quercus canariensis Willd.

Mesofanerófito. Mediterráneo-occidental. Termo-mesomediterráneo. Quejigales (Quercion broteroi). Especie vulnerable.

Quercus lusitanica Lam.

Nanofanerófito. Iberomarroquí-atlántico.

Termo-mesomediterráneo. Brezales xerófilos (Stauracanthenion boivinii).

Quercus pyrenaica Willd.

Mesofanerófito. Mediterráneo-occidental. Mesomediterráneo. Robledales (Quercenion pyrenaicae). Esta especie constituye en el Parque los bosques de melojo más meridionales de la Península Ibérica. Especie vulnerable.

\section{Quercus $x$ fontqueri $\mathrm{O}$. Schwarz}

Mesofanerófito. Mediterráneo occidental. Mesomediterráneo. Robledales ombrófilos (Quercenion pyrenaicae).

\section{Quercus $x$ marianica C. Vicioso}

Mesofanerófito. Iberomarroquí-atlántico. Termo-mesomediterráneo. Quejigales basófilos (Quercion broteroi).

\section{Ranunculus tripartitus DC.}

Hidrófito. Atlántico e iberomarroquí-atlántico. Termo-mesomediterráneo. Comunidades acuáticas turfófilas (Ranunculion aquatilis). Muy raro en la provincia de Cádiz, siendo Los Alcornocales su localidad europea más meridional.
Rhododendron ponticum L. (=Rhododendron baeticum Boiss. \& Reuter)

Microfanerófito. Aljíbico, monchiquense y divisorio-portugués. Termo-mesomediterráneo. Ojaranzales higrófilos (Rhododendro-Prunion lusitanicae). Especie en peligro.

\section{Rubia agostinhoi Dansereau \& P. Silva}

Caméfito escandente. Aljíbico y macaronésico. Termomediterráneo. Quejigales morunos (Quercion broteroi) y ojaranzales higrófilos (Pruno-Lauretea azoricae).

Salix eleagnos Scop. subsp. angustifolia (Cariot) Rech. fil.

Microfanerófito. Mediterráneo-occidental. Termomediterráneo. Saucedas arbustivas (Salicion pedicellatae). Especie vulnerable.

Satureja salzmannii P.W. Ball

Caméfito. Aljíbico, tingitano y rifeño. Termomesomediterráneo. Brezales (Stauracanthenion boivinii).

Scrophularia laxiflora Lange (= Scrophularia laevigata Vahl)

Hemicriptófito. Aljíbico y tingitano. Termomediterráneo. Ojaranzales higrófilos (Rhododendro-Prunion lusitanicae).

Sedum hirsutum All. subsp. baeticum Rouy (= Sedum winkleri (Willk.) Wolley-Dod)

Hemicriptófito. Aljíbico, tingitano y rifeño. Termo-mesomediterráneo. Fisurícola (BartramioPolypodion serrati).

Stauracanthus boivinii (Webb) Samp.

Caméfito. Tingitano-onubo-algarviense. Termo-mesomediterráneo. Brezales (Stauracanthenion boivinii).

Teucrium scorodonia L. subsp. baeticum (Boiss. \& Reuter) Tutin

Caméfito. Aljíbico y tingitano. Termomesomediterráneo. Alcornocales ombrófilos y orlas herbáceas (Quercion suberis, Stachyo lusitanicaeCheirolophenion sempervirentis).

Tolpis nemoralis Font Quer

Hemicriptófito. Aljíbico, tingitano y rifeño. 
Termo-mesomediterráneo. Umbrías y orlas forestales (Stachyo lusitanicae-Cheirolophenion sempervirentis).

\section{Trifolium baeticum Boiss.}

Hemicriptófito. Aljíbico y tingitano. Termomediterráneo. Praderas de vertisuelos (Gaudinio-Hordeion bulbosi).

Ulex baeticus Boiss. subsp. scaber (G. Kunze) P. Cubas

Nanofanerófito. Aljíbico y tingitano. Termomediterráneo. Matorrales basófilos (EryngioUlicion erinacei).

Ulex borgiae Rivas Martínez (= U. jussiaei sensu Vicioso, non Webb)

Nanofanerófito. Aljíbico y tingitano. Termomesomediterráneo. Jarales con aulagas (Ulici borgiae-Calicotomenion villosae).

Vicia lutea L. subsp. cavanillesii (Martínez) Romero Zarco

Hemicriptófito. Aljíbico y tingitano. Termomediterráneo. Comunidades ruderales (Stellarietea mediae).

Vandenboschia speciosa (Willd.) Kunkel

Hemicriptófito. Atlántico, aljíbico y macaronésico. Termomediterráneo. Ojaranzales (Rhododendro-Prunetalia lusitanicae), vegetación brio-pteridofítica terrestre de origen macaronésico (Hymenophilion tunbrigensis). Especie vulnerable.

\section{Comentarios y novedades sintaxonómicas}

Quercion suberis y Querco-Oleion sylvestris

De acuerdo con Loisel (1971), Quercion suberis reúne los alcornocales silicícolas termo-mesomediterráneos subhúmedohumedos del $\mathrm{N}$ de África, S de Francia y S de la Península Ibérica (provincia TingitanoOnubo-Algarviense), donde sustituyen a los mesomediterráneos de la alianza Quercion broteroi. Se distinguen como plantas características y diferenciales frente a QuercoOleion: Adenocarpus telonensis, Cytisus villosus, Genista linifolia, Genista monspessulana, Pulicaria odora, Quercus suber y Teucrium scorodonia subsp. baeticum. La alianza Querco rotundifoliae-Oleion sylvestris, en cambio, agrupa a encinares y acebuchales termomediterráneos de sustratos generalmente calizos y arcillosos o silíceos en ombroclima seco, y de areal mediterráneo occidental. Entre sus elementos característicos y diferenciales podemos destacar: Arisarum vulgare, Ceratonia siliqua, Gennaria diphylla, Olea europaea var. sylvestris y Vinca difformis (Braun-Blanquet, 1953; Debazac, 1958; Zeraia, 1981; Wojterski, 1985, 1990; Meddour y Géhu, 1998). Así, las asociaciones que constituyen el Quercion suberis en el $\mathrm{N}$ de África y $\mathrm{S}$ de la Península Ibérica son: Myrto communisQuercetum suberis (tingitano-onuboalgarviense, luso-extremadurense, bética, Argelia y Túnez), Teucrio baetici-Quercetum suberis (aljíbica y tingitana), Cytiso trifloriQuercetum suberis Br.-B1. 1953 (Argelia y Túnez), Telino linifoliae-Quercetum suberis Zeraia 1981 (Argelia), Erico scopariaeQuercetum suberis Khelifi 1987 (Argelia) y Pistacio lentisci-Quercetum suberis (Debazac 1958) Khelifi 1987 (Argelia y Túnez). Quedan, por tanto encuadradas en Querco-Oleion sylvestris: Clematido cirrhosae-Ceratonietum siliquae (bética, aljíbica, rifeña y atlásica), Tamo communis-Oleetum sylvestris (aljíbica, tingitana, rifeña y atlásica), Lonicero implexaeQuercetum cocciferae Nègre 1964 (Argelia) y Smilaco mauritanicae-Quercetum rotundifoliae (tingitano-onubo-algarviense, bética, rifeña, Argelia).

\section{Quercion broteroi}

Hasta el momento esta alianza reunía bosques meso y supramediterráneos donde son frecuentes árboles caducifolios y plantas nemorales de areal occidental oceánico (Rivas Martínez et al., 1986); sin embargo, se trata de una unidad fitosociológica cuyo significado está en los bosques (quejigales y alcornocales) 
que quedaron aislados durante los períodos glaciares en el SO de la Península Ibérica y NO de África (Jermy, 1984). Plantas como Centaurea sempervirens, Pyrus bourgaeana, Quercus broteroi, $Q$. canariensis y Sanguisorba hybrida son sus características que, desde la provincia Luso-Extremadurense, alcanzan las umbrías termo-mesomediterráneas de los sectores Aljíbico, Tingitano (Benabid y Fennane, 1994) y Malacitano-Axarquiense (Cabezudo y Pérez Latorre, 1999).

Oleo sylvestris-Quercetum broteroi Galán de Mera, Pérez Latorre y Cabezudo ass. nova

[Tabla 1, sintypus: inv. 1]

En los valles encajados termomediterráneos subhúmedo-húmedos de la sierras de las Cabras (Parque Natural Los Alcornocales), de la Sal, SO de la sierra de Grazalema, NO del Labradillo, Prado del Rey (Cádiz), y Valle del río Guadiaro (Málaga), los encinares térmicos de Smilaco-Quercetum rotundifoliae son sustituidos, en orientación N-NO y valles, por un bosque basófilo de quejigos que ocupa biótopos semejantes a los de Quercus canariensis, y que, por tanto, significan la cabecera de una nueva serie de vegetación: Oleo sylvestris-Querceto broteroi $S$. Estas poblaciones de Quercus broteroi muchas veces son hibridógenas y en algunas de ellas se hace dominante $Q$. $x$ marianica (= $Q$. broteroi $x Q$. canariensis), allí donde los quejigales morunos contactan con los basófilos, asentados sobre luvisoles crómicos. Son elementos diferenciales frente a Rusco hypophylli-Quercetum canariensis quercetosum broteroi (Pérez Latorre et al., 1996): Agrimonia euphatoria, Clematis flammula, Dorycnium hirsutum, Eryngium tricuspidatum, Iris foetidissima y Rhamnus oleoides.

Estos quejigales son endémicos del sector Aljíbico y geovicarios de Arisaro clusiiQuercetum broteroi Br.-Bl., P. Silva \& Rozeira 1956 del centro de Portugal, que igualmente se incluyen dentro de la provincia TingitanoOnubo-Algarviense (sectores DivisorioPortugués y Ribatagano-Sadense). Son diferenciales de Arisaro-Quercetum broteroi frente a Oleo-Quercetum broteroi (BraunBlanquet et al., 1956; Fernandes et al., 1990): Antirrhinum linkianum, Cephalanthera longifolia, Genista tournefortii, Geum sylvaticum, Helleborus foetidus, Hyacinthoides hispanica, Lonicera etrusca, Paeonia broteroi y Polygonatum odoratum.

Tamo communis-Oleetum sylvestris ceratonietosum siliquae Benabid 1984 ex Pérez Latorre, Galán de Mera y Cabezudo (designado aquí).

[Lectotypus: Benabid, 1984; tabla 2, inv. 6]

Los acebuchales son bosques de Olea europaea var. sylvestris característicos de los vertisuelos de ambos lados del Estrecho de Gibraltar. Al igual que en la Península Tingitana (Marruecos), los afloramientos calizos termomediterráneos que aparecen incluidos en las unidades geológicas de margas y areniscas son colonizados por el acebuchal de TamoOleetum sylvestris, pero en este caso como subasociación subrupícola con Ceratonia siliqua (Benabid et al., 1984) de la que presentamos el siguiente inventario: Málaga, Cortes de la Frontera, Loma de los Arrieros. Grietas anchas de lapiaz calizo, $350 \mathrm{~m}$. Características: Olea sylvestris 3, Tamus communis 1. Diferenciales de subasociación ceratonietosum siliquae: Ceratonia siliqua 1, Ficus carica 1, Ruscus hypophyllum 1. Unidades superiores: Jasminum fruticans +, Rubia peregrina +, Pistacia lentiscus 2, Phillyrea latifolia 1, Smilax aspera 1, Asparagus albus + , Ruscus aculeatus + . Compañeras: Crataegus monogyna + , Clematis cirrhosa 1, Geranium rotundifolium + , Melica minuta. +, Vinca difformis 1, Fumaria sepium + , Calicotome villosa 1, Geranium purpureum + , Centranthus macrosiphon,+ Rubus 
Tabla 1

Oleo sylvestris-Quercetum broteroi Galán de Mera, Pérez Latorre \& Cabezudo ass. nova (Quercetea ilicis, Quercetalia ilicis, Quercion broteroi)

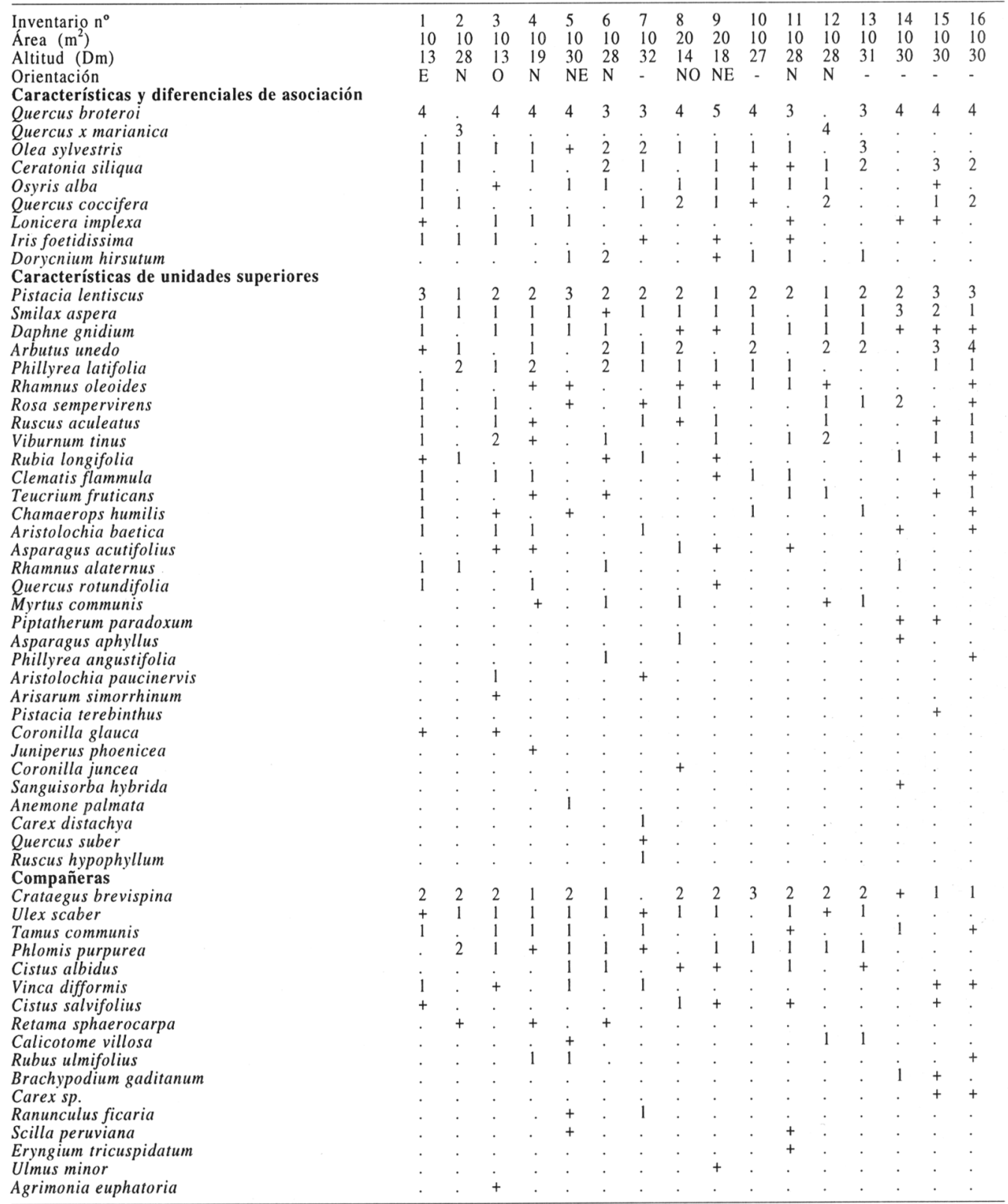

Otros táxones: Hedera helix + en 1; Elaeoselinum foetidum +, Dactylis hispanica + y Magydaris panacifolia + en $3 ;$ Origanum compactum + y Leuzea conifera 1 en 5; Stahelina dubia + en 6; Cistus monspeliensis 1 y Centaurium majus + en 10; Genista linifolia + y Brachypodium retusum 1 en $12 ;$ Arum italicum 1, Stachys cordigera + y Trifolium repens + en 14; Calamintha baetica + en $15 ;$ Polypodium cambricum + en 16.

Localidades.- 1 y 9: Tempul, Jerez de la Frontera, Cádiz. 2 y 12: Garganta del Caballo, Jerez de la Frontera, Cádiz. 3: Dehesa del Picado, Jerez de la Frontera, Cádiz. 4: Garganta de Bogas, Jerez de la Frontera, Cádiz. 5 y 11: Rancho del Hato, Jerez de la Frontera, Cádiz. 6 y 13: Cortijo de Fresnillo Bajo, Alcalá de los Gazules, Cádiz. 7: Montifarti, Jerez de la Frontera, Cádiz. 8: Cerro de las Alforjas, Jerez de la Frontera, Cádiz. 10: Cerro de la Cuna, Jerez de la Frontera, Cádiz. 14: Entre El Bosque y Algar, Jerez de la Frontera, Cádiz. 15: La Castilleja, Jerez de la Frontera, Cádiz. 
Tabla 2

\section{Asparago albi-Rhamnetum oleoidis Rivas Goday 1959 \\ ceratonietosum siliquae Galán de Mera subass. nova \\ (Quercetea ilicis, Pistacio-Rhamnetalia, Asparago-Rhamnion)}

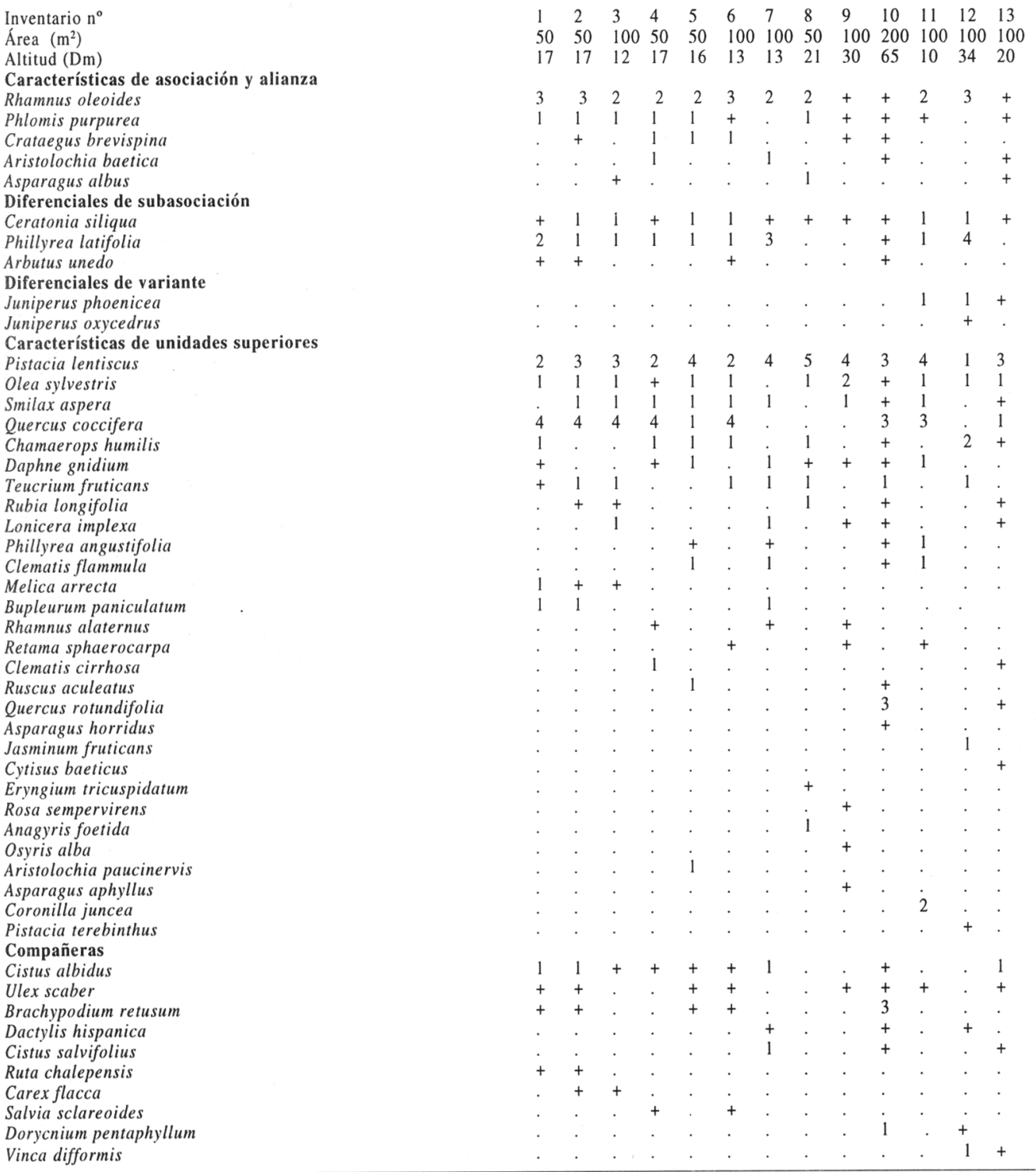

Otros táxones: Cistus monspeliensis + en 1; Centaurium major + en 2; Helichrysum stoechas + y Leuzea conifera + en 6; Calamintha baetica + en 9; Asphodelus ramosus +, Stipa tenacissima +, Astragalus lusitanicus + y Conopodium capillifolium + en 12; Thymbra capitata + , Teucrium pseuchamaepitys + y Brachypodium gaditanum + en 13.

Localidades.- 1 y 2: Quiebrahachas, Alcalá de los Gazules, Cádiz. 3 al 6: Valdegama, Alcalá de los Gazules, Cádiz. 7: Sierra de la Sal, Jerez de la Frontera, Cádiz. 8: Peña Arpada, Alcalá de los Gazules, Cádiz. 9: Dehesa del Picado, Jerez de la Frontera, Cádiz. 10: Sierra de las Cabras, Jerez de la Frontera, Cádiz. 11: Boca la Foz, Jerez de la Frontera, Cádiz. 12: Pico de la Pajarraca, Jerez de la Frontera, Cádiz. 13: Cortijo del Taramal, Jerez de la Frontera, Cádiz. 
ulmifolius +, Urtica membranacea. +, Mercurialis ambigua + . En estos biotopos, los rellanos de rocas con litosuelos están colonizados por la comunidad de plantas crasas Sedetum micrantho-sediformis en su variante termófila con Mucizonia hispida.

\section{Asparago albi-Rhamnetum oleoidis ceratonietosum siliquae Galán de Mera subass. nova}

[Tabla 2, sintypus: inv. 6]

La asociación Asparago-Rhamnetum oleoidis (típica) tiene una amplia extensión dentro del piso termomediterráneo secosubhúmedo-húmedo bético, tingitano-onuboalgarviense y luso-extremadurense. Representa espinales (Rhamnus oleoides), coscojares (Quercus coccifera) o lentiscares (Pistacia lentiscus) que se desarrollan sobre suelos básicos o neutros ricos en arcillas, cuya potencialidad son acebuchales, carrascales, algarrobales y quejigales. Se diferencia del resto de las asociaciones del AsparagoRhamnion por la presencia de Asparagus albus, Crataegus monogyna subsp. brevispina y Phlomis purpurea. En aquellas áreas donde existen sustratos calizos duros y el bosque climácico es un algarrobal (ClematidoCeratonietum phlomidetosum purpureae) o un quejigar (Oleo-Quercetum broteroi), Asparago-Rhamnetum se enriquece en algarrobos, madroños y labiérnagos en estado arbustivo (Rivas Goday et al., 1965) y permiten describir esta nueva subasociación. La variante con Juniperus phoenicea es de áreas con inclusiones de dolomías y marca el tránsito hacia las comunidades de la alianza PinoJuniperion phoeniceae (Pérez Latorre et al., 1998).

\section{Querco-Fagetea}

Las unidades sintaxonómicas de esta clase tienen un gran interés en nuestro territorio sobre todo por su relación con las comunidades de areal mauritánico y, en general, mediterráneo occidental. De esta forma, las saucedas pertenecen a un grupo particular diferente a las del Escudo Hespérico, y las choperas, a través de elementos esclerófilos de Quercetea ilicis, son muy similares a las de Argelia (Wojterski, 1985). Pero la asociación aljíbica (cumbre del Aljibe, sierras de Algeciras, Valle del Genal, Sierra de Ronda y montes de Cortes) más original son los melojares ombrófilos de Cytiso triflori-Quercetum pyrenaicae (Pérez Latorre et al., 1996). Se trata de los melojares más meridionales de la Península Ibérica, muy próximos geográfica y florísticamente a los norteafricanos, con los que comparten plantas características (Agrostis curtisii, Avenula sulcata subsp. albinervis, Clinopodium vulgare subsp. arundanum, Cytisus villosus, Festuca baetica, Genista monspessulana, Luzula forsteri subsp. baetica y Quercus canariensis). En el norte de África, Barbéro et al. (1981) incluyen al Cytiso-Quercetum pyrenaicae en la alianza Violo-Cedrion atlanticae basándose en características que, excediendo la cordillera del Rif, alcanzan la Península Ibérica (Arenaria pomelii, Daphne laureola subsp. latifolia, Elymus panormitanus y Geranium malviflorum), y en variedades de escasa entidad (Geum sylvaticum var. atlanticum, Myosotis alpestris var. rifana y Viola munbyana var. rifana). Solamente Vicia cedretorum, endémica de Marruecos, apoyaría la situación de estos melojares en Violo-Cedrion atlanticae, por lo que pensamos que esta asociación debe quedar encuadrada en Quercenion pyrenaicae.

Salicion pedicellatae Galán de Mera, Pérez Latorre y Cabezudo all. nova

[Sintypus: Equiseto telmateiae-Salicetum pedicellatae Díez Garretas, Cuenca y Asensi 1986]

Alianza que recoge a las saucedas de la Cuenca Mediterránea, las cuales están caracterizadas por Salix aggr. pedicellata $(S$. antiatlantica Maire \& Wilczec del S de Marruecos; S. arrigonii Brullo de Cerdeña; $S$. 
canariensis Chr. Smith de islas Canarias; $S$. gussonei Brullo \& Spampinato del NE de Sicilia; S. ionica Brullo, Scelsi \& Spampinato del S de Italia y $S$. pedicellata Desf. del N de África, $S$ de la Península Ibérica, Malta y Sicilia). Dentro de la Península Ibérica, $S$. pedicellata no sube a la Meseta (Blanco, 1993), y $S$. salviifolia Brot., especie diferencial de la alianza Salicion salviifoliae (Rivas Martínez et al., 1984), llega al sur influida por $S$. pedicellata no habiendo sido encontrada en el norte de África (Silvestre, 1987; Blanco, 1993). Todo hace pensar que las saucedas termomesomediterráneas del occidente de la Cuenca Mediterránea pertenecen a esta nueva alianza que hasta el momento engloba a las siguientes asociaciones: Equiseto telmateiae-Salicetum pedicellatae Díez Garretas, Cuenca \& Asensi 1986 (tingitano-onubo-algarviense), Erico erigenae-Salicetum pedicellatae Esteve 1973 (bética y murciano-almeriense) y Nerio oleandri-Salicetum pedicellatae Cano \& Valle 1990 (luso-extremadurense oriental).

En el territorio estudiado sólo está presente Equiseto telmateiae-Salicetum pedicellatae. Se trata de vegetación arbustiva dominada por Salix pedicellata que coloniza el lecho menor de ríos y arroyos alternando con alisedas u ojaranzales, ocupando biótopos riparios más estacionales y con suelos más aireados.

Equiseto telmateiae-Salicetum pedicellatae salicetosum angustifoliae Galán de Mera subass. nova

[Sintypus: Cádiz, Algar, río Majaceite, Pasada del Recodo, alt. $50 \mathrm{~m}, 100 \mathrm{~m}^{2}$, suelos guijarrosos calizo. Salix pedicellata $4, S$. eleagnos subsp. angustifolia 2, Brachypodium sylvaticum var. gaditanum + , Rubus ulmifolius 1, Smilax aspera 1, Crataegus monogyna subsp. brevispina + , Nerium oleander 1, Mentha suaveolens + ].

Constituyen las saucedas con Salix pedicellata y S. eleagnos subsp. angustifolia que se desarrollan sobre sustratos calizos, marcando la transición hacia la alianza Salicion triandro-neotrichae Br.-Bl. \& O. Bolòs 1958 y su areal es sidonense, aunque probablemente alcancen la Serranía de Ronda.

Pruno-Lauretea azoricae: Rhododendro pontici-Prunion lusitanicae Pérez Latorre, Galán de Mera y Cabezudo all. nova

[Sintypus: Frangulo baeticaeRhododendretum pontici Rivas Goday, Galiano y Rivas Martínez ex Rivas Martínez, Fuente y Sánchez Mata 1986 em. \& corr.]

Los bosques lauroides situados en las islas Canarias, Madeira y Azores son una reliquia de los bosques tropicales que cubrían Europa y África durante el Terciario (Axelrod, 1966), claramente relacionados con los bosques montanos actuales de África (Lösch y Fischer, 1994). Los elementos característicos de los bosques canarios (Apollonias barbujana, Bencomia caudata, Ilex canariensis, Laurus azorica, Ocotea foetens, Persea indica, Picconia excelsa, Prunus lusitanica subsp. hixa, Viburnum rigidum y Visnea mocanera) distinguen al orden macaronésico Pruno hixaeLauretalia azoricae que llega ya de forma muy empobrecida, mediante una comunidad de Laurus azorica (Lauretum azoricae Oberdorfer 1965 corr. Lüpnitz 1975) al Atlas de Ksiba (Marruecos) (Barbéro y Quézel, 1994).

Desde el punto de vista bioclimático, la circulación constante de masas de aire cálido y húmedo durante el verano es la responsable de la existencia de comunidades lauroides en el Mediterráneo occidental e islas macaronésicas. En la situación meteorológica típica del verano de la Península Ibérica, Azores, Madeira e islas Canarias, los vientos Alisios, originados por la posición del anticiclón de las Azores, producen un colchón de nubes entre los $600 \mathrm{y}$ $1000 \mathrm{~m}$ sobre la vertiente norte de Azores, Madeira y Canarias. De igual forma, la baja térmica que rodea al estrecho de Gibraltar origina vientos del E con acumulaciones de 
nubes en las cumbres de las montañas. Por ello, existen comunidades de Rhododendron ponticum en el centro y S de Portugal, y SO de España; y de Prunus lusitanica en áreas más frías del $\mathrm{O}$ de la Península Ibérica y $\mathrm{N}$ de Marruecos. Además, en el $\mathrm{S}$ de Portugal, Frangulo-Rhododendretum mantiene en su composición florística a Myrica faya lo que aproxima esta asociación a los bosques lauroides canarios.

Rhododendro-Prunion lusitanicae es una alianza ibérica y norteafricana, cuyas plantas características, aparte de otras propias de la clase, son: Daphne laureola subsp. latifolia, Festuca boissieri, Frangula alnus subsp. baetica, Ilex aquifolium, Prunus lusitanica, Rhododendron ponticum y Scrophularia laxiflora. Dentro de ella, en la Península Ibérica, tenemos dos asociaciones: Frangulo baeticae-Rhododendretum pontici (termomesomediterránea, aljíbica, monchiquense y divisorio-portuguesa) (Pereira Días y Barros de sa Nogueira, 1973; Malato Beliz, 1982; Pérez Latorre et al., 1996) y Viburno tiniPrunetum lusitanicae (mesomediterránea, lusoextremadurense) (Ladero Álvarez, 1976). En la cordillera del Rif y áreas internas de la península Tingitana, encontramos la comunidad meso-supramediterránea Polysticho setiferiPrunetum lusitanicae (Barbéro et al., 1981; Deil, 1984). Las comunidades briofíticas de los dominios de Frangulo-Rhododendretum pontici mantienen especies y comunidades de la laurisilva macaronésica (Allorge V. \& P., 1945; Gil y Guerra, 1981) tales como Ulota calvescens y Frullania teneriffae en el Neckero pumilae-Ulotetum calvescentis o como Porella canariensis y Neckera levifolia del Neckero levifoliae-Porelletum canariensis, complementando la posición sinecológica y sintaxonómica de estas singulares formaciones.

Rhododendro pontici-Prunetalia lusitanicae Pérez Latorre, Galán de Mera y Cabezudo ordo novo
[Sintypus: Rhododendro pontici-Prunion lusitanicae Pérez Latorre, Galán de Mera y Cabezudo all. nova]

De acuerdo con Oberdorfer (1960) y Hohenester y Welss (1993) la clase PrunoLauretea azoricae alcanza algunas áreas del continente europeo y africano, puesto que sus elementos están presentes (Culcita macrocarpa, Daphne laureola subsp. latifolia, Davallia canariensis, Diplazium caudatum, Dryopteris guanchica, Evonymus latifolius, Frangula alnus subsp. baetica, Laurus nobilis, Laurus azorica, Myrica faya, Polystichum setiferum, Prunus laurocerasus, P. lusitanica, Pteris incompleta, Rhododendron ponticum y Vandenboschia speciosa) e indican relaciones biogeográficas entre regiones húmedas de América del Sur, islas Canarias, Madeira, Azores, África, N de Anatolia y E de China (Raven y Axelrod, 1974). Para separar a las laurisilvas macaronésicas de las comunidades de la Cuenca Mediterránea creamos el orden Rhododendro-Prunetalia lusitanicae, que dividimos en dos alianzas: Prunion laurocerasi all. nov. prov. y Rhododendro pontici-Prunion lusitanicae. Prunion laurocerasi corresponde a las comunidades lauroides del norte de Anatolia, y Rhododendro-Prunion lusitanicae a las de la Península Ibérica y noroeste de África.

\section{Frangulo baeticae-Rhododendretum pontici} Rivas Goday, Galiano y Rivas Martínez ex Rivas Martínez, Fuente y Sánchez Mata 1986 em. \& corr.

culcitetosum macrocarpae Pérez Latorre, Galán de Mera y Cabezudo subass. nova

[Tabla 3, sintypus: inv. 7]

En el territorio estudiado, la vegetación lauroide de Frangulo-Rhododendretum está situada en gargantas profundas, cabeceras de valles y altiplanicies donde son abundantes las criptoprecipitaciones. En las localidades más térmicas y húmedas va acompañada por pteridófitos de origen terciario tropical (Culcita 
Tabla 3

Frangulo baeticae-Rhododendretum pontici Rivas Goday et al. ex Rivas-Martínez et al. 1986 rhododendretosum pontici, culcitetosum macrocarpae Pérez Latorre, Galán de Mera \& Cabezudo subass. nova

(Pruno-Lauretea azoricae, Rhododendro-Prunetalia, Rhododendro-Prunion lusitanicae)

Inventario $\mathrm{n}^{\mathrm{o}}$

Área

Altitud (Dm)

Orientación

$\begin{array}{lllllllllllll}1 & 2 & 3 & 4 & 5 & 6 & 7 & 8 & 9 & 10 & 11 & 12 & 13 \\ 100 & 100 & 100 & 100 & 50 & 50 & 100 & 100 & 100 & 100 & 50 & 100 & 100 \\ 72 & 67 & 66 & 63 & 40 & 86 & 64 & 66 & 65 & 41 & 36 & 20 & 39 \\ \text { NO } & \text { NO } & - & - & \text { SO } & \text { SO } & \text { S } & - & - & \text { N } & \text { N } & - & \text { N }\end{array}$

Características de asociación y unidades superiores

Rhododendron ponticum

Frangula baetica

Ilex aquifolium

Laurus nobilis

Daphne latifolia

Diferenciales de subasociación

Culcita macrocarpa

Diplazium caudatum

Pteris incompleta

Vandenboschia speciosa

Características de Quercetea ilicis y Quercion broteroi

Quercus canariensis

Smilax aspera

Quercus broteroi

Ruscus aculeatus

Ruscus hypophyllum

Asplenium onopteris

Teucrium baeticum

Daphne gnidium

Rubia longifolia

Luzula baetica

Características de Ericion arboreae

Viburnum tinus

Erica arborea

Arbutus unedo

Phillyrea latifolia

Características de Querco-Fagetea y Rhamno-Prunetea

Rubus ulmifolius

Hedera helix

Osmunda regalis

Blechnum spicant

Crataegus brevispina

Alnus glutinosa

Tamus communis

Athyrium filix-femina

Lonicera hispanica

Carex pendula

Sibthorpia europaea

Vitis sylvestris

Salix pedicellata

Características de Trifolio-Geranietea

Brachypodium gaditanum

Digitalis bocquetii

Calamintha baetica

Compañeras

Pteridium aquilinum

Cistus major

Polypodium cambricum

Oenanthe crocata

Otros táxones: Iris sp. + en 1; Erica erigena + en 6; Arisarum proboscideum 1 y Scilla monophyllos 1 en 7; Gnaphalium luteo-album + , Mercurialis reverchonii + , Nerium oleander + , Carex lusitanica 1 y Lobelia urens + en 12; Davallia canariensis 1 en 13.

Localidades.- 1: Llanos del Juncal, Tarifa, Cádiz. 2-4, 8 y 9: Tajos del Espino, Los Barrios, Cádiz. 5: El Montero, Alcalá de los Gazules, Cádiz. 6: Garganta de Puerto Oscuro, Alcalá de los Gazules, Cádiz. 7: Puerto de Barriga, Sierra del Niño, Los Barrios, Cádiz. 10 y 11 : Dehesa de Ojén, Los Barrios, Cádiz. 12: Molino de la Canaleja, Tarifa, Cádiz. 13: Garganta del Gandelar, Los Barrios, Cádiz. 
macrocarpa, Diplazium caudatum, Pteris incompleta y Vandenboschia speciosa), por lo que describimos la subasociación culcitetosum macrocarpae que está representada exclusivamente en el subsector Algecireño y constituye la expresión más hidrófila de la asociación.

A la vista de la composición de los inventarios correspondientes, la subasociación salicetosum pedicellatae (Díez Garretas et al., 1986) entraría a formar parte de FranguloRhododendretum típico, y la subasociación nerietosum oleandri (Díez Garretas et al., 1986) correspondería a las alisedas de ArisaroAlnetum glutinosae nerietosum oleandri (Martínez Parras y Peinado Lorca, 1987).

\section{Quercion fruticosae y Stauracanthenion} boivinii: Genisto tridentis-Stauracanthetum boivinii

\section{[Tabla 4]}

Aunque numerosos autores (Díez Garretas et al., 1986; Rivas Martínez et al., 1990 b) consideran que la alianza Quercion fruticosae significa vegetación de altifruticetas incluible en Pistacio-Rhamnetalia alaterni, este no es el sentido de Rothmaler (1954) quien introduce a las comunidades de Quercus lusitanica en Lavanduletalia stoechadis. Por la ecología y la estructura que muestra $Q$. lusitanica en el SO de la Península Ibérica, esta alianza puede ser un sinónimo, al menos en parte, de los brezales de Stauracanthenion boivinii que comprende, en la provincia Tingitano-Onubo-Algarviense (Galán de Mera y Vicente Orellana, 1996; Deil, 1997), a Genisto triacanthi-Cistetum palhinhae Rivas Martínez et al. 1990 (algarviense), Querco lusitanicae-Stauracanthetum boivinii Rothmaler 1954 ex Malato Beliz 1982 (monchiquense), Tuberario majorisStauracanthetum boivinii Br.-Bl., P. Silva \& Rozeira in Rivas Martínez 1979 (algarviense), Genisto tridentis-Stauracanthetum boivinii Rivas Martínez 1979 [= Erico scopariaeStauracanthetum boivinii Quézel et al. 1988] (aljíbica y tingitana), Erico umbellataeHalimietum multiflori Quézel et al. 1988 (tingitana) y Stauracantho boiviniiDrosophylletum lusitanici Quézel et al. 1988 (aljíbica y tingitana).

Genisto tridentis-Stauracanthetum boivinii son brezales con aulagas termomesomediterráneos, húmedo-hiperhúmedos, que se desarrollan sobre suelos lavados, lixiviados e incluso algo podsolizados. Se trata de un matorral camefítico y nanofanerofítico denso, presidido por Stauracanthus boivinii y un cierto número de plantas de óptimo aljíbico y tingitano, a parte de un cortejo florístico bastante extenso de carácter atlántico (Genista triacanthos, G. tridens, G. tridentata, Halimium lasianthum, Klasea alcalae, Lithodora prostrata subsp. lusitanica, Polygala baetica, P. microphylla y Thymelaea villosa).

El aclarado de alcornocales ombrófilos (Teucrio baetici-Quercetum suberis), quejigales morunos (Rusco hypophylliQuercetum canariensis) y melojares ombrófilos (Cytiso triflori-Quercetum pyrenaicae) conduce a esta comunidad endémica de las sierras del Aljibe y de la península Tingitana demostrando, una vez más, las relaciones fitogeográficas que existen entre ambos territorios. La variabilidad de esta asociación en el área del estrecho de Gibraltar es bastante amplia (Pérez Latorre et al., 1993; Nezadal et al., 1994; Deil, 1997 a, 1997b). Sobre suelos más profundos destacamos a la subasociación quercetosum lusitanicae. En áreas mesomediterráneas con suelos arenosos (sierras del Aljibe, de la Luna, del Castillo y Ojén), potenciales de Cytiso triflori-Quercetum pyrenaicae, el brezal muestra una variante con Erica australis y Cistus populifolius subsp. major, aspecto que lo aproxima al Erico australis-Cistetum populifolii lusoextremadurense (Rivas Goday, 1964) y al Cisto atlantici-Genistetum quadrifoliae rifeño (Deil, 1984). La presencia de Cistus ladanifer subsp. africanus en la Serranía de Ronda (Málaga) 
(Demoly y Montserrat, 1993) y en las sierras del Aljibe (García Murillo y Palacios, 1998) aumenta el conocimiento sobre la afinidad fitogeográfica entre las cordilleras Béticas y el $\mathrm{N}$ de África. Desde el punto de vista ecológico, en el territorio estudiado se encuentra en áreas de brezales que han sido repetidamente incendiados constituyendo una variante con Cistus ladanifer subsp. africanus y C. crispus. En las grietas anchas de areniscas con cierto grado de inclinación $\left(50^{\circ}-60^{\circ}\right)$, la asociación se enriquece en Cytisus tribracteolatus marcando la subasociación aljíbica cytisetosum tribracteolati Pérez Latorre, Galán de Mera y Cabezudo comb. nova [Phillyreo-Quercetum lusitanicae cytisetosum tribracteolati Pérez Latorre, Nieto Caldera \& Cabezudo 1994, Sedo brevifolii-Cytisetum tribracteolati stipetosum giganteae Deil 1994]. Esta nueva combinación se hace necesaria en el sur de la Península Ibérica ya que Phillyreo-Quercetum sólo está presente en la Península Tingitana.

\section{Cytiso tribracteolati-Juniperetum oxycedri} Pérez Latorre, Galán de Mera y Cabezudo ass. nova

\section{[Tabla 5, sintypus: inv. 1]}

En varios puntos al norte del Parque Natural existen biotopos muy xéricos, caracterizados geomorfológicamente por ser lajas de areniscas muy expuestas y soleadas, con litosuelos (El Salado, El Picacho, Sierra Gallina). En estas condiciones se desarrolla una formación abierta de Juniperus oxycedrus subsp. oxycedrus. Con marcado carácter ecológico (roquedos) y fitogeográfico (endemismo aljíbico) aparece también Cytisus tribracteolatus y especies diferenciales para con el madroñal de Cytiso-Arbutetum unedonis como Osyris quadripartita. Así mismo, son frecuentes los táxones de los brezales de Stauracanthenion boivinii (Pérez Latorre et al., 1996) y diversas especies de PistacioRhamnetalia que aportan la mayor parte de la biomasa de la comunidad, por lo que nos inclinamos a incluir esta nueva asociación en Pino halepensis-Juniperion phoeniceae, que agrupa a formaciones arbustivas caracterizadas por gimnospermas que ocupan los biótopos edafoxéricos no colonizables por las comunidades climácicas de fagáceas (Pérez Latorre et al., 1998,1999). En el subsector Marbellí (sector Aljíbico, Málaga) y dentro del dominio de alcornocales, son frecuentes formaciones de Juniperus oxycedrus en biotopos similares, que podrían incluirse en esta asociación.

\section{Genisto-Stauracanthetum}

boivinii quercetosum lusitanicae Pérez Latorre, Nieto Caldera \& Cabezudo 1993

\section{Forma relictual con Pinus pinaster}

[Tabla 6]

Vegetación edafoxerófila caracterizada por Pinus pinaster que, en exposiciones S-SO y sobre lajas de arenisca con fuerte inclinación, se presenta como una formación abierta en mosaico con el brezal de Stauracanthenion boivinii. El carácter relictual de esta comunidad ya fue advertido por Ceballos y Martín Bolaños (1930) y Rivas Goday et al. (1965). Estos últimos autores además indican que se trata de una disyunción geográfica procedente de Sierra Bermeja (Málaga), donde son climácicos los pinares serpentinícolas de Pino pinastriQuercetum cocciferae (Cabezudo et al., 1989). La presencia natural de esta conífera en la Sierra del Aljibe queda confirmada con los datos polínicos de Gutiérrez et al. (1997) que proceden de las cercanías del El Picacho, localidad muy cercana a la Cancha del Pinar (Sierra del Aljibe) de donde se describe esta variante. Al igual que con Cytiso-Juniperetum oxycedri, su significado fitocenológico es el de ser un aspecto marginal de la alianza PinoJuniperion phoeniceae (Pérez Latorre et al., 1999) hacia el occidente de Andalucía, siendo los brezales xerófilos quienes dan cobijo en este caso a Pinus pinaster. En el subsector Marbellí (sector Aljíbico, Málaga) se dan 
Tabla 4

Genisto tridentis-Stauracanthetum boivinii Rivas-Martínez 1979

stauracanthetosum boivinii, quercetosum lusitanicae Pérez Latorre et al. 1993

(Calluno-Ulicetea, Calluno-Ulicetalia, Ericion umbellatae, Stauracanthenion boivinii)

\begin{tabular}{lllllllllll}
\hline Inventario n $^{\circ}$ & 1 & 2 & 3 & 4 & 5 & 6 & 7 & 8 & 9 & 10 \\
Area m $^{2}$ & 100 & 100 & 100 & 100 & 50 & 100 & 100 & 100 & 100 & 100 \\
Altitud $(\mathrm{Dm})$ & 44 & 10 & 19 & 16 & 44 & 90 & 51 & 59 & 55 & 54 \\
Orientación & - & $\mathrm{S}$ & - & - & $\mathrm{NO}$ & $\mathrm{NO}$ & SO & - & SE & -
\end{tabular}

Características de asociación y unidades superiores

Stauracanthus boivinii

Genista tridens

Calluna vulgaris

Thymelaea villosa

Erica umbellata

Halimium lasianthum

Satureja salzmannii

Tuberaria lignosa

Klasea alcalae

Polygala microphylla

Erica scoparia

Bupleurum foliosum

Pedicularis lusitanica

Lithodora lusitanica

Centaurea africana

Drosophyllum lusitanicum

Diferencial de subasociación

Quercus lusitanica

Diferenciales de variantes

Cistus ladanifer africanus

Erica australis

Cistus crispus

Cistus major

Compañeras

Lavandula stoechas

Avenula albinervis

Agrostis curtisii

Cistus salvifolius

Pulicaria odora

Festuca baetica

Erica arborea

\begin{tabular}{|c|c|c|c|c|c|c|c|c|}
\hline 2 & 3 & 4 & 4 & 4 & 4 & 2 & 2 & 1 \\
\hline 1 & 1 & . & 2 & 1 & + & . & + & 1 \\
\hline 1 & . & 2 & . & 1 & + & 1 & 1 & 1 \\
\hline . & 1 & + & 1 & + & . & 1 & + & + \\
\hline . & 1 & + & 2 & 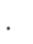 & 3 & 1 & 1 & 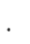 \\
\hline . & + & 1 & & 1 & 1 & 1 & . & 1 \\
\hline 1 & + & + & . & . & . & . & + & 1 \\
\hline 1 & 1 & . & + & . & . & . & . & 1 \\
\hline 1 & . & . & & 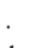 & . & + & . & + \\
\hline . & . & . & . & 1 & . & + & 1 & . \\
\hline 3 & . & 3 & & . & + & . & . & . \\
\hline . & + & . & . & . & + & . & . & \\
\hline . & . & . & & . & . & 1 & . & . \\
\hline · & . & $\cdot$ & + & . & . & $\cdot$ & . & . \\
\hline . & . & . & . & . & . & . & + & . \\
\hline . & . & $\cdot$ & . & . & . & $\cdot$ & . & $\cdot$ \\
\hline . & . & . & . & . & 1 & 1 & 1 & 2 \\
\hline+ & + & 1 & + & + & + & 1 & + & 1 \\
\hline . & . & . & . & . & . & 4 & 4 & 4 \\
\hline . & + & . & 1 & & . & . & + & . \\
\hline . & $\cdot$ & $\cdot$ & $\cdot$ & . & . & . & 2 & 2 \\
\hline 1 & + & 1 & + & + & 1 & + & . & 1 \\
\hline 2 & + & 1 & . & . & . & 1 & 1 & + \\
\hline . & 1 & . & . & + & + & 1 & 1 & 1 \\
\hline 1 & + & . & + & 1 & . & . & . & . \\
\hline+ & . & . & . & . & . & + & + & . \\
\hline · & $\cdot$ & . & . & . & & & 1 & 1 \\
\hline . & + & . & . & + & . & . & . & . \\
\hline
\end{tabular}

Otros táxones.- Quercus suber + , Pistacia lentiscus + , Brachypodium phoenicoides 1 , Halimium halimifolium 2, Dactylis hispanica + , Calicotome villosa + , Olea sylvestris + y Teucrium baeticum + en 1; Rubus ulmifolius +, Briza maxima + , Arbutus unedo + y Pteridium aquilinum 1 en 2; Crepis tingitana + en 3; Teucrium fruticans + en $4 ;$ Holcus lanatus + y Holcus grandiflorus 1 en 6; Centaurium erythraea + y Pinus acutiscuama + en 7; Carex distachya + y Thapsia villosa + en 10.

Localidades.- 1: Los Calabozos, Sierra de Ojén, Tarifa, Cádiz. 2: Montera del Torero, Los Barrios, Cádiz. 3: El Cuervo, Benalup, Cádiz. 4: Los Garlitos, Sierra Blanquilla, Los Barrios, Cádiz. 5: Garganta de Enmedio, Jerez de la Frontera, Cádiz. 6: Puerto de la Yegua, Alcalá de los Gazules, Cádiz. 7: Piedra de los Padrones, Alcalá de los Gazules, Cádiz. 8 y 9: Casas del Corchadillo, Jerez de la Frontera, Cádiz. 10: Puerto de las Cruces, Alcalá de los Gazules, Cádiz. 
Tabla 5

Cytiso tribracteolati-Juniperetum oxycedri Pérez Latorre, Galán de Mera \& Cabezudo ass. nova

(Quercetea ilicis, Pistacio-Rhamnetalia, Pino-Juniperion phoeniceae)

Inventario $\mathrm{n}^{\circ}$

Area $\mathrm{m}^{2}$

Altitud (Dm)

Inclinación $^{\circ}$

Orientación
1

200

25

15

SO

Características de asociación

Juniperus oxycedrus

Cytisus tribracteolatus

Osyris quadripartita

Odontites foliosa

Características de unidades superiores

Phillyrea angustifolia

Adenocarpus telonensis

Arbutus unedo

Calicotome villosa

Quercus suber

Myrtus communis

Erica arborea

Daphne gnidium

Teucrium baeticum

Viburnum tinus

Rubia peregrina

Olea sylvestris

Smilax aspera

Ruscus aculeatus

Ruscus hypophyllum

\section{Compañeras}

Erica australis

Calluna vulgaris

Stauracanthus boivinii

Cistus ladanifer africanus

Lavandula stoechas

Erica scoparia

Erica umbellata

Asphodelus albus

Cistus salvifolius

Romulea bulbocodium

3

$+$

2

\section{4}

$+$

$+$

$+$

$+$

$+$

1

1

$+$

$+$

.

$+$

$+$

$+$

$+$

2 3

150

100

25

30

25

SE

30

SE

1

1

1

1

$+$

42

$+$

$+$

3

Localidades.- 1-3: El Salado, Jimena de la Frontera, Cádiz. 
Tabla 6

Genisto tridentis-Stauracanthetum boivinii Rivas-Martínez 1979

quercetosum lusitanicae Pérez Latorre, Nieto Caldera \& Cabezudo 1993

forma relictual de Pinus pinaster

(Calluno-Ulicetea, Calluno-Ulicetalia, Ericion umbellatae, Stauracanthenion boivinii)

\begin{tabular}{lcccc}
\hline Inventario $^{\circ}$ & 4 & 5 & 6 & 7 \\
Area $\mathrm{m}^{2}$ & 100 & 100 & 100 & 100 \\
Altitud (Dm) & 46 & 46 & 47 & 60 \\
Inclinación & 30 & 30 & 15 & 40 \\
Orientación & $\mathrm{SO}$ & $\mathrm{S}$ & $\mathrm{S}$ & $\mathrm{S}$
\end{tabular}

Características de asociación y unidades superiores

Erica australis

Calluna vulgaris

Stauracanthus boivinii

$\begin{array}{llll}3 & 2 & 4\end{array}$

Quercus lusitanica

$+\quad+$

22

Polygala microphylla

Klasea alcalae

Cytisus tribracteolatus

Diferencial de variante

Pinus pinaster

2

2

2

2

Características de Quercetea ilicis y Pino acutisquamae-Quercetum cocciferae

Phillyrea angustifolia

Erica scoparia

Scilla monophyllos

\section{Compañeras}

Cistus ladanifer africanus

Lavandula stoechas

Festuca baetica

Bellis rotundifolia

Agrostis curtisii

Avenula albinervis

Digitalis bocquetii

Carex hallerana

$\begin{array}{lll}. & + & + \\ 1 & . & 1 \\ + & . & \text {. }\end{array}$

Localidades.- 1-3: Cancha del Pinar, Alcalá de los Gazules, Cádiz. 4: La Cueva del Zapato, Alcalá de los Gazules, Cádiz. 
formaciones similares a ésta ya denunciadas por Ceballos y Vicioso (1933) cuando Pinus pinaster (procedente de las sierras peridotíticas) invade dominios del alcornocal sobre pizarras y esquistos en suelos degradados, y se instala formando parte de jarales-brezales.

Cistetum africani-monspeliensis Pérez Latorre, Galán de Mera y Cabezudo ass. nova

[Tabla 7, sintypus: inv. 1]

Comunidad camefítica y nanofanerofítica, que en nuestro territorio se asienta sobre sustratos derivados de areniscas y con suelos erosionados de horizonte superior pobre en nutrientes. Alterna con espinales (AsparagoCalicotometum villosae) y alcornocales (Myrto communis-Quercetum suberis, TeucrioQuercetum suberis), siendo Cistus ladanifer subsp. africanus y Ulex borgiae las plantas que dan carácter a la asociación, y difercnciales frente a otros jarales Calicotome villosa y Adenocarpus telonensis.

Al igual que la subalianza UliciCalicotomenion villosae, su distribución es aljíbica, bermejense y tingitana (Martínez Parras et al., 1987; Asensi y Díez Garretas, 1988; Jung, 1994; Pérez Latorre et al., 1997) y vicariante de otros jarales iberomarroquíatlánticos como Cisto ladaniferi-Ulicetum argentei Br.-Bl., P. Silva \& Rozeira 1964 (monchiquense), Genisto hirsutae-Cistetum ladaniferi Rivas Goday 1955 (lusoextremadurense) y Ulici eriocladi-Cistetum ladaniferi (araceno-pacense). La amplitud de su distribución geográfica hace que estos jarales presenten una elevada diversidad de razas geográficas y formas ecológicas.

Los nombres utilizados anteriormente para los jarales sobre materiales silíceos del Campo de Gibraltar y litoral occidental de Málaga han sidoCalicotomo villosae-Genistetum lanuginosae y Ulici borgiae-Cistetum ladaniferi. El primero de ellos constituiría una subasociación oriental (marbellí) sobre esquistos del Cistetum africani-monspeliensis y el segundo (exceptuando la subasociación sobre serpentinas) es un sinónimo de Calicotomo-Genistetum lanuginosae, éste publicado con anterioridad. Las subasociaciones genistetosum umbellatae y genistetosum triacanthi del CalicotomoGenistetum pasarían automáticamente a subordinarse al Cistetum africanimonspeliensis, igualmente ocurre con la subasociación halimietosum serpentinicolae de Ulici borgiae-Cistetum ladaniferi. Por tanto, el esquema sintaxonómico de esta nueva asociación, con sus correspondientes subasociaciones y las novedades sintaxonómicas quedaría del siguiente modo: Cistetum africani-monspeliensis Pérez Latorre, Galán de Mera y Cabezudo ass. nova cistetosum monspeliensis

genistetosum lanuginosae (Martínez Parras, Peinado y De la Cruz 1987) Pérez Latorre, Galán de Mera y Cabezudo comb. et stat. nov. (gneises, micaesquistos y pizarras. Marbellí occidental)[Calicotomo villosaeGenistetum lanuginosae Martínez Parras, Peinado Lorca \& De la Cruz Rot 1987 corr. Pérez Latorre, Galán de Mera, Deil y Cabezudo 1996, Ulici borgiae-Cistetum ladaniferi Asensi \& Díez Garretas 1988]

halimietosum serpentinicolae (Asensi y Díez 1988) Pérez Latorre, Galán de Mera y Cabezudo comb. nova (serpentinas. Bermejense) [Ulici borgiae-Cistetum ladaniferi halimietosum serpentinicolae Asensi y Díez Garretas 1988]

genistetosum umbellatae (Martínez Parras, Peinado y De la Cruz 1987) Pérez Latorre, Galán de Mera y Cabezudo comb. nova (gneises, micaesquistos y pizarras. Marbellí oriental) [Calicotomo villosaeGenistetum hirsutae genistetosum umbellatae Martínez Parras, Peinado Lorca \& De la Cruz Rot 1987]

genistetosum triacanthi (Pérez Latorre, Nieto Caldera y Cabezudo 1993) Pérez Latorre, Galán de Mera y Cabezudo comb. nova (tránsito 
Tabla 7

Cistetum africani-monspeliensis Pérez Latorre, Galán de Mera y Cabezudo ass. nova cistetosum monspeliensis, genistetosum triacanthi subass. nova

(Cisto-Lavanduletea, Lavanduletalia, Ulici-Cistion, Ulici-Calicotomenion)

\begin{tabular}{|c|c|c|c|c|c|c|c|c|c|c|c|c|c|c|c|}
\hline Inventario $\mathrm{n}^{\circ}$ & 1 & 2 & 3 & 4 & 5 & 6 & 7 & 8 & 9 & 10 & 11 & 12 & & & 15 \\
\hline Área $\mathrm{m}^{2}$ & 30 & 100 & 50 & 100 & 100 & 100 & 100 & 100 & 100 & 100 & 150 & & & & 100 \\
\hline Altitud (Dm) & 20 & 23 & 23 & 3 & 14 & 14 & 7 & 6 & 15 & 5 & 20 & 82 & 2 & 80 & 18 \\
\hline Orientación & - & - & - & - & SE & SE & - & - & - & $\mathrm{S}$ & $\mathrm{S}$ & - & $\mathrm{S}$ & $\mathrm{N}$ & NO \\
\hline \multicolumn{16}{|c|}{ Características y diferenciales de asociación y subalianza } \\
\hline Cistus ladanifer africanus & + & 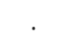 & . & . & 4 & 4 & 1 & 1 & 2 & 4 & 4 & 4 & 2 & 2 & 3 \\
\hline Adenocarpus telonensis & 2 & & & & 1 & 2 & & 1 & 1 & + & + & + & + & + & 1 \\
\hline Ulex borgiae & . & 1 & 1 & 2 & . & . & . & . & & + & . & 2 & 1 & + & . \\
\hline Calicotome villosa & . & . & . & + & + & + & . & . & + & + & . & . & 1 & . & . \\
\hline \multicolumn{16}{|c|}{ Diferenciales de subasociación } \\
\hline Genista triacanthos & . & . & . & . & & & . & & . & + & + & 1 & + & + & 1 \\
\hline Erica scoparia & . & . & . & . & 2 & 1 & . & . & + & . & . & . & . & . & 3 \\
\hline Genis & . & . & . & . & . & . & + & + & . & & & . & . & . & . \\
\hline Calluna & . & . & . & . & . & . & . & & . & . & 1 & . & . & . & + \\
\hline Staur & . & . & . & . & . & . & . & . & . & . & $\cdot$ & . & & + & + \\
\hline Cistu & . & . & . & . & . & . & & . & . & . & . & . & . & 3 & . \\
\hline mbellata & . & . & . & . & . & . & . & & . & . & . & . & . & . & + \\
\hline Thymelaea villosa & & . & . & . & . & . & . & . & . & . & . & . & . & . & + \\
\hline \multicolumn{16}{|c|}{ Características de unidades superiores } \\
\hline Cistus monspeliensis & 3 & 5 & 4 & 5 & 2 & 2 & 4 & 4 & 4 & . & 2 & 2 & 3 & 1 & 1 \\
\hline Lava & 1 & . & . & . & . & . & & + & + & + & 1 & 1 & 2 & 1 & 1 \\
\hline Cistu & 1 & . & 1 & . & . & . & . & . & . & + & + & . & . & . & + \\
\hline Cistu & 2 & & 1 & & . & . & . & . & . & + & . & . & . & + & + \\
\hline Cistus albidus & . & . & 1 & 1 & . & . & . & . & & . & . & . & & & $\cdot$ \\
\hline \multicolumn{16}{|l|}{ Compañeras } \\
\hline Phlomis purpurea & 1 & 2 & 2 & 1 & 1 & 1 & 1 & 1 & 1 & 1 & + & + & 2 & 1 & + \\
\hline Pistacia lentiscu & + & 2 & 2 & 2 & 1 & 1 & 1 & & 1 & 1 & + & . & + & + & 1 \\
\hline Phillyre & . & + & . & . & 1 & 1 & + & 1 & 1 & . & . & + & + & + & + \\
\hline Que & . & . & . & . & 2 & + & . & & . & + & + & . & + & + & 1 \\
\hline Cham & . & + & . & + & 1 & . & . & 1 & . & 1 & + & . & 1 & & . \\
\hline Querc & + & . & . & . & & . & + & + & . & . & . & + & 1 & 1 & \\
\hline Myrtus communis & . & . & . & . & 1 & . & & 1 & & . & . & 1 & + & . & 1 \\
\hline Asphodelus ramosus & + & . & . & . & 1 & + & . & & + & . & . & . & . & & . \\
\hline$n$ fruticans & & . & . & + & . & . & . & . & . & . & . & . & + & 1 & + \\
\hline Eric & . & + & + & . & . & . & . & & & . & . & . & . & + & 1 \\
\hline Olea & & . & . & . & . & + & . & . & . & + & . & . & + & & + \\
\hline Osyris quadripartita & . & & . & & . & 1 & . & . & & . & 1 & . & + & . & . \\
\hline Phillyrea latifolia & . & 1 & . & 1 & . & . & & & . & . & $\cdot$ & $\cdot$ & $\cdot$ & $\cdot$ & + \\
\hline Vinca difformis & & . & . & . & . & $\cdot$ & 1 & 1 & . & . & . & & . & . & . \\
\hline Smilax aspera & . & + & . & . & . & . & . & . & . & . & . & . & . & . & + \\
\hline & . & & . & . & . & . & . & . & . & . & + & i & + & . & . \\
\hline & . & . & . & . & . & $\cdot$ & . & . & . & . & . & 1 & . & + & . \\
\hline Cytisus grandiflorus & & . & . & . & . & . & . & . & . & . & . & + & . & + & . \\
\hline Arbutus unedo & . & . & . & . & . & . & . & . & $\cdot$ & $\cdot$ & $\cdot$ & $\cdot$ & . & + & + \\
\hline
\end{tabular}

Otros táxones.- Brachypodium retusum 1 en 3; Aristolochia baetica + en 7; Rhamnus oleoides + en 9; Genista linifolia + en 10; Anthyllis gerardi + en 11; Quercus broteroi + en 12; Daphne gnidium +, Rubia peregrina + y Quercus broteroi 1 en 14; Viburnum tinus + y Ruscus aculeatus + en 15.

Localidades.- 1: Patrite, Alcalá de los Gazules, Cádiz. 2, 4, 8 y 9: Casas de las Peñas, Alcalá de los Gazules, Cádiz. 3, 5 y 6: Tajo de Figura, Benalup, Cádiz. 7: De Cerro de Malpica a la Nava, Medina Sidonia, Cádiz. 8: Cerro de Malpica, Medina Sidonia, Cádiz. 10: Sierra del Retín, Barbate, Cádiz. 11: Cerro Almazán, Medina Sidonia, Cádiz. 12 y 14: Monte Guadares, Grazalema, Cádiz. 13: Torre Guadiaro, San Roque, Cádiz. 15: Garcisobaco, Jerez de la Frontera, Cádiz. 
a Stauracanthenion boivinii) [Calicotomo villosae-Genistetum hirsutae genistetosum triacanthi Pérez Latorre, Nieto Caldera \& Cabezudo 1993]

La subasociación genistetosum triacanthi indica la variante más húmeda del Cistetum africani-monspeliensis y significa la transición hacia los brezales de Calluno-Ulicetea a través de plantas como Genista triacanthos y Stauracanthus boivinii, apareciendo en áreas con ombroclima húmedo del Parque.

\section{Trifolio cherleri-Plantaginetum bellardii anthoxanthetosum ovati Galán de Mera subass. nova}

\section{[Tabla 8, sintypus: inv. 4]}

Pastizal terofítico silicícola de carácter pionero que se asienta sobre suelos arenosos formados a partir de las areniscas aljíbicas. Se suele desarrollar en pendientes suaves donde no existe acumulación del agua de escorrentía que conduzca a hidromorfía alguna.

Trifolio-Plantaginetum es una asociación de óptimo luso-extremadurense (Rivas Goday, 1957, 1964) aunque se muestra muy bien representada en el sector Aljíbico mediante esta nueva subasociación, cuyas diferenciales son Anthoxanthum ovatum (onubense y aljíbica) y Biscutella baetica (araceno-pacense, bética, aljíbica y tingitana).

Desde el punto de vista dinámico es una etapa muy avanzada del aclarado de alcornocales subhúmedos (Myrto-Quercetum suberis) y húmedos (Teucrio-Quercetum suberis). Hacia medios más encharcados y arenosos contacta con la asociación de hidroterófitos Loto-Chaetopogonetum fasciculati, a la que llega a sustituir fenológicamente al secarse el suelo con el avance de la primavera.

Laurentio-Juncetum tingitani Rivas Goday y Borja in Rivas Goday 1968 ex Galán de Mera (designado aquí).

[Tabla 9, neosintypus: inv. 2 ]
Comunidad tingitano-onubo-algarviense que se asienta sobre suelos arenosos poco cohesionados, ácidos y con aguas efímeras superficiales corrientes, en zonas con ombroclima húmedo-hiperhúmedo.

Si bien el nombre de la asociación está basado en Juncus tingitanus, endemismo iberomarroquí-atlántico (Fernández Carvajal, 1983), algunos autores (Nezadal et al., 1994) insisten en la sinonimia de $J$. tingitanus $(=J$. fasciculatus Schousboe) y J. hybridus $(=J$. fasciculatus Bertol.), tal vez debido a que $J$. tingitanus es muy escaso; la ausencia de material herborizado es evidente, pues este taxon no aparece citado en la Flora de Andalucía Occidental. Laurentio-Juncetum es vicariante del Isoeto-Cicendietum cántabro-atlántico (Braun-Blanquet, 1967) y del Isoeto histricisJuncetum capitati- Argelia y Túnez (BraunBlanquet, 1936). Se diferencia del LaurentioAnthoceretum - península Tingitana (BraunBlanquet, 1936; Moor, 1937; Chevassut y Quézel, 1956) por la ausencia de estrato muscinal al no desarrollarse en cubetas y oquedades de aguas estancadas. La subasociación pinguiculetosum lusitanicae (Deil, 1997) significa la transición hacia suelos profundos con muy baja oxigenación.

\section{Molinio-Arrhenatheretea: Gaudinio fragilis- Hordeion bulbosi \\ Hedysaro-Phalaridetum glossopappetosum macroti (Galán de Mera 1995) Galán de Mera comb. nova}

(Convolvulo meonanthi-Hedysaretum coronarii glossopapetosum macroti Galán de Mera 1995)

La alianza Gaudinio-Hordeion bulbosi reúne a comunidades de prados vivaces caracterizados por gramíneas bulbosas (Hordeum bulbosum, Phalaris coerulescens) y leguminosas (Hedysarum coronarium, Trifolium baeticum, $T$. isthmocarpum, $T$. squamosum) que les confieren un buen valor pastoral. Su óptimo es mediterráneo occidental, 
Tabla 8

Trifolio cherleri-Plantaginetum bellardii Rivas Goday 1957

anthoxanthetosum ovati Galán de Mera subass. nova

(Helianthemetea, Helianthemetalia, Helianthemion)

Inventario $\mathrm{n}^{\circ}$

Área $\left(\mathrm{m}^{2}\right)$

Altitud (Dm)

$\begin{array}{lllllllllll}1 & 2 & 3 & 4 & 5 & 6 & 7 & 8 & 9 & 10 & 11 \\ 20 & 5 & 10 & 10 & 10 & 10 & 10 & 10 & 10 & 10 & 5 \\ 10 & 10 & 12 & 13 & 12 & 5 & 5 & 39 & 10 & 10 & 41\end{array}$

Características de asociación y alianza

Plantago bellardii

Trifolium cherleri

Ornithopus pinnatus

Hypochaeris glabra

Paronychia echinulata

Stachys arvensis

Diferenciales de subasociación

Anthoxanthum ovatum

Biscutella baetica

Características de orden y clase

Vulpia myuros

Tuberaria guttata

Leontodon longirrostris

Rumex bucephalophorus

Tolpis barbata

Ornithopus compressus

Euphorbia exigua

Logfia gallica

Briza maxima

Brachypodium distachyon

Trifolium campestre

Ornithopus isthmocarpus

Tuberaria macrosepala

Trifolium arvense

Anthyllis lotoides

Pistorinia brevifolia

Reseda media

Compañeras

Linum bienne

Petrorhagia dubia

Plantago coronopus

Lotus subbiflorus

Anthemis arvensis

Erodium primulaceum

Anagallis arvensis

Vulpia ciliata

Gaudinia fragilis

\begin{tabular}{|c|c|c|c|c|c|c|c|c|c|c|}
\hline 4 & 4 & 4 & 4 & 5 & 4 & 4 & 3 & 2 & 5 & 3 \\
\hline . & 1 & 3 & 1 & 3 & 1 & 2 & 2 & 3 & 1 & 2 \\
\hline 1 & 1 & 1 & 1 & 3 & 1 & . & . & 1 & 1 & 1 \\
\hline . & + & . & + & 1 & + & . & + & . & . & 1 \\
\hline 1 & + & + & 1 & . & . & . & . & . & . & . \\
\hline+ & . & . & + & . & & . & . & . & + & . \\
\hline 1 & + & . & 1 & 1 & . & . & 1 & 1 & 2 & 1 \\
\hline 1 & . & + & 1 & 1 & & . & . & . & 1 & . \\
\hline 2 & 1 & 1 & . & 1 & 1 & 2 & 1 & 1 & 2 & . \\
\hline 1 & 1 & 2 & 1 & 2 & 1 & . & 1 & . & 1 & 1 \\
\hline 1 & 1 & . & + & . & 1 & 1 & & . & + & . \\
\hline 1 & . & + & 1 & + & & . & 1 & + & & . \\
\hline 1 & 1 & + & . & 1 & 1 & . & 1 & . & & . \\
\hline & & 2 & & 1 & . & 1 & 2 & 1 & . & 1 \\
\hline 1 & 1 & . & . & + & & . & + & . & 1 & . \\
\hline 2 & + & 1 & . & . & . & 1 & . & . & & \\
\hline 1 & . & . & + & & & . & . & 1 & & + \\
\hline 1 & . & . & 1 & 1 & + & . & . & . & & . \\
\hline & & . & . & . & 1 & 1 & 1 & . & . & 1 \\
\hline & . & 2 & 1 & . & & . & . & . & 4 & \\
\hline . & . & + & . & 2 & . & . & . & . & + & \\
\hline 1 & . & . & . & & . & 1 & . & . & & . \\
\hline+ & . & . & . & . & & . & & . & & + \\
\hline . & + & . & . & & & . & 1 & . & . & . \\
\hline & . & . & 1 & . & & . & . & . & + & . \\
\hline+ & + & + & 1 & 1 & + & . & . & + & & . \\
\hline & . & 1 & . & 1 & & & 1 & 1 & 1 & 1 \\
\hline 1 & 1 & 3 & . & . & + & 1 & . & . & . & \\
\hline . & & . & + & 1 & & 1 & . & + & + & . \\
\hline . & & + & . & + & . & . & . & 1 & . & + \\
\hline+ & & + & . & + & . & . & . & . & & \\
\hline . & . & . & + & + & . & . & . & . & + & . \\
\hline . & . & $\cdot$ & . & 1 & & & & . & 1 & . \\
\hline . & . & . & . & . & & 2 & . & . & & 1 \\
\hline
\end{tabular}

Otras características de orden y clase: Filago pyramidata 1 en 1; Campanula lusitanica 1, Asterolinon linum-stellatum 1 en 4; Trifolium scabrum + en 7; Aira uniaristata I en 8 y Moenchia octandra + en 9.

Otros táxones: Echium plantagineum + , Trifolium angustifolium,+ Poa bulbosa + , Trifolium glomeratum + y Chaetopogon fasciculatus + en 1; Anacyclus clavatus 1 en 1 y 4; Ranunculus paludosus + , Lythrum junceum +, Briza minor + y Medicago polymorpha + en 2 ; Centaurium maritimum + en 2 y 3; Otospermum glabrum + e Hypochaeris platylepis + en 3; Molineriella australis + en 3 y 9; Misopates grandiflorum +, Juncus capitatus + y Kickxia cirrhosa + en 4; Cynodon dactylon + en 5; Avena barbata + en 5 y 6 ; A egilops geniculata + en 5 y 8; Eruca longirostris + en 5 y 10; Bromus hordeaceus +. Hedypnois cretica + y Crepis capillaris + en 6; Trifolium tomentosum 2 en 6 y 7; Trifolium squamosum + en 6 y 11; Ononis filicaulis +, Vulpia geniculata +, Carduus pycnocephalus + y Spergularia rubra + en 7; Silene gallica +, Corrigiola perez-larae +, Scorpiurus vermiculatus + y Galactites tomentosa + en 8; Scorpiurus sulcatus +, Carex distans + y Erodium cicutarium + en 9; Plantago serraria + en 10; Dactylis hispanica + , Centranthus calcitrapae + . Cynosurus echinatus + , Bellis sylvestris + y Trifolium stellatum + en 11 .

Localidades.- 1: Majada de los Lirios, Alcalá de los Gazules, Cádiz. 2: La Palmosa, Alcalá de los Gazules, Cádiz. 3 y 5: La Peguera, Alcalá de los Gazules, Cádiz. 6 y 7: El Brecial Chico, Medina Sidonia, Cádiz. 8: K12 carretera del Picacho, Alcalá de los Gazules, Cádiz. 9: Entre El Torero y El Jautor, Alcalá de los Gazules, Cádiz. 10: El Jautor, Alcalá de los Gazules, Cádiz. 11: Puerto de Gális, Jerez de la Frontera, Cádiz. 
Tabla 9

Laurentio-Juncetum tingitani Rivas Goday \& Borja in Rivas Goday 1968 (Isoeto-Nanojuncetea, Scirpetalia, Cicendion)

\begin{tabular}{lccccccccc}
\hline Inventario $\mathrm{n}^{\circ}$ & 1 & 2 & 3 & 4 & 5 & 6 & 7 & 8 & 9 \\
Área $\left(\mathrm{m}^{2}\right)$ & 1 & 1 & 0.5 & 0.2 & 2 & 2 & 3 & 1 & 1 \\
Altitud $(\mathrm{Dm})$ & 40 & 40 & 40 & 18 & 39 & 40 & 40 & - & -
\end{tabular}

Características de asociación y unidades superiores:

Solenopsis laurentia

Juncus tenageia

Scirpus cernuus

Lotus subbiflorus

Juncus capitatus

Juncus hybridus

Cicendia filiformis

Radiola linoides

Lythrum portula

Juncus buffonius

Scirpus pseudosetaceus

Mentha pulegium

Illecebrum verticillatum

Centaurium maritimum

Diferenciales de subasociación

Pinguicula lusitanica

Isoetes histrix

Eleocharis multicaulis

\section{Compañeras:}

Briza minor

Anthoxanthum ovatum

Aira uniaristata

Filago gallica

Lythrum junceum

Ornithopus pinnatus

Tolpis barbata

Euphorbia exigua

$\begin{array}{lllllllll}2 & 3 & 2 & 4 & + & 1 & 1 & 2 & 1 \\ 1 & 1 & 1 & 1 & + & . & 1 & . & . \\ 1 & 1 & 1 & . & 1 & 1 & 1 & . & . \\ 1 & + & + & + & + & . & + & . & . \\ . & 1 & + & 1 & 2 & 1 & 3 & 1 & + \\ + & 2 & 1 & 1 & . & 1 & . & + & + \\ + & 1 & 1 & + & . & . & . & 2 & 1 \\ . & . & . & 3 & 2 & . & 1 & + & 1 \\ 1 & . & 1 & . & . & . & . & . & . \\ . & . & . & . & . & + & 2 & . & . \\ . & . & . & . & . & . & . & 2 & 1 \\ + & . & . & . & . & . & . & . & . \\ 1 & . & . & . & . & . & . & . & . \\ . & . & . & . & . & . & . & . & +\end{array}$

Otros táxones: Trifolium dubium + , Silene laeta + y Baldellia ranunculoides + en 1; Anagallis tenella + en 3; Gastridium ventricosum + en 5; Anagallis crassifolia + en 6; Xolantha guttata + en 7; Danthonia decumbens 1 en 8; Carex serrulata + , Anagallis arvensis + , Juncus striatus 1 y Plantago coronopus + en 9.

Localidades.- 1 y 3: Altos de Majada Escobar, Alcalá de los Gazules, Cádiz. 2, 5, 6 y 7: Cerro de las Callejuelas, Puerto de Gális, Jerez de la Frontera, Cádiz. 4: Sierra del Niño, Moheda del Muerto, Los Barrios, Cádiz. 8 y 9: Sierras de Algeciras, Cádiz (tomados de Deil, 1997). 
desde Italia al $\mathrm{S}$ de la Península Ibérica, en áreas con una alta humedad oceánica (Gounot, 1958; Lucchese y Pignatti, 1990; Scoppola y Pelosi, 1995; Galán de Mera et al., 1997). En el territorio estudiado está representada por la asociación Hedysaro coronarii-Phalaridetum coerulescentis que muestra una variabilidad bastante amplia en función de su uso por el hombre. El abandono del pastizal de HedysaroPhalaridetum conduce al enriquecimiento con Convolvulus meonanthus y, por tanto, a Hedysaro-Phalaridetum convolvuletosum meonanthi, que se desarrolla sobre suelos silíceos (Deil, 1998). Sobre suelos básicos, se incorpora Glossopapus macrotus a la composición del pastizal, lo que hace necesaria la nueva combinación Hedysaro-Phalaridetum glossopapetosum macroti.

Anagallido-Juncetum bulbosi Br. - B1. 1967 [Tabla 10]

Es una asociación descrita por BraunBlanquet (1967) en el N de España con pequeñas plantas vivaces atlánticas que pueblan lodos inundados temporalmente, y tiene una composición florística (Anagallis tenella, Eleocharis multicaulis, Hypericum elodes, Pinguicula lusitanica, Scutellaria minor y Wahlenbergia hederacea) que se vuelve a repetir al O y S de la Península Ibérica (Rivas Goday, 1964; Velasco Negueruela, 1980). Aunque nuestros inventarios han sido levantados en un área relativamente próxima a donde se tomaron los de la asociación Junco emmanuelis-Eleocharitetum multicaulis, descrita por Rivas Martínez et al. (1980) de Doñana, en el sector Aljíbico están ausentes sus plantas características (Juncus emmanuelis, J. heterophyllus, Thorella verticillatinundata y Scorzonera fistulosa) lo que no permite ampliar el área de esa asociación hasta nuestro territorio.

Callitricho stagnalis-Ranunculetum saniculifolii Galán de Mera ass. nova
[Tabla 11, sintypus: inv. 16]

La alianza Ranunculion aquatilis tiene su centro de distribución en Europa central (Passarge, 1992), y al SO de la Península Ibérica llega ya empobrecida, aunque con algunos táxones, de areal mediterráneo o atlántico (Pizarro, 1995), por lo que es posible describir algunos sintáxones.

Callitricho-Ranunculetum representa vegetación mediterránea occidental que coloniza cubetas poco profundas, arroyos y pequeños regatos que se secan rápidamente a principios del verano. El medio en el que se desarrolla son aguas ligeramente ácidas con un cierto grado de eutrofía. Su combinación florística habitual está constituida por Callitriche brutia, C. cribosa, C. stagnalis y Ranunculus saniculifolius. Las comunidades más próximas a esta asociación desde el punto de vista ecológico son: Ranunculetum baudotii Br.-B1. 1952 (europea y norteagricana, eútrofa, basófila) y Ranunculetum peltati Segal 1967 (europea y norteafricana, de aguas oligótrofas, acidófilas).

Ranunculetum tripartiti Galán de Mera ass. nova

[Tabla 11, sintypus: inv. 20]

Comunidad acuática turfófila, atlántica e iberomarroquí-atlántica, de aguas térmicas someras estancadas, caracterizada por Ranunculus tripartitus.

Callitrichetum regis-jubae Galán de Mera ass. nova

[Tabla 11, sintypus: inv. 21]

Fitocenosis mediterránea occidental caracterizada por Callitriche regis-jubae, que se desarrolla sobre suelos ácidos por donde discurren aguas distróficas superficiales de rápida desaparición. Al presentarse sobre sustratos bastante ácidos se puede dar el contacto con los elementos turfófilos de Anagallido-Juncetum bulbosi. 
Tabla 10

Anagallido-Juncetum bulbosi Br.-Bl. 1967

(Isoeto-Littorelletea, Littorelletalia, Hyperico-Sparganion)

$\begin{array}{lccccccccccccccc}\text { Inventario } \mathrm{n}^{\mathbf{0}} & 1 & 2 & 3 & 4 & 5 & 6 & 7 & 8 & 9 & 10 & 11 & 12 & 13 & 14 & 15 \\ \text { Área }\left(\mathrm{m}^{2}\right) & 1 & 1 & 2 & 2 & 1 & 1 & 2 & 1 & 2 & 0.5 & 1 & 2 & 1 & 1 & 1 \\ \text { Altitud }(\mathrm{Dm}) & 59 & 37 & 80 & 40 & 44 & 40 & 39 & 37 & 46 & 37 & 19 & 40 & 8 & 2 & 2\end{array}$

Características de asociación y unidades superiores:

Eleocharis multicaulis

Anagallis crassifolia

Juncus bulbosus

Pinguicula lusitanica

Anagallis tenella

Juncus fontanesii

Baldellia ranunculoides

Hydrocotyle vulgaris

Sphagnum auriculatum

\section{Compañeras:}

Briza minor

Lythrum junceum

Juncus hybridus

Scirpus cernuus

Anthoxanthum ovatum

Potentilla erecta

Erica ciliaris

Trifolium dubium

Silene laeta

Danthonia decumbens

Mentha pulegium

Gaudinia fragilis

Hypochoeris platylepis

Fuirena pubescens

Juncus buffonius

Ranunculus ophioglossifolius+

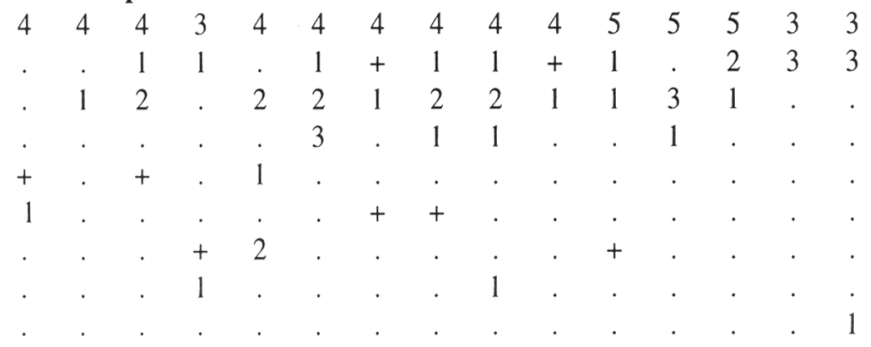

Isoetes hystrix

Otros táxones: Lotus subbiflorus y Cotula coronopifolia en 1; Trifolium pallidum y Oenanthe globulosa en 2; Juncus tenageia I en 2 y 9; Samolus valerandi y Ranunculus macrophyllus en 3; Lobelia urens y Juncus articulatus en 4; Carex distans en 4 y 8; Holcus lanatus en 4 y 11; Centaurium maritimum en 6; Aira uniaristata en 7; Juncus striatus en 10; Cicendia filiformis en 12 y 13; Carex sp. en 13.

Localidades.- 1: Refugio del Picacho, Alcalá de los Gazules, Cádiz. 2: K16 de Alcalá de los Gazules al Puerto de Gális, Cádiz. 3: Fuente de Juan Vela, Alcalá de los Gazules, Cádiz. 4: Altos de Majada Escobar, Alcalá de los Gazules, Cádiz. 5: Base del Picacho, Alcalá de los Gazules, Cádiz. 6, 7 y 12: Cerro de las Callejuelas en el Puerto de Gális, Jerez de la Frontera, Cádiz. 8 y 10: Garganta de los Laureles, Alcalá de los Gazules, Cádiz. 9: Hoya de los Calderos en el Puerto de Gális, Jerez de la Frontera, Cádiz. 11: Sierra del Niño, Moheda del Muerto, Los Barrios, Cádiz. 13: Cap Spartel, Tanger, Marruecos. 14 y 15: A 20 Km desde Larache a Tetuán, Marruecos. 
Tabla 11

1-18: Callitricho stagnalis-Ranunculetum saniculifolii Galán de Mera ass. nova

19-20: Ranunculetum tripartiti Galán de Mera ass. nova

21-22: Callitrichetum regis-jubae Galán de Mera ass. nova

(Potametea, Potametalia, Ranunculion aquatilis)

Inventario $\mathrm{n}^{\text {? }}$

Área $\left(\mathrm{m}^{2}\right)$

Altitud (Dm)

Profundidad $(\mathrm{cm})$

$\begin{array}{ccccccccccccccccccccc}1 & 2 & 3 & 4 & 5 & 6 & 7 & 8 & 9 & 10 & 11 & 12 & 13 & 14 & 15 & 16 & 17 & 18 & 19 & 20 & 2122 \\ 0.5 & 2 & 0.50 .50 .5 & 3 & 1 & 1 & 0.2 & 0.1 & 0.2 & 0.5 & 5 & 0.2 & 2 & 2 & 5 & 10 & 0.3 & 0.30 .51 \\ 30 & 20 & 30 & 45 & 50 & 8 & 48 & 45 & 41 & 40 & 30 & 30 & 30 & 40 & 10 & 40 & 30 & 30 & 7 & 30 & 2020 \\ 2 & 20 & 10 & 5 & 1 & 90 & 2 & 2 & 10 & 5 & - & 5 & 4 & - & 10 & 5 & 3 & 2 & 20 & 2 & -\end{array}$

Características de asociaciones y unidades superiores:

Callitriche stagnalis

Callitriche stagnalis

Callitriche brutia

Ranunculus saniculifolius

Ranunculus tripartitus

Callitriche regis-jubae

Callitriche cribosa

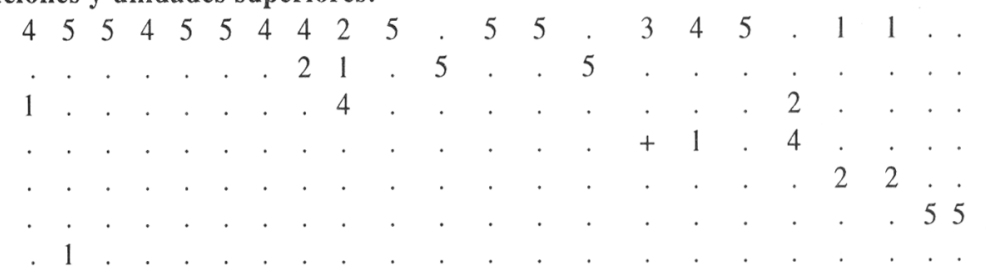

\section{Compañeras:}

Apium nodiflorum

Ranunculus macrophyllus

Juncus hybridus

Baldellia ranunculoides

Nasturtium officinale

Juncus striatus

Hydrocotyle vulgaris

Poa sylvicola

Lemna minor

Stellaria alsine

Chara sp.

Juncus capitatus

Glyceria declinata

Scirpus maritimus

Lythrum portula

Lythrum junceum

Juncus bulbosus

Localidades.- 1: Las Gargantillas, Los Barrios, Cádiz, aguas estancadas. 2: Zanona, Los Barrios, Cádiz, aguas estancadas. 3: Montifarti, Jerez de la Frontera, Cádiz, aguas estancadas. 4: Garganta del Medio, Jerez de la Frontera, Cádiz, aguas corrientes. 5: Hoya de los Calderos, Jerez de la Frontera, Cádiz, aguas corrientes. 6: Cortijo del Alamo, Alcalá de los Gazules, Cádiz, pozo. 7 y 8: Base del Picacho, Alcalá de los Gazules, Cádiz, aguas corrientes. 9, 10 y 16: Altos de Majada Escobar, Alcalá de los Gazules, Cádiz, aguas corrientes. 11: Garganta de Alberite, Alcalá de los Gazules, Cádiz, terrestre. 12: Garganta de los Laureles, Alcalá de los Gazules, Cádiz, aguas estancadas. 13: El Sauzal, Alcalá de los Gazules, Cádiz, aguas estancadas. 14: Garganta de Puerto Oscuro, Alcalá de los Gazules, Cádiz, terrestre. 15: Valle de la Peguera, Alcalá de los Gazules, Cádiz, aguas estancadas. 17: Garganta del Montero, Alcalá de los Gazules, Cádiz, aguas estancadas. 18: Salida de Benalup hacia los Barrios, Cádiz, aguas estancadas. 19 y 20: Altos de Majada Escobar, Alcalá de los Gazules, Cádiz, aguas estancadas. 21: Sierra Blanquilla, Casa de los Garlitos, Los Barrios, Cádiz, aguas superficiales. 22: Charco Dulce, Medina Sidonia, Cádiz, aguas superficiales. 


\section{Series de vegetación}

Aunque la vegetación del Parque se encuentra en un estado bastante óptimo de conservación, con predominio de cabeceras de series forestales, también son muy abundantes las etapas seriales debido a las actuaciones antrópicas. Los usos de la vegetación más frecuentes en el Parque Natural son la ganadería brava y retinta, el ganado caprino, la extracción del corcho de los alcornoques, y ya en menor grado, el carboneo, aprovechamiento del palmito (Chamaerops humilis) y brezos (Erica) y la repoblación forestal (Eucaliptus camaldulensis y Pinus pinaster). A ello hay que añadir la construcción reciente de embalses (Charco Redondo), infraestructuras para el turismo, la instalación de generadores de electricidad a partir de la energía eólica (Ibarra Benlloch, 1993), autovías, conducciones de gas natural e instalaciones militares.

En este apartado, además de las comunidades implicadas en el dinamismo de las series, se citan aquellas que aún siendo dinámicamente independientes o permanentes tienen su expresión más común en el dominio territorial (climácico) de dichas series, algunas de las cuales son novedades corológicas o sinfitosociológicas para el Parque y el sector Aljíbico (Smilaci-Querceto rotundifoliae $S$, Oleo-Querceto broteroi $S$, Cytiso-Junipereto oxycedri $S$, comunidad de Pinus pinaster).

\section{Series de vegetación climatófilas}

\section{Alcornocales}

1. Myrto communis-Querceto suberis $S$. Serie iberomarroquí-atlántica, silicícola-sabulícola, termomediterránea, subhúmeda del alcornoque (Quercus suber). Faciación sobre sustratos compactos quercetoso suberi.

La vegetación climácica la constituyen alcornocales termófilos ricos en elementos arbustivos y lianas (Myrto-Quercetum suberis) que tan sólo se encuentran en el extremo norte y oeste del Parque Natural en cotas bajas. La orla o primera etapa de sustitución son madroñales con coscojas (Cytiso baeticiArbutetum unedonis quercetosum cocciferae) acompañados de pastizales nemorales de lindero (Calamintho-Galietum scabri); sobre suelos degradados se desarrollan lentiscares (Asparago aphylli-Calicotometum villosae). Al destruirse la vegetación climácica y sus orlas aparecen jarales (Cistetum africanimonspeliensis).

Pastizales: anuales (TrifolioPlantaginetum bellardii anthoxanthetosum ovati), majadales (Trifolio subterraneiPlantaginetum serrariae) y vivaces (Gaudinio fragilis-Agrostietum castellanae hypochaeridetosum platylepidis).

2. Teucrio baetici-Querceto suberis S. Serie aljíbico-tingitana, silicícola, termomesomediterránea, húmeda del alcornoque (Quercus suber). Faciación típica quercetosum suberis. Faciación ombrófila con quejigo moruno quercetoso canariensis. Faciación basófila con encina quercetoso rotundifoliae.

La vegetación forestal climácica de esta serie son alcornocales ombrófilos (TeucrioQuercetum suberis) que constituyen la mayor formación boscosa del Parque Natural y presentan tres faciaciones. La típica se desarrolla en solanas, suelos más superficiales o áreas de producción corchera donde el hombre a sustituido al quejigo por alcornoques. La faciación con Quercus canariensis aparece en laderas umbrías, suelos puntualmente hidromorfos en el interior del alcornocal o fondo de valles, y entonces los quejigos aparecen dispersos entre los alcornoques. La faciación con Quercus rotundifolia se desarrolla en zonas mesomediterráneas, sobre sustratos margo-calizos del subsector Aljíbico y lleva como etapa serial un matorral pobre en especies, aunque caracterizado por Cistus albidus y Ulex borgiae y que contrasta con el 
predominio de los brezales de Stauracanthenion boivinii de la faciación típica. Las dos primeras faciaciones presentan similares etapas seriales. La orla o primera etapa de sustitución la constituyen madroñales (Cytiso baetici-Arbutetum unedonis) y pastizales nemorales de linderos y patios de corchas (Calamintho-Galietum scabri digitaletosum bocquetii). Sobre suelos degradados se origina un lentiscar con genisteas ombrófilas (Asparago aphylli-Calicotometum villosae genistetosum linifoliae). Por destrucción de la vegetación forestal y preforestal se desarrollan brezales xerófilos con aulagas (Genisto tridentisStauracanthetum boivinii) que en zonas repetidamente incendiadas aparecen como variante de Cistus ladanifer subsp. africanus y en suelos un poco más profundos como subasociación quercetosum lusitanicae. En taludes, cortafuegos y lajas de areniscas se desarrolla el singular nanobrezal de atrapamoscas (Stauracantho-Drosophylletum lusitanici). Es destacable una variante psammófila en la zona de La Almoraima, cuya principal representación queda fuera del Parque pero que es posible caracterizar por la presencia de jaguarzales psammófilos (Cisto salvifoliiUlicetum australis).

Pastizales: Anuales (TrifolioPlantaginetum bellardii anthoxanthetosum ovati), majadales (Trifolio subterraneiPlantaginetum serrariae) y vivaces (Gaudinio fragilis-Agrostietum castellanae hypochaeridetosum platylepidis).

\section{Quejigales morunos}

\section{Rusco hypophylli-Querceto canariensis $S$.} Serie aljíbico-tingitana, silicícola, termomesomediterránea, húmedo-hiperhúmeda del quejigo moruno (Quercus canariensis).

La vegetación climácica de esta serie son los quejigales morunos (Rusco-Quercetum canariensis) que constituyen una de las formaciones forestales más singulares del Parque. Constituyen un bosque marcescente, rico en especies epífitas y lianas así como herbazales de sotobosque. Ocupan biótopos de laderas umbrías, gargantas y suelos hidromorfos, paisajísticamente muy típicos, a modo de lenguas que ascienden por el fondo de los valles. En zonas muy localizadas aparece la variante de Polystichum setiferum, indicando zonas bastante conservadas. Como orla 0 primera etapa de sustitución sobre suelos hidromorfos llevan zarzales (LoniceroRubetum ulmifolii), mientras que en los suelos normales son madroñales (Cytiso baeticiArbutetum unedonis) y pastizales nemorales de lindero (Calamintho-Galietum scabri lamietosum flexuosi). Cuando el hombre no aclara el bosque para extraer el corcho, los madroñales presentan la variante de Laurus nobilis. Sobre suelos degradados, por sustitución del madroñal, se origina un espinal con genisteas ombrófilas (Asparago aphylliCalicotometum villosae genistetosum linifoliae), que sobre suelos superficiales y podsolizados es sustituido por el brezal-aulagar con robledilla (Genisto tridentisStauracanthetum boivinii quercetosum lusitanicae) y en litosuelos por el nanobrezal (Stauracantho-Drosophylletum lusitanici).

Pastizales: Anfibios terofíticos (Laurentio-Juncetum tingitani, Pulicario uliginosae-Agrostietum salmanticae), majadales (Trifolio subterranei-Plantaginetum serrariae) y vivaces (Gaudinio fragilisAgrostietum castellanae hypochaeridetosum platylepidis).

\section{Robledales}

\section{Cytiso triflori-Querceto pyrenaicae S. Serie} aljíbico-tingitana y rifeña, silicícola, mesomediterránea, húmedo-hiperhúmeda del roble melojo (Quercus pyrenaica).

La etapa climácica de la serie son los robledales de Cytiso-Quercetum pyrenaicae 
que aparecen en las cumbres más elevadas del Parque, siempre orientados a poniente y por encima de $800 \mathrm{~m}$. La mayor parte de su areal potencial está ocupada por herrizas y pastizales xerófilos. Como orla o primera etapa de sustitución se presenta un zarzal (LoniceroRubetum ulmifolii). Cuando desaparece el robledal y el suelo se erosiona, aparecen los brezales-aulagares de carácter continental o herrizas (Genisto tridentis-Stauracanthetum boivinii quercetosum lusitanicae, variante de Erica australis) que sobre lajas de areniscas llevan Cytisus tribracteolatus y Stipa gigantea (Genisto-Stauracanthetum cytisetosum tribracteolati). En los cortafuegos y taludes o en claros con litosuelos se desarrollan nanobrezales (Stauracantho-Drosophylletum lusitanici) y en los claros del brezal, sobre suelos más profundos y arenosos el pastizal xerófilo vivaz (Deschampsio strictaeAgrostietum curtisii).

Vegetación rupícola: Sedo-Cytisetum tribracteolati.

\section{Encinares}

\section{Smilaco mauritanicae-Querceto} rotundifoliae $S$. Serie tingitano-onuboalgarviense, bética y mauritánica, basófila, termomediterránea, seca-subhúmeda de la encina (Quercus rotundifolia).

La etapa climácica de esta serie la constituyen encinares de Smilaco-Quercetum rotundifoliae, exclusivos de la zona $\mathrm{NO}$ del Parque sobre calizas y margocalizas. En hondonadas o zonas de contacto con las areniscas aljíbicas, el encinar se enriquece en quejigos (Quercus broteroi). La orla o primera etapa de sustitución son lentiscares (Asparago albi-Rhamnetum oleoidis). Sobre suelos erosionados se instalan matorrales basófilos (Asperulo hirsutae-Ulicetum scabri) que muestran una subasociación sobre suelos yesosos (Asperulo-Ulicetum anthyllidetosum cytisoidis).
Pastizales: anuales (Velezio rigidaeAstericetum aquaticae) y majadales (Trifolio subterranei-Plantaginetum serrariae).

\section{Quejigales basófilos}

6. Oleo sylvestris-Querceto broteroi S. Serie aljíbica, basófila, termomediterránea, subhúmedo-húmeda del quejigo lusitano (Quercus broteroi).

La vegetación climácica de esta serie está constituída por quejigales de Oleo-Quercetum broteroi que llevan como orla o primera etapa de sustitución lentiscares con madroños y algarrobos (Asparago albi-Rhamnetum oleoidis ceratonietosum siliquae) y pastizales nemorales de lindero (Clinopodio villosiOriganetum virentis). Cuando desaparece la vegetación forestal y preforestal, se erosionan los suelos y destacan los aulagares basófilos (Asperulo hirsutae-Ulicetum scabri).

Pastizales: anuales (Velezio rigidaeAstericetum aquaticae) y majadales (Trifolio subterranei-Plantaginetum serrariae).

\section{Series mixtas de vegetación climatófilo- edafófilas}

\section{Acebuchales}

7. Tamo communis-Oleeto sylvestris S. Serie bética, aljíbica, tingitana, atlásica y rifeña, verticícola, termo-mesomediterránea, subhúmedo-húmeda del acebuche (Olea europaea var. sylvestris). Faciación típica sobre vertisuelos xéricos oleetosum sylvestris. Faciación sobre vertisuelos con hidromorfía subterránea fraxinetosum angustifoliae. Faciación sobre margoareniscas con alcornoque quercetoso suberis. Faciación subrupícola sobre calizas ceratonietosum siliquae.

Los acebuchales (Tamo-Oleetum sylvestris) aparecen generalmente sobre los sustratos margosos que conforman la base de las sierras silíceas del Parque y a veces en 
isleos calizos o margosos ya en el interior. Dependiendo del sustrato y su grado de hidromorfía varían en su composición florística, dando como resultado la aparición de cuatro faciaciones que pueden tener etapas tanto comunes como distintivas. Como orla o primera etapa de sustitución sobre arcillas vérticas se desarrollan lentiscares con espinos (Asparago albi-Rhamnetum oleoidis), sobre margoareniscas aparecen lentiscares con jérguenes (Asparago-Calicotometum villosae), a veces difícilmente separables de la clímax por su gran desarrollo, y sobre calizas se encuentran lentiscares con algarrobos (Asparago-Rhamnetum oleoidis ceratonietosum). En el sotobosque son comunes en todas las faciaciones los herbazales escionitrófilos anuales (Fumario sepii-Geranietum purpurei). El matorral de sustitución corresponde a aulagares basófilos (Asperulo hirsutae-
Ulicetum scabri) sobre arcillas básicas y a jarales empobrecidos (Cistetum africanimonspeliensis) sobre margoareniscas.

Pastizales: anuales mesegueros (Ridolfio segeti-Capnophylletum peregrini) y de barbechos (Chrozophoro tinctoriaeTeucrietum spinosi y Kickxio lanigeraeTanacetetum annui); praderas vivaces (Hedysaro coronari-Phalaridetum coerulescentis).

Vegetación rupícola: iitosuelos en rocas calizas (Sedetum micrantho-sediformis).

$$
\text { Ojaranzales }
$$

\section{Frangulo baeticae-Rhododendreto pontici}

$S$. Serie aljíbica, monchiquense y divisorioportuguesa, silicícola, termo-mesomediterránea, húmedo-hiperhúmeda del ojaranzo (Rhododendron ponticum). Faciación típica

Figura 1. Mapa de las principales series y complejos de vegetación del Parque Natural Los Alcornocales. 1- Alcornocales silicícolas termomediterráneos subhúmedos (Myrto communis-Querceto suberis S.), faciación sobre sustratos duros; 2 - Alcornocales silicícolas termo-mesomediterráneos húmedos (Teucrio baetici-Querceto suberis $S$.); 3- Robledales silicícolas mesomediterráneos húmedo-hiperhúmedos (Cytiso triflori-Querceto pyrenaicae $S$.); 4- Quejigales silicícolas termo-mesomediterráneos húmedo-hiperhúmedos (Rusco hypophylli-Querceto canariensis S.); 5- Acebuchales verticícolas termomediterráneos subhúmedohúmedos (Tamo communis-Oleeto sylvestris S.); 6- Quejigales calcícolas termomediterráneos subhúmedohúmedos (Oleo sylvestris-Querceto broteroi S.); 7- Algarrobales calcícolas termomediterráneos subhúmedohúmedos (Clematido cirrhosae-Ceratonieto siliquae S.); 8- Encinares calcícolas termomediterráneos secosubhúmedos (Smilaco mauritanicae-Querceto rotundifoliae S.); 9- Ojaranzales silicícolas húmedohiperhúmedos (Frangulo baeticae-Rhododendreto pontici S.); 10- Quejigales enanos termomesomediterráneos (Genisto tridentis-Stauracanthetum boivinii quercetosum lusitanicae); 11- Choperas (Crataego brevispinae-Populeto albae S.); 12- Fresnedas (Ranunculo ficariae-Fraxineto angustifoliae S.); 13- Enebrales silicícolas termo-mesomediterráneos húmedos (Cytiso tribracteolati-Junipereto oxycedri S.); 14- Alisedas (Arisaro proboscidei-Alneto glutinosae S.); 15-Pinares negrales termo-mesomediterráneos (Genisto tridentis-Stauracanthetum boivinii quercetosum lusitanicae, forma relictual con Pinus pinaster).

Map of vegetation series (indicating the climax type of forest) and vegetation complexes of the Natural Park Los Alcornocales. 1- thermomediterranean subhumid Quercus suber forests on sandstones; 2 thermo-mesomediterranean humid Quercus suber forests on sandstones; 3- mesomediterranean humidhiperhumid Quercus pyrenaica forests on sandstones; 4- thermo-mesomediterranean humid-hiperhumid Quercus canariensis forests on sandstones; 5- thermo-mesomediterranean subhumid-humid Olea sylvestris forests on vertisols; 6- thermomediterranean subhumid-humid Quercus broteroi forests on limestones; 7 thermomediterranean subhumid-humid Ceratonia siliqua forests on karstic limestones; 8thermomediterranean dry-subhumid Quercus rotundifolia forests on limestones; 9- thermomesomediterranean humid-hiperhumid Rhododendron ponticum relic community; 10- thermomesomediterranean Quercus lusitanicacommunity on rocky summits; 11- Populus alba riverine forests; 12 Fraxinus angustifolia riverine groves; 13 - thermo-mesomediterranean humid Juniperus oxycedrus relic community; 14- Alnus glutinosa riverine forests; 15- thermo-mesomediterranean Pinus pinaster relic community. 


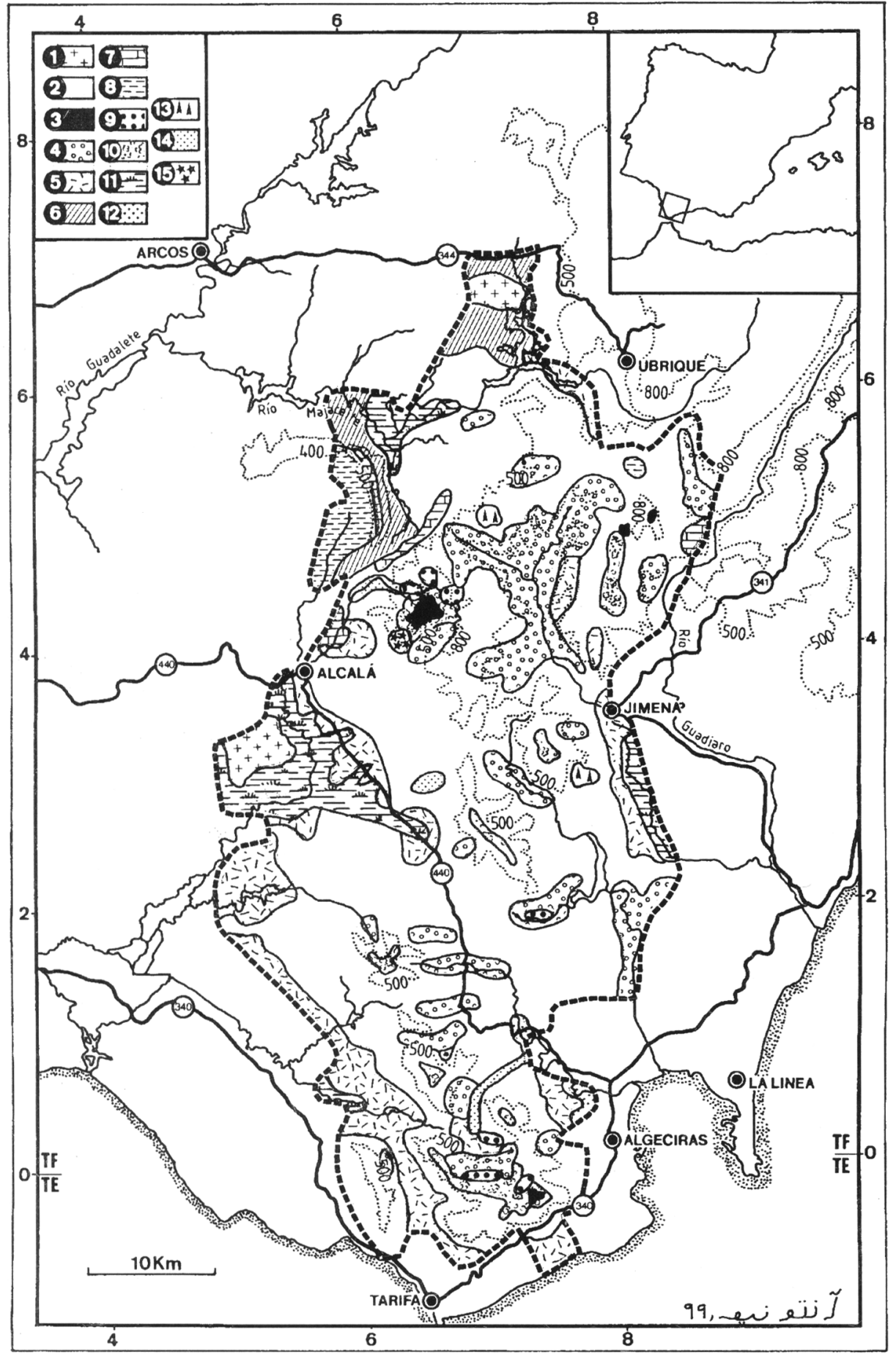


rhododendretoso pontici y faciación termomediterránea de carácter subtropical culcitetoso macrocarpae.

Esta serie constituye la vegetación más original del Parque Natural al tratarse de los relictos de laurisilva mejor conservados y de mayor extensión de la Península Ibérica y por tanto de Europa Occidental. Se desarrolla en tramos altos de gargantas y altiplanicies con suelos hidromorfos o bajo régimen constante de nieblas. La vegetación climácica corresponde a un bosque lauroide de ojaranzo (Frangulo-Rhododendretum pontici) que como orla o primera etapa de sustitución lleva un zarzal con madreselvas (Lonicero hispanicaeRubetum ulmifolii) y pastizales nemorales (Calamintho-Galietum scabri lamietosum flexuosi). Son frecuentes las comunidades briofíticas epífitas de óptimo macaronésico (Neckero pumilae-Ulotetum calvescentis, Neckero levifoliae-Porelletum canariensis). En la faciación culcitetoso macrocarpae son frecuentes comunidades brio-pteridófiticas relícticas de saltos de agua y rezumaderos (comunidad de Vandenboschia speciosa). La destrucción de estas etapas llevan a la instalación de comunidades de cárices (Caricetum mauritanicae) y otras menos exigentes como juncales (Juncetum rugosoeffusi).

Pastizales: Vivaces con pequeños helófitos y esfagnos (Anagallido-Juncetum bulbosi).

\section{Series de vegetación edafoxerófilas}

Algarrobales

\section{Clematido cirrhosae-Ceratonieto siliquae}

S. Serie bética, aljíbica, rifeña y atlásica, basófila, termomediterránea, subhúmedohúmeda del algarrobo (Ceratonia siliqua). Faciación aljíbica phlomidetoso purpureae.

La etapa climácica está constituída por un bosque de algarrobos (Clematido-Ceratonietum siliquae), cuya orla o primera etapa de sustitución son lentiscares con madroños y algarrobos (Asparago albi-Rhamnetum oleoidis ceratonietosum siliquae), y pastizales nemorales de lindero (Clinopodio villosiOriganetum virentis). Al destruirse la vegetación forestal y preforestal aparecen matorrales basófilos (Asperulo hirsutaeUlicetum scabri) que en zonas con afloramiento de yesos se enriquece con Anthyllis cytisoides (Asperulo hirsutae-Ulicetum anthyllidetosum cytisoidis).

Pastizales: Anuales (Velezio rigidaeAstericetum aquaticae).

\section{Enebrales}

10. Cytiso tribracteolati-Junipereto oxycedri $S$. Serie aljíbica, silicícola, termomesomediterránea, húmeda del enebro (Juniperus oxycedrus).

La etapa climácica de esta serie corresponde a enebrales de Cytiso-Juniperetum oxycedri, que se encuentran en pequeñas áreas del Parque sobre suelos poco desarrollados y lajas de areniscas. En mosaico con el enebral (como corresponde generalmente a la vegetación edafoxerófila) aparecen matorrales, en este caso brezales-aulagares xerófilos con Nothobartsia aspera y jaras pringosas (Genisto tridentis-Stauracanthetum boivinii var. Cistus ladanifer subsp. africanus). En zonas elevadas los pastizales son vivaces xerófilos (Deschampsio strictae-Agrostietum curtisii).

Vegetación rupícola: Sedo-Cytisetum tribracteolati.

\section{Complejos de vegetación permanente}

\section{Quejigales enanos}

\section{Genisto tridentis-Stauracanthetum} boivinii quercetosum lusitanicae. Vegetación permanente aljíbica y tingitana, termomesomediterránea, de suelos podsolizados, con 
quejigo enano (Quercus lusitanica).

Esta comunidad está constituída por brezales-aulagares de tipo herriza que se desarrollan en cumbres no colonizables por las formaciones forestales de fagáceas e incluso por formaciones arbustivas preforestales, debido al efecto abrasivo del viento y la escasa profundidad y abundante rocosidad del suelo. En mosaico aparecen pastizales vivaces xerófilos (Deschampsio strictae-Agrostietum curtisii). Son muy frecuentes en todas las cumbres más elevadas del Parque. Su situación topográfica y dinámica ya fue denunciada por Ceballos y Martín Bolaños (1930) y Ceballos y Vicioso (1933).

\section{Pinares}

\section{Genisto tridentis-Stauracanthetum} boivinii quercetosum lusitanicae, forma relictual edafoxerófila con Pinus pinaster. Vegetación aljíbica, silicícola, termomesomediterránea, de medios subrupícolas, con pino negral (Pinus pinaster)

Se trata de pinares negrales relícticos, incluidos en brezales-aulagares de carácter continental y xérico (Genisto tridentisStauracanthetum boivinii quercetosum lusitanicae var. de Erica australis) y con pastizales vivaces xerófilos (Deschampsio strictae-Agrostietum curtisii). Aparecen como vegetación permanente en canchas y lajas de areniscas muy xéricas y soleadas, donde está impedido el avance sucesional de la vegetación. Hasta el momento presentan localización muy puntual en el Parque (Cancha del Pinar, Alcalá de los Gazules, Cádiz).

\section{Nanobrezales}

\section{Stauracantho boivinii-Drosophylletum} lusitanici saturejetosum salzmannii. Vegetación permanente aljíbica, termomesomediterránea, húmeda, de litosuelos oligotrofos, con atrapamoscas (Drosophyllum lusitanicum).

Vegetación permanente de hemicriptófitos y caméfitos de pequeños biótopos xéricos y oligotróficos como taludes, cortafuegos y litosuelos, donde está impedida la colonización por especies más exigentes y de mayor biomasa. En mosaico tan sólo aparecen pastizales anuales fugaces (Trifolio-Plantaginetum bellardii anthoxantetosum ovati).

\section{Series de vegetación edafohidrófilas}

\section{Fresnedas}

14. Ranunculo ficariae-Fraxineto angustifoliae $S$. Serie iberomarroquí-atlántica del fresno (Fraxinus angustifolia). Faciación típica fraxinetoso, faciación con sauces salicetoso pedicellatae y faciación con tarajes tamaricetoso africanae.

Las fresnedas (Ficario-Fraxinetum angustifoliae) constituyen la vegetación climácica de esta serie riparia que tiene tres faciaciones. La típica se desarrolla sobre suelos arcillosos aunque arenosos en superficie, en la parte más externa de los cursos medios de los ríos; la faciación con sauces (Salix pedicellata) aparece hacia el contacto directo con el agua y finalmente la faciación con tarajes (Tamarix africana) corresponde a los fragmentos de cauces que discurren por suelos con alto contenido en sales o bases, como sucede al extremo NO del Parque y que se transforman en tarajales en cursos de agua más erráticos y con grandes avenidas. Como orla o primera etapa de sustitución se desarrolla un zarzal con madreselvas (Lonicero hispanicae-Rubetum ulmifolii), pastizales nemorales terofíticos escionitrófilos (Fumario sepii-Geranietum purpurei) y herbazales escionitrófilos (Urtico dubiae-Smyrnietum olusatri).

Pastizales: Juncales (HoloschoenoJuncetum acuti, Galio palustri-Juncetum maritimi y Scirpetum maritimi), gramadales (Trifolio resupinati-Caricetum chaetophyllae). 


\section{Choperas}

15. Crataego brevispinae-Populeto albae $S$. Serie tingitano-onubo-algarviense del chopo blanco (Populus alba).

La vegetación climácica de esta serie ripícola corresponde a choperas blancas de Crataego-Populetum albae que se desarrollan en suelos profundos arcillo-limosos de vegas en el curso bajo de los ríos y que se encharcan con las crecidas. La orla o primera etapa de sustitución la constituyen zarzales con madreselvas (Lonicero hispanicae-Rubetum ulmifolii), pastizales terofíticos nemorales escionitrófilos (Fumario sepii-Geranietum purpurei) y herbazales escionitrófilos (Urtico dubiae-Smyrnietum olusatri).

Pastizales: Juncales (HoloschoenoJuncetum acuti, Galio palustri-Juncetum maritimi y Scirpetum maritimi), gramadales (Trifolio resupinati-Caricetum chaetophyllae)

\section{Alisedas}

\section{Arisaro proboscidei-Alneto glutinosae $S$.} Serie aljíbica del aliso (Alnus glutinosa). Faciación típica alnetoso glutinosae y faciación con adelfas nerietoso oleandri.

La vegetación climácica corresponde a las alisedas (Arisaro-Alnetum glutinosae) de cursos bajos o medios (gargantas) de los ríos que transcurren sobre sustratos silíceos. Como orla o primera etapa de sustitución presentan un zarzal con madreselvas (Lonicero hispanicae-Rubetum ulmifolii), son frecuentes las comunidades de cárices en los grandes bloques del curso del río (Caricetum mauritanicae) y los pastizales escionitrófilos (Urtico dubiae-Smyrnietum olusatri). La faciación con adelfas aparece en los cursos con mayor estiaje estival.

\section{Saucedas}

\section{Equiseto telmateiae-Salicetum}

pedicellatae $S$. Serie tingitano-onuboalgarviense del sauce pedicelado (Salix pedicellata). Faciación típica salicetoso pedicellatae, faciación de cursos bajos salicetoso albae y faciación sobre sustratos calizos salicetoso angustifoliae.

La vegetación climácica de esta serie riparia corresponde a saucedas arbustivas (Equiseto-Salicetum pedicellatae) que presentan tres faciaciones. La faciación típica corresponde a cursos de agua rápidos en áreas serranas. La faciación con sauces blancos corresponde a tramos con aguas más lentas y suelos más desarrollados. Finalmente la faciación con Salix angustifolia son las saucedas sobre sustratos calizos.

Como orla o primera etapa de sustitución estas saucedas llevan un zarzal con madreselvas (Lonicero hispanicae-Rubetum ulmifolii) y herbazales escionitrófilos (Urtico dubiaeSmyrnietum olusatri). Cuando la formación riparia desaparece, se instalan comunidades de juncales (Holoschoeno-Juncetum acuti, Galio palustriJuncetum maritimi y Scirpetum maritimi).

Pastizales: gramadales (Trifolio resupinati-Caricetum chaetophyllae).

\section{Adelfares}

18. Rubo ulmifolii-Nerieto oleandri S. Serie ibérica de la adelfa (Nerium oleander).

La etapa climácica se corresponde con adelfares (Rubo-Nerietum oleandri) que se desarrollan en cauces de arroyos con estiaje total y que llevan como etapa de sustitución juncales (Holoschoeno-Juncetum acuti, Galio palustri-Juncetum maritimi y Scirpetum maritimi) y gramadales (Trifolio resupinatiCaricetum chaetophyllae).

Tarajales

19. Polygono equisetiformis-Tamariceto africanae S. Serie tingitano-onubo-algarviense y bética del taraje africano (Tamarix africana). 
Faciación típica tamaricetosum africanae y faciación aretoso italici.

La vegetación climácica corresponde a tarajales (Polygono-Tamaricetum africanae) que ocupan el lecho de arroyos y colas de embalses con fuerte encharcamiento estacional y también fuerte estiaje, en zonas con suelos y aguas ricas en sales o bases. La faciación aretoso italici aparece sobre suelos menos sometidos a grandes fluctuaciones y que permiten el desarrollo de especies arbóreas como Fraxinus angustifolia o Populus alba. Las etapas de sustitución corresponden a juncales (Holoschoeno-Juncetum acuti, Galio palustri-Juncetum maritimi y Scirpetum maritimi) y gramadales (Trifolio resupinatiCaricetum chaetophyllae).

\section{Brezales turfófilos}

20. Genisto anglicae-Ericeto ciliaris S. Serie aljíbica y tingitana del brezo ciliado (Erica ciliaris).

La vegetación climácica de esta serie corresponde a brezales hidrófilos (GenistoEricetum ciliaris) que se desarrollan en trampales y rezumaderos de aguas oligotróficas, biótopos algo frecuentes en el Parque pero de muy poca extensión. Respecto a los brezales de la Península Tingitana, en el Parque presentan la característica florística de estar sustituida Genista anglica por Genista triacanthos. Cuando estas pequeñas comunidades son destruidas aparecen como etapas de sustitución vegetación anfibia terofítica (Laurentio-Juncetum tingitani), pastizales vivaces con pequeños helófitos y esfagnos (Anagallido-Juncetum bulbosi) y juncales (Juncetum rugoso-effusi).

Mosaicos de comunidades estáticas dentro del dominio de las series de vegetación climatófilas.

21. Comunidades de corredores ecológicos (carreteras, vías pecuarias y linderos de piedra): Albardinales (Andryalo laxifloraeHyparrhenietum hirtae), vegetación viaria anual (Crassulo tillaeae-Saginetum apetalae, Anacyclo radiati-Hordeetum leporini (típica y con Chrysanthemum coronarium), cardales de taludes de carreteras y entornos antropizados (Notobasio syriacae-Scolymetum maculati y Scolymo maculati-Sylibetum mariani), y altabacares (Oryzopsio miliacei-Daucetum maximi).

22. Comunidades nitrófilas ligadas al entorno humano: Chenopodietum muralis.

23. Comunidades fisurícolas ligadas al entorno humano: vegetación de muros (Parietarietum judaicae) y paredes encaladas muy húmedas (Trachelio coeruleae-Adiantetum capilliveneris).

24. Comunidades rupícolas y de taludes húmedos de las areniscas aljíbicas: Davallio canariensis-Sedetum baetici (típica y psilotetosum nudi), Sedo baetici-Cytisetum tribracteolati y Selaginello-Anogrammetum leptophyllae (típica y arisaretosum proboscidei).

25. Comunidades epífitas con briófitos, líquenes, y pteridófitos: comunidad de Davallia canariensis y Polypodium cambricum subsp. serrulatum.

26. Comunidades rupícolas aerohalófilas: de acantilados Limonietum emarginati y de taludes arcillosos Leontodo tingitaniReichardietum picroidis.

Mosaicos de comunidades estáticas dentro del dominio de las series de vegetación edafohidrófilas

27. Comunidades nitrófilas hidrófilas: pastizales de borde de lagunas y embalses 
(Cypero micheliani-Heleochloetum alopecuroidis, Glino lotoidis-Verbenetum supinae), pastizales nitrificados y húmedos (Astero squamati-Panicetum repentis) y pastizales de graveras (Heliotropio supiniPaspaletum paspaloidis).

28. Comunidades de cauces con aguas rápidas: herbazal de grandes cárices (Caricetum mauritanicae) y herbazales helofíticos (Oenanthetum crocatae).

29. Comunidades acuáticas flotantes y sumergidas: Vegetación talofítica de ficófitos (Charetea fragilis), de acropleustófitos (Lemnetea minoris) y de hidrófitos (Potametea).

30. Comunidades halófilas y halonitrófilas de las salinas y sus canales (comunidad de Sarcocornia perennis y PlantaginiHordeetum marini).

\section{ESQUEMA SINTAXONÓMICO}

I. Vegetación potencial y orlas arbustivas siempreverdes y aciculifolias

QUERCETEA ILICIS Br.-Bl. ex A. Bolòs 1950

+ Quercetalia ilicis Br.-Bl. ex Molinier 1934 em. Rivas Martínez 1975

* Quercion suberis Loisel 1971

1. Myrto communis-Quercetum suberis Barbéro, Quézel \& Rivas Martínez 1981 (Simetho-Ericetum arboreae quercetosum suberis Nègre 1964) [Alcornocales termófilos].

quercetosum suberis [Alcornocales termófilos de sustratos duros].

2. Teucrio baetici-Quercetum suberis Rivas Martínez in Díez Garretas, Cuenca \& Asensi 1988 [Alcornocales ombrófilos]. quercetosum suberis var. de Quercus pyrenaica [variante con robles].

var. de Pistacia lentiscus [variante termomediterránea]. var. de Halimium commutatum [variante sobre arenales de interior].

quercetosum canariensis Asensi \& Díez Garretas in Díez Garretas, Cuenca \& Asensi 1988 [Alcornocales ombrófilos con quejigo moruno].

quercetosum rotundifoliae Nieto Caldera, Pérez Latorre \& Cabezudo 1990 [Alcornocal con encinas].

* Querco rotundifoliae-Oleion sylvestris Barbéro, Quézel \& Rivas Martínez in Rives Martínez, Costa \& Izco 1986

3. Smilaco mauritanicae-Quercetum rotundifoliae Barbéro, Quézel \& Rivas Martínez ex Rivas Martínez 1987 [Encinares termófilos].

4. Clematido cirrhosae-Ceratonietum siliquae phlomidetosum purpureae Martín Osorio, Díez Garretas \& Asensi 1991 [Algarrobales calcícolas]

5. Tamo communis-Oleetum sylvestris Benabid ex Pérez Latorre, Galán de Mera, Deil \& Cabezudo 1996 [Acebuchales verticícolas].

oleetosum sylvestris

quercetosum suberis Pérez Latorre, Nieto Caldera \& Cabezudo 1993 [Acebuchales verticícolas con alcornoques].

fraxinetosum angustifoliae Benabid 1984 ex Pérez Latorre, Galán de Mera, Deil \& Cabezudo 1996 [Acebuchales verticícolas con fresnos]. ceratonietosum siliquae Benabid 1984 [Acebuchales calcícolas con algarrobos].

* Quercion broteroi Br.-Bl., P. Silva \& Rozeira 1956 em. Rivas Martínez 1975 corr. Fuente 1986

6. Rusco hypophylli-Quercetum canariensis Rivas Goday \& Rivas Martínez ex Rivas Martínez 1974 (Rusco-Quercetum canariensis quercetosum suberis Asensi \& Díez Garretas in Díez Garretas, Cuenca \& Asensi 1988) [Quejigales morunos ombrófilos].

quercetosum canariensis (Rusco-Quercetum canariensis crataegetosum brevispinae Benzler, Deil \& Jung 1998)

var. de Laurus nobilis (lauretosum nobilis Nezadal, Deil \& Welss 1994) [Quejigales morunos con laureles].

var. de Polystichum setiferum (polystichetosum setiferi Benzler, Deil \& Jung 1998) [Quejigales morunos con helechos].

7. Oleo sylvestris-Quercetum broteroi Galán de Mera, Pérez Latorre \& Cabezudo ass. nova [Quejigales basófilos]. 
+ Pistacio lentisci-Rhamnetalia alaterni Rivas Martínez 1975

* Asparago albi-Rhamnion oleoidis Rivas Goday ex Rivas Martínez 1975

8. Asparago aphylli-Calicotometum villosae Rivas Martínez 1975 [Lentiscares silicícolas]. calicotometosum villosae genistetosum linifoliae Pérez Latorre, Nieto Caldera \& Cabezudo 1993 [Lentiscares silicícolas con escobones].

9. Asparago albi-Rhamnetum oleoidis Rivas Goday 1959 [Lentiscares calcícolas].

\section{rhamnetosum oleoidis}

ceratonietosum siliquae Galán de Mera subass. nova [Lentiscares calcícolas con algarrobos]. var. de Juniperus phoenicea [Variante de áreas con afloramientos de dolomías].

* Ericion arboreae Rivas Martínez (1975) 1987

10. Cytiso baetici-Arbutetum unedonis Nieto

Caldera, Pérez Latorre \& Cabezudo 1990

[ Madroñales]. arbutetosum unedonis var. de Laurus nobilis [Madroñales con laurel]. quercetosum cocciferae Nieto Caldera, Pérez Latorre \& Cabezudo 1990 [Madroñales termófilos].

* Pino pinastri-Juniperion phoeniceae Pérez Latorre \& Cabezudo 1998 in Pérez Latorre, P. Navas, D. Navas, Gil \& Cabezudo 1998

11. Cytiso tribracteolati-Juniperetum oxycedri Pérez Latorre, Galán de Mera y Cabezudo ass. nova [Enebrales edafoxerófilos silicícolas].

II. Vegetación potencial caducifolia y sus orlas arbustivas. Vegetación riparia

QUERCO-FAGETEA Br.-BI. \& Vlieger in Vlieger 1937

+ Quercetalia roboris R. Tx. 1931

* Quercion robori-pyrenaicae (Br.-Bl., P. Silva, Rozeira \& Fontes 1956) Rivas Martínez 1975

** Quercenion pyrenaicae Rivas Martínez (1962) 1975

12. Cytiso triflori-Quercetum pyrenaicae Barbéro, Quézel \& Rivas Martínez 1981

[Robledales ombrófilos].

+ Populetalia albae Br.-Bl. ex Tchou 1948

* Populion albae Br.-Bl. ex Tchou 1948

** Fraxino angustifoliae-Ulmenion minoris Rivas Martínez 1975
13. Ranunculo ficariae-Fraxinetum angustifoliae Rivas Martínez \& Costa in Rivas Martínez, Costa, Castroviejo \& Valdés 1980 [Fresnedas].

fraxinetosum angustifoliae

salicetosum pedicellatae Díez Garretas, Cuenca \& Asensi 1986 [Fresnedas con sauces].

tamaricetosum africanae (Rivas Martínez, Costa, Castroviejo \& Valdés 1980) FernándezGonzález \& Molina 1988 [Fresnedas con tarajes].

14. Crataego brevispinae-Populetum albae Galán de Mera in Pérez Latorre, Galán de Mera, Deil \& Cabezudo 1996 [Choperas de vegas].

* Osmundo-Alnion (Br.-Bl., P. Silva \& Rozeira 1956) Dierschke \& Rivas Martínez in Rivas Martínez 1975

15. Arisaro proboscidei-Alnetum glutinosae Martínez Parras \& Peinado Lorca 1987

[Alisedas].

alnetosum glutinosae

nerietosum oleandri Martínez Parras \& Peinado Lorca 1987 (incl. Frangulo-Rhododendretum nerietosum oleandri Díez Garretas, Cuenca \& Asensi 1986) [Alisedas con adelfas]

+ Salicetalia purpureae Moor 1958

* Salicion pedicellatae Galán de Mera, Pérez Latorre \& Cabezudo all. nova

16. Equiseto telmateiae-Salicetum pedicellatae Díez Garretas, Cuenca \& Asensi 1986

[Saucedas arbustivas]. salicetosum pedicellatae

salicetosum albae Pérez Latorre \& Cabezudo 1996 in Pérez Latorre, Galán de Mera, Deil \& Cabezudo 1996 [Saucedas de cursos bajos]. salicetosum angustifoliae Galán de Mera subass. nova [Saucedas sobre sustratos calizos].

RHAMNO CATHARTICAE-PRUNETEA SPINOSAE Rivas Goday \& Borja Carbonell 1961

+ Prunetalia spinosae R. Tx. 1952

* Pruno-Rubion ulmifolii O. Bolòs 1954

* Rosenion carioto-pouzinii Arnaiz ex Loidi 1989 17. Lonicero hispanicae-Rubetum ulmifolii Rivas Martínez, Costa, Castroviejo \& Valdés 1980 [Zarzales con madreselvas].

NERIO-TAMARICETEA Br.-BI. \& O. Bolòs 1958 + Tamaricetalia africanae Br.-Bl. \& O. Bolòs 1958 
em. Izco, Fernández-González \& Molina 1984

* Rubo-Nerion oleandri O. Bolòs 1985

18. Rubo ulmifolii-Nerietum oleandri $\mathrm{O}$. Bolòs 1956 [Adelfares].

* Tamaricion africanae Br.-Bl. \& O. Bolòs 1958

19. Polygono equisetiformis-Tamaricetum africanae Rivas Martínez \& Costa in Rivas Martínez, Costa, Castroviejo \& Valdés 1980 [Tarajales].

\section{tamaricetosum africanae}

aretosum italici Rivas Martínez, Costa, Castroviejo \& Valdés ex Pérez Latorre, Galán de Mera, Deil \& Cabezudo 1996 [Tarajales higrófilos].

III. Vegetación siempreverde lauroide

PRUNO-LAURETEA AZORICAE Oberdorfer eX Rivas Martínez, Arnaiz, Barreno \& Crespo 1977

+ Rhododendro pontici-Prunetalia lusitanicae Pérez Latorre, Galán de Mera \& Cabezudo ordo novo

* Rhododendro-Prunion lusitanicae Pérez Latorre, Galán de Mera \& Cabezudo all. nova (Rhododendro baetici-Alnenion glutinosae Rivas Goday \& Rivas Martínez in Rivas Martínez 1964, p.p.; Prunenion lusitanicae Benabid 1982, p.p.)

20. Frangulo baeticae-Rhododendretum pontici Rivas Goday, Galiano \& Rivas Martínez ex Rivas Martínez, Fuente \& Sánchez Mata $1986 \mathrm{~cm}$. \& corr. (incl. Frangulo-Rhododendretum salicetosum pedicellatae Díez Garretas, Cuenca \& Asensi 1986) [Ojaranzales]

\section{rhododendretosum pontici}

culcitetosum macrocarpae Pérez Latorre, Galán de Mera \& Cabezudo subass. nova [Ojaranzales con relictos tropicales pteridofíticos].

IV. Matorrales y orlas herbáceas

CALLUNO-ULICETEA Br.-Bl. \& R. Tx.ex Klika \& Hadac 1944

+ Ulicetalia minoris Quantin 1935

* Ericion umbellatae Br.-Bl., P. Silva, Rozeira \& Fontes $1952 \mathrm{em}$. Rivas Martínez 1979

** Stauracanthenion boivinii Rivas Martínez 1979 (Quercion fruticosae Rothmaler 1954, p.p.)

21. Genisto tridentis-Stauracanthetum boivinii Rivas Martínez 1979 (Erico scopariae-
Stauracanthetum boivinii Quézel, Barbéro, Benabid, Loisel \& Rivas Martínez 1988) [Brezales].

\section{stauracanthetosum boivinii}

quercetosum lusitanicae Pérez Latorre, Nieto Caldera \& Cabezudo 1993 (PhillyreoQuercetum lusitanicae Barbero. Quézel y Rivas Martínez 1981 sensu auct. hispan.) [Brezales con quejigo enano].

cytisetosum tribracteolati Pérez Latorre, Galán de Mera \& Cabezudo comb. nova (PhillyreoQuercetum lusitanicae cytisetosum tribracteolati Pérez Latorre, Nieto Caldera \& Cabezudo 1994, Sedo brevifolii-Cytisetum tribracteolati stipetosum giganteae Deil 1994) [Vegetación de lajas y fisuras anchas inclinadas].

var. de Pinus pinaster [Pinares negrales relícticos].

var. de Erica australis [Variante de herrizas sobre suelos arenosos].

var. de Cistus ladanifer subsp. africanus [Variante de brezales repetidamente incendiados].

22. Stauracantho boivinii-Drosophylletum lusitanici saturejetosum salzmannii Galán de Mera \& Vicente Orellana 1996 [Brezales xerófilos con atrapamoscas].

* Genistion micrantho-anglicae Rivas Martínez 1979

23. Genisto anglicae-Ericetum ciliaris Quézel, Barbéro, Benabid, Loisel \& Rivas Martínez 1988 [Brezales de suelos hidroturbosos].

CISTO-LAVANDULETEA Br.-Bl. in Br.-Bl., Molinier \& Wagner 1940

+ Lavanduletalia stoechadis Br.-Bl. in Br.-Bl., Molinier \& Wagner 1940 em. Rivas Martínez 1968 * Ulici argentei-Cistion ladaniferi Br.-B1., P. Silva \& Rozeira 1964

** Ulici borgiae-Calicotomenion villosae Pérez Latorre, Navas Fernández, Nieto Caldera \& Cabezudo 1997

24. Cistetum africani-monspeliensis Pérez Latorre, Galán de Mera \& Cabezudo ass. nova [Jarales]. cistetosum monspeliensis genistetosum triacanthi (Pérez Latorre, Nieto y Cabezudo 1993) Pérez Latorre, Galán de Mera \& Cabezudo comb. nova [Jarales con brezos y aulagas]. 
+ Stauracantho genistoidis-Halimietalia commutati Rivas Martínez, Lousa, Díaz, Fernández-González \& Costa 1990

* Coremion albi Rothmaler 1954

25. Cisto salvifolii-Ulicetum australis Pérez Latorre, Nieto Caldera \& Cabezudo 1993 [Jarales y tomillares de suelos arenosos].

\section{CISTO-MICROMERIETEA JULIANAE Oberdorfer} 1954

(Rosmarinetea officinalis Br.-Bl. $1931 \mathrm{em}$. Rivas Martínez, Díaz, Prieto, Loidi \& Penas 1991)

+ Rosmarinetalia Br.-Bl. ex Molinier 1934

* Eryngio-Ulicion erinacei Rothmaler 1943

26. Asperulo hirsutae-Ulicetum scabri Díez Garretas, Asensi \& Fernández-González 1995 [Aulagares de calizas y vertisuelos].

ulicetosum scabri

anthyllidetosum cytisoidis Galán de Mera in Pérez Latorre, Galán de Mera, Deil \& Cabezudo 1996 [Matorrales de suelos con yesos].

TRIFOLIO-GERANIETEA Th. Müller 1962

+ Melampyro-Holcetalia Passarge 1979

* Origanion virentis Rivas Martínez \& O. Bolòs in Rivas Martínez, Díaz, Prieto, Loidi \& Penas 1984 ** Origanenion virentis

27. Clinopodio villosi-Origanetum virentis $\mathrm{Rivas}$ Martínez, Díaz, Prieto, Loidi \& Penas 1984 [Pastizales humícolas de lindero de bosques calcícolas]

* Stachyo lusitanicae-Cheirolophenion sempervirentis Capelo 1996

28. Calamintho baeticae-Galietum scabri Pérez Latorre, Nieto Caldera \& Cabezudo 1993 [Pastizales humícolas de lindero de bosques silicícolas]. galietosum scabri

lamietosum flexuosi Pérez Latorre, Nieto Caldera \& Cabezudo 1993 [Pastizales humícolas del lindero de quejigales morunos]. digitaletosum bocquetii Pérez Latorre, Nieto Caldera \& Cabezudo 1993 [Pastizales humícolas del lindero de alcornocales aljíbicos].

\section{Vegetación de pastizales y prados}

KOELERIO-CORYNEPHORETEA Klika in Klika \& Novák 1941 (Sedo-Scleranthetea Br.-Bl. 1955)
+ Jasonio sessiliflorae-Koelerietalia crassipedis Rivas Martínez \& Cantó 1986

* Festucion elegantis Rivas Martínez \& Sánchez Mata in Rivas Martínez, Fernández-González \& Sánchez Mata 1986.

29. Deschampsio strictae-Agrostietum curtisii Galán de Mera, Deil, Haug \& Vicente Orellana 1997 [Graminales xerofíticos mesomediterráneos].

+ Sedo-Scleranthetalia Br.-Bl. 1955

* Sedion micrantho-sediformis Rivas Martínez, Sánchez Gómez \& Alcaraz in Sánchez Gómez \& Alcaraz 1993

30. Sedetum micrantho-sediformis O. Bolòs \& R. Masallés in O. Bolòs 1981 var. de Mucizonia hispida [Pastizal vivaz crasifolio y termófilo].

\section{LYGEO SPARTI-STIPETEA TENACISSIMAE Rivas} Martínez 1978

+ Hyparrhenietalia podotrichae Rivas Martínez 1978 corr. Rivas Martínez, Costa, Soriano, Pérez, Llorens \& Roselló 1992

* Dauco crinitae-Hyparrhenion hirtae Br.-Bl, P. Silva \& Rozeira $1956 \mathrm{em}$. O. Bolòs 1962.

31. Andryalo laxiflorae-Hyparrhenietum hirtae Peinado, Martínez Parras \& Alcaraz in Bartolomé, Peinado, Martínez Parras, Alcaraz, Álvarez y Cruz 1989 [Albardinales].

HELIANTHEMETEA (Br.-Bl. ex Rivas Goday 1958) Rivas Goday \& Rivas Martínez 1963 (Xolanthetea guttatae pro nom. mut.)

+ Trachynietalia distachyae Rivas Martínez 1978 (Brachypodietalia distachyae pro nom. mut.)

* Trachynion distachyae Rivas Martínez 1978

(Brachypodion distachyae pro nom. mut.)

32. Velezio rigidae-Astericetum aquaticae Rivas Goday 1964 [Pastizal anual de suelos calizos]. astericetosum aquaticae

sedetosum rubentis Santos 1987

[Subasociación de suelos petranos y litosuelos].

+ Helianthemetalia guttati Br.-Bl. in Br.-Bl., Molinier \& Wagner $1940 \mathrm{em}$. Rivas Martínez 1978 (Xolanthetalia guttatae pro nom. mut.)

* Helianthemion guttati Br.-B1. in Br.-Bl., Molinier \& Wagner 1940 (Xolanthion guttatae pro nom. mut.)

33. Trifolio-Plantaginetum bellardii Rivas Goday 1957 anthoxanthetosum ovati Galán de Mera subass. nova [Pastizal anual de suelos 
silíceos, raza geográfica aljíbica].

POETEA BULBOSAE Rivas Goday \& Rivas Martínez in Rivas Martínez 1978

+ Poetalia bulbosae Rivas Goday \& Rivas Martínez ex Rivas Goday \& Ladero 1970

* Plantaginion serrariae Galán de Mera, Morales Alonso \& Vicente Orellana 1999

34. Trifolio subterranei-Plantaginetum serrariae Martín Osorio \& Galán de Mera in Galán de Mera, Morales Alonso \& Vicente Orellana 1999 [Majadales].

VI. Vegetación de suelos húmedos, helofítica, anfibia y acuática

ISOETO-NANOJUNCETEA Br.-BI. \& R. Tx. ex Westhoff, Dijk \& Passchier 1946 [Juncetea bufonii (Br.-Bl. \& R. Tx. 1943) Foucault 1988, Isoetetea velatae (Br.-Bl. \& R. Tx. 1943) Foucault 1988]

+ Scirpetalia setacei Foucault 1988

* Cicendion (Rivas Goday \& Borja Carbonell 1961) Br.-B1. 1967

35. Laurentio-Juncetum tingitani Rivas Goday \& Borja in Rivas Goday 1968 (Junco tingitaniSolenopsietum laurentiae pro nom. mut. et inv.) [Vegetación anfibia terofítica de aguas efímeras superficiales ácidos].

juncetosum tingitani

pinguiculetosum lusitanicae Deil 1997 [Subasociación turfófila].

36. Loto subbiflori-Chaetopogonetum fasciculati Rivas Martínez, Costa, Castroviejo \& Valdés 1980 [Vegetación anfibia terofítica de suelos arenosos o limo-arenosos ácidos encharcados].

* Agrostion salmanticae Rivas Goday (1955) 1957

(Agrostion pourretii pro nom. mut.)

37. Pulicario uliginosae-Agrostietum salmanticae Rivas Goday 1955 (Pulicario paludosae-Agrostietum pourretii pro nom. mut.) [Vegetación anfibia terofítica de suelos arenolimosos con hidromorfía temporal].

agrostietosum salmanticae

holcetosum lanati Rivas Goday 1957 [Variante de tránsito hacia los vallicares vivaces].

+ Isoetetalia Br.-Bl. 1936 em. Rivas Goday 1970

* Preslion cervinae Br.-Bl. ex Moor 1936

38. Junco pygmaei-Isoetetum velati $\mathrm{Rivas}$ Goday 1955 [Vegetación geófita efímera de pteridófitos y juncos enanos].
+ Nanocyperetalia Klika 1935

* Heleochloo-Cyperion (Br.-Bl. 1952) Pietsch 1961 39. Cypero micheliani-Heleochloetum alopecuroidis Rivas Goday \& Valdés in Rivas Goday 1970 [Vegetación anfibia terofítica, nitrófila, de bordes de lagunas y embalses encharcados hasta el otoño].

* Verbenion supini Slavnic 1951

40. Glino lotoidis-Verbenetum supinae Rivas Goday 1964 [Vegetación anfibia terofítica tardoestival de bordes de lagunas y embalses con encharcamiento fugaz].

MOLINIO-ARRHENATHERETEA R. Tx. 1937

+ Molinietalia coeruleae W. Koch 1926

* Juncion acutiflori Br.-Bl. in Br.-Bl. \& R. Tx. 1952 41. Juncetum rugoso-effusi Rivas Martínez \& Costa in Rivas Martínez, Costa, Castroviejo \& Valdés 1980 [Juncales de suelos húmedos ácidos].

+ Holoschoenetalia Br.-BI. (1931) 1947

* Molinio-Holoschoenion Br.-Bl. (1931) 1947

42. Holoschoeno-Juncetum acuti Rivas Martínez \& Costa in Rivas Martínez, Costa, Castroviejo \& Valdés 1980 [Juncales ligeramente halófilos de suelos con escasa humedad edáfica].

43. Galio palustri-Juncetum maritimi Rivas Martínez \& Costa in Rivas Martínez, Costa, Castroviejo \& Valdés 1980 [Juncales ligeramente halófilos de suelos arcillosos].

+ Agrostietalia castellanae Rivas Martínez in Rivas Martínez, Costa, Castroviejo \& Valdés 1980

* Agrostion castellanae Rivas Goday 1958 corr. Rivas Goday \& Rivas Martínez 1963.

44. Gaudinio fragilis-Agrostietum castellanae hypochaeridetosum platylepidis Galán de Mera, Deil, Haug \& Vicente Orellana 1997 [Pastizales vivaces de gramíneas de suelos húmedos ácidos]. + Plantaginetalia majoris R.Tx. \& Preising in R.Tx. 1950

* Trifolio fragiferi-Cynodontion dactylionis Br.Bl. \& O. Bolòs 1958.

45. Trifolio resupinati-Caricetum chaetophyllae Rivas Martínez \& Costa in Rivas Martínez, Costa, Castroviejo y Valdés 1980 [Gramadales de suelos húmedos nitrificados y pastoreados].

* Paspalo-Polypogonion semiverticillati Br.-BI. in Br.-Bl., Roussine \& Nègre 1952

46. Astero squamati-Panicetum repentis Martínez Parras \& Peinado Lorca 1993 [Pastizales 
graminoides de suelos húmedos nitrificados y temporalmente encharcados, con plantas de origen tropical].

47. Heliotropio supini-Paspaletum paspaloidis Martínez Parras, Peinado, Bartolomé \& Molero Mesa 1988 [Pastizales de las graveras de los ríos].

+ Phalaridetalia coerulescentis Galán de Mera, Deil, Haug \& Vicente Orellana 1997

* Gaudinio fragilis-Hordeion bulbosi Galán de Mera, Deil, Haug \& Vicente Orellana 1997

48. Hedysaro coronarii-Phalaridetum coerulescentis Galán de Mera, Deil, Haug \& Vicente Orellana 1997 [Praderas de vertisuelos]. phalaridetosum coerulescentis convolvuletosum meonanthi (Peinado, Martínez Parras \& Bartolomé 1986) Deil 1998 (Convolvulo meonanthi-Hedysaretum coronarii) [Pastizal pionero sobre sustratos silíceos].

glossopappetosum macroti (Galán de Mera 1995) Galán de Mera comb. nova (Convolvulo meonanthi-Hedysaretum coronarii glossopappetosum macroti) [Pastizal pionero sobre sustratos básicos].

ISOETO-LITTORELLETEA Br.-Bl. \& Vlieger in Vlieger 1937

+ Littorelletalia W. Koch 1926

* Hyperico helodis-Sparganion Br.-Bl. \& R. Tx. ex Oberdorfer 1957

49. Anagallido-Juncetum bulbosi Br.-B1. 1967

[Vegetación de pequeños helófitos y esfagnos de suelos higroturbosos].

PHRAGMITO-MAGNOCARICETEA Klika in Klika \& Novák 1941

+ Magnocaricetalia Pignatti 1953

* Magnocaricion elatae W. Koch 1926

** Magnocaricenion elatae

50. Irido-Polygonetum serrulati O. Bolòs 1957 [Herbazal de talla elevada].

* Caricenion broterianae Rivas Martínez, Fernández-González \& Sánchez Mata 1986

51. Caricetum (elatae) mauritanicae Díez Garretas, Cuenca \& Asensi 1986 corr. (Caricetum (acutae) mauritanicae) [Comunidad de grandes cárices de bloques silíceos en cauces permanentes].

+ Nasturtio-Glycerietalia Pignatti 1953
* Sparganio-Glycerion Br.-Bl. \& Sissingh in Boer 1942

52. Glycerio declinatae-Eleocharitetum palustris Rivas Martínez \& Costa in Rivas Martínez, Costa, Castroviejo \& Valdés 1980 [Comunidades de helófitos de talla mediana de fuentes, aguas poco profundas y lagunas temporales con suelos arenosos].

53. Oenantho fistulosae-Glycerietum spicatae Brullo \& Grillo 1978 (Glycerio spicataeEleocharitetum palustris Molina Abril, Galán de Mera \& Sardinero in Molina Abril 1996) [Comunidades de helófitos de talla mediana, de lagunas temporales con suelos arcillosos pesados].

* Apion nodiflori Segal in Westhoff \& Den Held 1969

54. Glycerio declinatae-Apietum nodiflori Molina Abril 1996 [Herbazal helofítico termófilo silicícola].

55. Oenanthetum crocatae Br.-Bl., Berset \& P. Silva in Br.-Bl. \& R. Tx. 1952 (Glycerio declinatae-Oenanthetum crocatae Rivas Martínez, Belmonte, Fernández-González \& Sánchez Mata in Sánchez Mata 1989) [Herbazal helofítico de cursos rápidos].

+ Phragmitetalia communis W. Koch $1926 \mathrm{em}$. Pignatti 1953

* Phragmition communis W. Koch 1926

56. Typho-Schoenoplectetum tabernaemontani Br.-Bl. \& O. Bolòs 1957 [Carrizales y espadañares de aguas dulces lentas].

57. Scirpetum maritimi (Christiansen 1934) R. Tx. 1937 [Cañaveral de corta talla sobre suelos arcillosos].

POTAMETEA Klika in Klika \& Novák 1941

+ Potametalia W. Koch 1926

* Potamion (W. Koch 1926) Libbert 1931

58. Potamogetonetum nodosi Soó (1928) 1960 [Comunidades de hidrófitos de aguas profundas enraizados en arcillas].

59. Potamogetonetum polygonifolii Segal 1965 [Vegetación de medios hidroturbosos que rara vez se exondan]

60. Myriophylletum alterniflori Chouard 1924 [Comunidad de miriofílidos de aguas oligótrofas] * Ranunculion aquatilis Passarge 1964 (CallitrichoBatrachion Den Hartog \& Segal 1964)

61. Callitricho stagnalis-Ranunculetum saniculifolii Galán de Mera ass. nova [Vegetación 
mediterránea occidental de batráquidos de aguas someras].

62. Ranunculetum tripartiti Galán de Mera ass. nova [Comunidad acuática turfófila de aguas térmicas someras].

63. Callitrichetum regis-jubae Galán de Mera ass. nova [Comunidad de aguas distróficas superficiales].

CHARETEA FRAGILIS Fukarek ex Krausch 1964

+ Charetalia hispidae Sauer ex Krausch 1964

* Charion vulgaris (Krause ex Krause \& Lang 1977)

Krause 1981

64. Charetum vulgaris Krause 1969 [Vegetación talofítica de aguas oligo-mesotrofas].

\section{LEMNETEA MINORIS R. Tx. ex O. Bolòs \&} Masclans 1955

+ Lemnetalia minoris R. Tx. ex O. Bolòs \& Masclans 1955

* Lemnion trisulcae Den Hartog \& Segal ex R. Tx. \& Schwabe-Braun in R. Tx. 1974 (RicciofluitantisLemnion trisulcae Schwabe-Braun \& R. Tx. 1981) 65. Comunidad de Lemna minor [Comunidad de lentejas de aguas, de aguas oligótrofas ligeramente ácidas].

VII. Vegetación nitrófila, viaria y arvense

\section{POLYGONO-POETEA ANNUAE Rivas Martínez} 1975

+ Polygono arenastri-Poetalia annuae R. Tx. in Géhu, Richard \& R. Tx. 1972 corr. Rivas Martínez, Báscones, Díaz, Fernández-González \& Loidi 1991

* Polycarpion tetraphylli Rivas Martínez 1975

66. Crassulo tillaeae-Saginetum apetalae Rivas Martínez 1975 [Vegetación viaria anual de suelos arenosos y areno-limosos].

STELLARIETEA MEDIAE R.Tx., Lohmeyer \& Preising $e x$ von Rochow 1951

Stellarienea mediae

+ Centaureetalia cyani R.Tx. 1950 ex von Rochow 1951 (Secalietalia cerealis Br.-B1. 1931)

* Ridolfion segeti Nègre ex El Antri 1983

67. Ridolfio segeti-Capnophylletum peregrini Guinochet 1977 (Capnophyllo peregriniRidolfietum segeti pro nom. inv.) [Comunidades mesegueras de vertisuelos].

+ Solano nigri-Polygonetalia convolvuli (Sissingh ex Westhoff, Dijk \& Passchier 1946) O. Bolòs 1962 em. Brullo \& Marceno 1979

* Diplotaxion erucoidis Br.-Bl. in Br.-Bl., Gajewski, Wraber \& Walas 1936

68. Chrozophoro tinctorieae-Teucrietum spinosi Galán de Mera 1996 [Comunidad estival de barbechos sobre vertisuelos].

69. Kickxio lanigerae-Tanacetetum annui Galán de Mera 1996 [Comunidad autumnal sobre suelos inundables].

Chenopodienea muralis Rivas Martínez, Báscones, Díaz, Fernández González \& Loidi ex Théurillat, Aeschimann, Küpfer \& Spichiger 1995

+ Chenopodietalia muralis Br.-Bl. in Br.-Bl., Gajewuski, Wraber \& Walas $1936 \mathrm{em}$. Rivas Martínez 1977

* Chenopodion muralis Br.-Bl. in Br.-Bl., Gajewuski, Wraber \& Walas 1936

70. Chenopodietum muralis Br.-Bl. \& Maire 1924 [Herbazales estivo-autumnales de tendencia urbanícola].

+ Sisymbrietalia officinalis J. Tx. in Lohmeyer et al. 1962 em. Rivas Martínez, Báscones, Díaz, Fernández-González \& Loidi 1991

* Hordeion leporini Br.-Bl. in Br.-B1., Gajewuski, Wraber \& Walas 1936

71. Anacyclo radiati-Hordeetum leporini 0 . Bolòs \& Rivas Martínez in Rivas Martínez 1978 [Vegetación viaria nitrófila].

hordeetosum leporini

chrysanthemetosum coronarii Rivas Martínez 1978

[Variante sobre suelos enriquecidos en bases].

++ Brometalia rubenti-tectorum Rivas Martínez \& Izco 1977

* Echio-Galactition tomentosae O. Bolòs \& Molinier 1969

** Cerintho majoris-Fedienion cornucopiae (Rivas Martínez \& Izco ex Peinado, Martínez Parras \& Bartolomé 1986) Galán de Mera, Hagen \& Vicente Orellana (1999) (Cerintho majoris-Fedion cornucopiae)

72. Trifolio pallidi-Vulpietum geniculatae Galán de Mera 1995 [Pastizal subnitrófilo de suelos areno-limosos].

73. Arenario hispanicae-Chamaemeletum fuscati Galán de Mera 1995 [Pastizal de barbechos en vertisuelos arenosos]

Geranio purpurei-Cardaminenea hirsutae Rivas Martínez, Fernández-González \& Loidi 1998

+ Geranio purpurei-Cardaminetalia hirsutae Brullo in Brullo \& Marceno 1985 
* Geranio pusilli-Anthriscion caucalidis Rivas Martínez 1977

74. Fumario sepii-Geranietum purpurei Peinado Lorca, Martínez Parras \& Bartolomé 1986 [Comunidades terofíticas escionitrófilas y humícolas].

GALIO APARINES-URTICETEA DIOICAE Passarge ex Kopecky 1969

+ Glechometalia hederaceae R. Tx. in R. Tx. \& Brun-Hool 1975 (Urtico-Scrophularietalia peregrinae Brullo 1985)

* Alliarion petiolatae Oberdorfer (1957) 1962 (Allion triquetri O. Bolòs 1957)

75. Urtico dubiae-Smyrnietum olusatri (A. \& O. Bolòs 1950) O. Bolòs \& Molinier 1958 [Comunidades escionitrófilas vivaces de mediana talla y de suelos húmedos].

ARTEMISIETEA VULGARIS Lohmeyer, Preising \& R. Tx. ex von Rochow 1951

Onopordenea acanthii Rivas Martínez, Báscones, Díaz, Fernández-González \& Loidi 1991

+ Carthametalia lanati Brullo in Brullo \& Marceno 1985

* Onopordion nervosi Br.-Bl. \& O. Bolòs 1958 corr. Rivas Martínez 1975

**Scolymo-Carthamenion lanati Rivas Goday 1961 ex Ladero et al. 1981

76. Notobasio syriacae-Scolymetum maculati (Rivas Goday 1964) Ladero et al. 1981 [Asociación de suelos profundos removidos].

* Silybo-Urticion Sissingh ex Br.-Bl. \& O. Bolòs 1958 (Silybion mariani Rivas Martínez in Rivas Martínez, Costa \& Loidi 1992)

77. Scolymo maculati-Sylibetum mariani Rivas Martínez in Rivas Martínez, Costa, Castroviejo \& Valdés 1980 [Cardales termófilos de suelos húmedos muy nitrificados].

+Ononidetalia ramosissimae Galán de Mera, Sánchez García \& Vicente Orellana 1997

* Bromo-Oryzopsion miliacei O. Bolòs 1970

78. Oryzopsio miliacei-Daucetum maximi $\mathrm{O}$. Bolòs \& Vigo ex O. Bolòs 1975 [Altabacares termófilos].

VIII. Vegetación rupícola

ASPLENIETEA TRICHOMANIS (Br.-Bl. in Meier \& Br.-Bl. 1934) Oberdorfer 1977
+ Parietarietalia Rivas Martínez ex Rivas Goday 1964

* Parietario-Galion murale Rivas Martínez ex Rivas Goday 1964

79. Parietarietum judaicae K. Buchwald 1953 [Vegetación heliófila nitrófila de base de cantiles y muros].

+ Anomodonto-Polypodietalia O. Bolòs \& Vives in O. Bolòs 1957

* Bartramio-Polypodion serrati O. Bolòs \& Vives in O. Bolòs 1957 (Anogrammion leptophyllae Bellot \& Casaseca in Bellot 1967)

80. Davallio canariensis-Sedetum baetici Deil 1994 [Comunidad pteridofítica de grietas verticales].

sedetosum baetici

psilotetosum nudi Galán de Mera, Hagen \& Vicente Orellana 1995 [Comunidad relíctica con Psilotum nudum].

81. Comunidad de Davallia canariensis y Polypodium cambricum subsp. serrulatum [Comunidad brio-pteridofítica de horquillas de Quercus canariensis y $Q$. suber].

82. Selaginello-Anogrammetum leptophyllae $\mathrm{R}$. Molinier 1937 [Comunidad anual pteridofítica de suelos terrosos].

anogrammetosum leptophyllae

arisaretosum proboscidei Deil 1994 [Variante de suelos más húmedos].

* Hymenophilion tunbrigensis R. Tx. in R. Tx. \& Oberdorfer 1958

83. Comunidad de Vandenboschia speciosa [Vegetación brio-pteridofítica hidrófila de origen macaronésico].

+ Rumicetalia indurati (Rivas Goday 1964) Rivas Goday \& Rivas Martínez 1971

* Rumici-Dianthion lusitani Rivas Martínez, Izco \& Costa 1973

84. Sedo brevifolii-Cytisetum tribracteolati Deil 1994 [Asociación de lajas y fisuras anchas verticales de areniscas].

ADIANTETEA CAPILLI-VENERIS Br.-Bl. in Br.B1., Roussine \& Nègre 1952

+ Adiantetalia capilli-veneris Br.-Bl. ex Horvatiç 1939

* Adiantion capilli-veneris Br.-Bl. ex Horvatiç 1939 85. Trachelio coeruleae-Adiantetum capilliveneris O. Bolòs 1957 [Vegetación de tobas calizas y muros rezumantes]. 
CRITHMO-STATICETEA Br.-Bl. in Br.-Bl., Roussine \& Nègre 1952 (Crithmo-Limonietea pro nom. mut.)

+ Crithmo-Staticetalia Molinier 1934 (CrithmoLimonietalia pro nom. mut.)

* Crithmo-Daucion halophili Rivas Martínez, Lousa, Díaz, Fernández-González \& Costa 1990

86. Limonietum emarginati Asensi 1984 [Comunidad aerohalófila de acantilados marinos].

87. Leontodonto tingitani-Reichardietum picroidis Deil 1994 [Comunidad aerohalófila de laderas margosas expuestas al mar].

SALICORNIETEA FRUTICOSAE Br. - Bl. \& R. Tx. 1943 ex A. y O. Bolós 1950

+ Salicornietalia fruticosae Br. - B1. $1933 \mathrm{em}$. R. Tx. in R. Tx. \& Oberdorfer 1958

* Salicornion fruticosae Br. - Bl. 1933

** Arthrocnemenion perennis Rivas Martínez 1980

88. Comunidad de Sarcocornia perennis [Comunidad halófila de canales salinos].

SAGINETEA MARITIMAE Westhoff, Van Leeuwen \& Adriani 1962

+ Frankenietalia pulverulentae Rivas Martínez ex Castroviejo y Porta 1976

* Hordeion marini Ladero, F. Navarro, C. J. Valle, Marcos, Ruiz Téllez y M. T. Santos 1984

89. Plantagini coronopi-Hordeetum marini $O$. Bolós y Molinier in O. Bolós 1962 [Comunidad herbácea halonitrófila de salinas].

\section{BIBLIOGRAFÍA}

ALLORGE, V. \& P. -1945- La végétation et les groupements muscinaux des montagnes d'Algésiras. Mém. Mus. Natl. Hist. Nat. París 21: 85-116.

ASENSI MARFIL, A. y B. DÍEZ GARRETAS 1988- Ulici borgiae-Cistetum ladaniferi, nueva asociación para el sector Gaditano (SW de España). Monogr. Inst. Pir. Ecología 4: 405407.

AXELROD, D.I. - 1966- Origin of deciduous and evergreen habits in temperature forest. Evolution 20: $1-15$.

BARBÉRO, M. y P. QUÉZEL -1994- Place, role and historic value of laurifolious elements in Western Mediterranean preforest and forest vegetation. Ann. Bot. (Rome) 52: 81-133.

BARBÉRO, M., P. QUÉZEL y S. RIVAS MARTÍNEZ -1981- Contribution à l'étude des groupements forestiers et préforestiers du Maroc. Phytocoenologia 9 (3): 311-412.

BARKMAN, J.J., J. MORAVEC y S. RAUSCHERT -1986- Code der pflanzensoziologischen Nomenklatur. Vegetatio 67 (3): 145-195.

BENABID, A. -1984- Étude phytoécologique des peuplements forestiers et préforestiers du Rif Centro-Occidental (Maroc). Trav. Inst. Sci. Chérifien, Sér. Bot. 34: 1-64.

BENABID, A. y M. FENNANE -1994Connaissances sur la végétation du Maroc: Phytogéographie, phytosociologie et séries de végétation. Lazaroa 14: 21-97.

BENZLER, A., U. DEIL \& C. JUNG -1998Eichenwälder in der Sierra del Aljibe (Andalusien) im vergleich zu Wäldern im Westrif (Nordmarokko). Doc. Phytosoc., 13:122.

BLANCO, P. -1993- Salix L., in: Flora Iberica III. Ed. CSIC. Madrid.

BRAUN-BLANQUET, J. -1936- Un joyau floristique et phytosociologique, "L'Isoetion» méditerranéen. Commun. Stat. Int. Géobot. Médit. Montpellier 42: 1-23.

BRAUN-BLANQUET, J. -1953- Irradiations européennes dans la végétation de la Kroumirie. Vegetatio 4: 182-194.

BRAUN-BLANQUET, J. - 1967-Vegetationsskizzen aus dem Baskenland mit ausblicken auf das weitereibero-atlanticum, 2 Teil. Vegetatio 14: 1-126.

BRAUN-BLANQUET, J. -1979- Fitosociología. Bases para el estudio de las comunidades vegetales. Ed. Blume. Madrid.

BRAUN-BLANQUET, J., A. R. PINTO DA SILVA \& A. ROZEIRA - 1956- Résultats de deux excursions géobotaniques à travers le Portugal septentrional et moyen. II. Chenaies à feuilles caduques (Quercion occidentale) et chenaies à feuilles persistantes (Quercion fagineae) au Portugal. Agron. Lusit. 18(3): 167-234.

CABEZUDO, B., NIETO CALDERA, J. M. y A. V. PÉREZ LATORRE -1989- Contribución al estudio edafófilo-serpentinícola del sector Rondeño (Málaga, España). Acta Bot. Malacitana 14:291-294.

CABEZUDO, B., J. MOLERO MESA y A.V. PÉREZ 
LATORRE -1998- Vegetación de Andalucía, in Naturaleza de Andalucía vol. 3. (La Flora). Ed. Giralda. Sevilla.

CABEZUDO, B. y A. V. PÉREZ LATORRE -1999Notas sobre la vegetación de Andalucía. Acta Bot. Malacitana, 24: 247-256.

CEBALLOS, L. y M. MARTÍN BOLAÑOS -1930Estudio sobre la vegetación forestal de la provincia de Cádiz. Ed. Instituto Forestal de Investigaciones y Experiencias. Madrid.

CEBALlOS, L. y C. VICIOSO -1933-Estudio sobre la vegetación y la flora forestal de la provincia de Málaga. IX Inspección del I.C.O.N.A. Madrid

CHAUVE, P. -1968-Étude géologique du Nord de la Province de Cadix. Mem. IGME 60: 1-377.

CHEVASSUT, G. \& P. QUÉZEL -1956Contribution à l'étude des groupements végétaux de mares temporaires à Isoetes velata et de dépressions humides à Isoetes hystrix en Afrique du Nord. Bull. Soc. Hist. Nat. Afrique N. $47(3,4): 59-73$.

DEBAZAC, E.F. - 1958- La végétation forestière de la Kroumirie. Ann. Ecol. Nat. Eaux For. Stat. Rech. Exp. 16 (1): 1-133.

DEIL, U. -1984- Zur Vegetation im Zentralen Rif (Nordmarokko). Diss. Bot. 74: 1-179.

DEIL, U. -1997 a- Zur geobotanischen Kennzeichnung von Kulturlandschaften. Franz Steiner Verlag. Stuttgart.

DEIL, U. - 1997 b- Distribution and ecology of some rare plant species in Northern Morocco I: Teucrium afrum ssp. rubriflorum and Euphorbia transtagana. Acta Bot. Malacitana 22: 250-254.

DEIL, U. -1998- Lineare und punktuelle Vegetationsstrukturen in traditionellen und modernen Kulturlandschaften-untersucht in Südspanien und Nordmarokko. Braunschweig. Geobot. Arb. 5: 171-184.

DEMOLY, J. P. y P. MONTSERRAT-1993-Cistus, in: Flora Iberica III. Ed. CSIC. Madrid.

DÍEZ GARRETAS, B., J. CUENCA y A. ASENSI 1986- Datos sobre la vegetación del subsector Aljíbico (provincia Gaditano-OnuboAlgarviense). Lazaroa 9: 315-332.

FERNANDES LOUSÃ, M. y ESPIRITO SANTO, M.D. -1990- Os carvalhais do Parque Natural das Serras de Aire e Candeeiros (Centro de Portugal). Sua conservaçao. Acta Bot. Malacitana 15: 247-251.
FERNÁNDEZ-CARVAJAL, M.C. -1983- Revisión del género Juncus L. en la Península Ibérica IV. Subgéneros Juncinella (Fourr.) Krecz. \& Gontsch., Septati Buchenau y Alpini Buchenau. Anales Jard. Bot. Madrid 39 (2): 301-379.

GALÁN DE MERA, A. -1991- De plantis gaditanis, notula I. Rivasgodaya 6: 149-152.

GALÁN DE MERA, A. -1993- Flora y vegetación de los términos municipales de Alcalá de los Gazules y Medina Sidonia (Cádiz, España). Tesis Doctoral. Universidad Complutense. Madrid.

GALÁN DE MERA, A. -1994- De plantis gaditanis, notula II. Stud. Bot. 12: 275-277.

GALÁN DE MERA, A. -1995- Contribución a las floras de la provincia de Cádiz y de la Península Tingitana. Lagascalia 18(1): 43-49.

GALÁN DE MERA, A., U. DEIL, H. HAUG y J. A. VICENTE ORELLANA -1997- Contribución a la clasificación fitosociológica de los pastizales de la provincia de Cádiz (España). Acta Bot. Malacitana 22: 147-169.

GALÁN DE MERA, A., M. A. HAGEN y J. A. VICENTE ORELLANA -1999- Lanscape in the western Iberian Peninsula: subnitrofilous pasturages caused by antropogenous influence. J. Veg. Sci. (en prensa).

GALÁN DE MERA, A., J. A. VICENTE ORELLANA, J. L. GONZÁLEZ y J.C. FERNÁNDEZ LUNA - 1995 a- New populations of Psilotum nudum in SW Europe (Psilotaceae: Pteridophyta). Fern Gaz. 15 (3): 109-112.

GALÁN DE MERA, A., J. A. LUCAS, A. PROBANZA y J. A. VICENTE ORELLANA 1995 b- Análisis multivariante de las comunidades terofíticas pioneras de la provincia de Cádiz (España). Orsis 11: 141-153.

GALÁN DE MERA, A., R. MORALES ALONSO y J. A. VICENTE ORELLANA -1999- Pasture communities linked to ovine stock. A synthesis of the Poetea bulbosae class in the Western Mediterranean Region. Phytocoenologia 30 (en prensa).

GALÁN DE MERA, A. y J. A. VICENTE ORELLANA -1996- Phytosociological study of the plant communities with Stauracanthus boivinii of the SW of the Iberian Peninsula and NW of Africa, using multivariate analysis. Bot. Helv. 106: 45-56.

GARCÍA MURILLO, P. y M. PALACIOS -1998- 
Cistus ladanifer L. subsp. africanus Dans., un nuevo taxon para Andalucía Occidental. Acta Bot. Malacitana 23: 269-271.

GARRIDO DÍAZ, B. y R. HIDALGO MAQUEDA 1998- Nueva localidad de Vandenboschia speciosa (Willd.) Kunkel. Acta Bot. Malacitana 23: 229-232.

GIL, J. A. y J. GUERRA -1981- Aportaciones briosociológicas ibéricas. I. Comunidades epífitas de las Sierras de Algeciras. Anales Jard. Bot. Madrid 37 (2): 703-719.

GIL JIMÉNEZ, Y., P. NAVAS, D. NAVAS, A. V. PÉREZ LATORRE Y J. M. NIETO CALDERA -1995- Tipos de hábitats naturales contemplados en la directiva 92/43 CEE presentes en el Campo de Gibraltar y espacios naturales de interés para su conservación. Almoraima 15:255-266.

GOUNOT, M. -1958- Contribution à l'étude des groupements végétaux messicoles et rudereaux de la Tunisie. Ann. Serv. Bot. Tunisie 31: 32244.

GUTIÉRREZ, A., M.J. DÍEZ, M. NEBOT y M. CELIS -1997- Nuevas aportaciones al estudio polínico del Parque Natural de los Alcornocales (Cádiz, Sur de España). Acta Bot. Malacitana 22: 123-130.

HOHENESTER, A. y W. WELB -1993Excursionsflora für die Kanarischen Inseln. Ed. Ulmer. Stuttgart.

IBARRA BENLLOCH, P. -1993- Naturaleza y hombre en el sur del campo de Gibraltar: un análisis paisajístico integrado. Ed. Junta de Andalucía. Sevilla.

JERMY, A.C. -1984- Origin and distribution of pteridophytes in the mediterranean area. Webbia 38: 397-416.

JUNG, C. -1994- Heiden beiderseits der Strabe von Gibraltar. Dipl.-Arb. Universität Bayreuth.

LADERO ÁLVAREZ, M. -1976- Prunus lusitanica L. (Rosaceae) en la Península Ibérica. Anales Inst. Bot. Cavanilles 33: 207-218.

LÖSCH, R. y E. FISCHER -1994- Vicariiende Heidebuschwälder und ihre Kontaktgesellschaften in Makaronesien und Zentralafrika. Phytocoenologia 24: 695-720.

LOISEL, R. -1971- Séries de végétation propes, en Provence, aux massifs des Maures et de l'Estérel (ripisilves exclues). Bull. Soc. Bot. France 118: 203-236.

LUCCHESE, F. y S. PIGNATTI -1990- Cynaro-
Cichorietum pumili, un example de diversité floristique exceptionnelle dans les environs de Rome (Italie). Ecol. Medit. 16: 279-290.

MALATO BELIZ, J. -1982- A Serra de Monchique. Flora e Vegetaçao. Serviço Nacional de Parques, Reservas e Património Paisagístico. Lisboa.

MARTINEZ PARRAS, J.M. \& M. PEINADO LORCA - 1987-Datos sobre la vegetación riparia del sector Gaditano. Secret. Public. ser. Informes 22: 199-206. Universidad de La Laguna.

MARTÍNEZ PARRAS, J.M., M. PEINADO y M. DE LA CRUZ -1987- Aportación al estudio fitosociológico de los matorrales del sector Rondeño. Stud. Bot. 6: 39-45.

MEDDOUR, R. y J. M. GÉHU -1998- Observations sur le synsystème des communautés forestières et preforestières en Algérie. Doc. Phytosoc. 18: 33-47.

MOOR, M. -1937- Ordnung der Isoetetalia. Prodromus der Pflanzengesellschaften 4: 1-24.

NEZADAL, W., U. DEIL y W. WELB -1994- Karte der aktuellen Vegetation des Campo de Gibraltar (Provinz Cádiz, Spanien). Hoppea, Denkschr. Regensb. Bot. Gess. 55: 717-756.

NIETO CALDERA, J.M., A.V. PÉREZ LATORRE y B. CABEZUDO - 1990- Datos sobre la vegetación silicícola de Andalucía, I. Acta Bot. Malacitana 15: 179-192.

NIETO CALDERA, J. M., A. V. PÉREZ LATORRE y B. CABEZUDO -1994-Caracterización bioclimática de los alcornocales andaluces (series de vegetación). Anais Inst. Sup. Agron., 44 (1): 269-283.

OBERDORFER, E. -1960- Pflanzensoziologische Studien in Chile. Ein Vergleich mit Europa. Flora et Vegetatio Mundi 2. Weinheim.

OJEDA, F., J. ARROYO y T. MARAÑÓN -1995Biodiversity components and conservation of Mediterranean heathlands in southern Spain. Biol. Conservation 72: 61-72.

OJEDA, F., T. MARAÑÓN y J. ARROYO -1996Patterns of ecological, chorological and taxonomic diversity at both sides of the Strait of Gibraltar. J. Veg. Sci. 7: 63-72.

PASSARGE, H. -1992- Mitteleuropäische Potamogetonetea I. Phytocoenologia 20 (4): 489-527.

PEINADO LORCA, M., J. M. MARTÍNEZ PARRAS y C. BARTOLOMÉ -1986- Notas sobre 
vegetación nitrófila II: Algunas novedades fitosociológicas en Andalucía. Stud. Bot. 5: 5369.

PEREIRA DÍAS, M. H. y G. BARROS DE SA NOGUEIRA - 1973- Notas sobre Rhododendron ponticum L. subsp. baeticum (Boiss. \& Reut.) Handel-Mazzetti do Concelho de Vouzela. Bol. Soc. Brot. 47: 125-132.

PÉREZ LATORRE, A. V. -1993-. Estudio Fitocenológico de los Alcornocales Andaluces. Tesis Doctoral. Universidad de Málaga. PÉREZ LATORRE, A. V., J. M. NIETO CALDERA y B. CABEZUDO -1993-Contribución al conocimiento de la vegetación de Andalucía. II. Los alcornocales. Acta Bot. Malacitana 18: 223258.

PÉREZ LATORRE, A.V., J. M. NIETO CALDERA y B. CABEZUDO -1994- Datos sobre la vegetación de Andalucía. III. Series de vegetación caracterizadas por Quercus suber $\mathrm{L}$. Acta Bot. Malacitana 19: 169-185.

PÉREZ LATORRE, A.V., A. GALÁN DE MERA,

U. DEIL y B. CABEZUDO -1996- Fitogeografía y vegetación del sector Aljíbico (Cádiz-Málaga, España). Acta Bot. Malacitana 21: 241-267.

PÉREZ LATORRE, A. V., P. NAVAS, B. CABEZUDO y J. M. NIETO CALDERA - 1997 -

Los jarales de la clase Cisto-Lavanduletea en el sur de la Península Ibérica (Andalucía, España). Acta Bot. Malacitana 22:171-185.

PÉREZ LATORRE, A.V., P. NAVAS, D. NAVAS, Y. GIL y B. CABEZUDO -1998- Datos sobre la flora y vegetación de la Serranía de Ronda (Málaga, España). Acta Bot. Malacitana 23: 149-191.

PÉREZ LATORRE, A.V., A. GALÁN DE MERA y

B. CABEZUDO -1999- Propuesta de aproximación a la sintaxonomía de las formaciones de gimnospermas de la provincia Bética (España). Acta Bot. Malacitana 24: 257262.

PIZARRO, J. -1995- Contribución al estudio taxonómico de Ranunculus L. subgen. Batrachium (DC.) A. Gray (Ranunculaceae). Lazaroa 15: 21-113.
QUÉZEL, P., M, BARBÉRO, A. BENABID, R. LOISEL \& S. RIVAS MARTÍNEZ -1988Contribution à l'étude des groupements préforestiers et des matorrals rifains. Ecol. Medit. 14 (1/2): 77-122.

RAVEN, P.H. \& D.I. AXELROD -1974Angiosperms biogeography and past continental movements. Ann. Missouri Bot. Gard. 61: 539673.

RIVAS GODAY, S. -1957- Nuevos órdenes y alianzas de Helianthemetea annua Br.-Bl. Anales Inst. Bot. Cavanilles 15: 539-651.

RIVAS GODAY, S. -1964- Vegetación y flórula de la cuenca extremeña del Guadiana. Dip. Badajoz. Madrid.

RIVAS GODAY, S., E. FERNÁNDEZ GALIANO y S. RIVAS MARTÍNEZ -1965-Vegetación natural, in: Estudio agrobiológico de la provincia de Cádiz. INIA. Sevilla.

RIVAS MARTÍNEZ, S. -1987- Memoria y mapa de las series de vegetación de España. ICONA. Madrid.

RIVAS MARTÍNEZ, S., M. COSTA, S. CASTROVIEJO y E. VALDÉS -1980Vegetación de Doñana (Huelva, España). Lazaroa 2: 5-189.

RIVAS MARTÍNEZ, S., M. COSTA y J. IZCO 1986- Sintaxonomía de la clase Quercetea ilicis en el Mediterráneo occidental. Not. Fitosoc. 19 (2): 71-98.

RIVAS MARTÍNEZ, S., T. E. DÍAZ, J. A. F. PRIETO, J. LOIDI y A. PENAS -1984- La vegetación de la alta montaña cantábrica. Los Picos de Europa. Ed. Leonesas. León.

RIVAS MARTÍNEZ, S., F. FERNÁNDEZ GONZÁLEZ, D. SÁNCHEZ MATA y J.M. PIZARRO -1990 a- Vegetación de la Sierra de Guadarrama. Itinera Geobot. 4: 3-132.

RIVAS MARTÍNEZ, S., M. LOUSA, T. E. DÍAZ, F. FERNÁNDEZ-GONZÁLEZ y J.C. COSTA 1990 b- La vegetación del sur de Portugal (Sado, Alentejo y Algarve). Itinera Geobot. 3: 5-126. RIVAS MARTÍNEZ, S., J.C. BASCONES, T. E. DÍAZ, F. FERNÁNDEZ GONZÁLEZ y J. LOIDI -1991- Vegetación del Pirineo occidental y 
Navarra. Itinera Geobot. 5: 5-456.

ROTHMALER, W. -1954- Vegetationsstudien in Nordwestspanien. Vegetatio 5-6: 595-601.

SÁNCHEZ GARCÍA, I. y A. GALÁN DE MERA 1997- Fragmenta Chorologica Occidentalia (5927-5933). Anales Jard. Bot. Madrid 55 (1): 152.

SCHUHWERK, F. -1990- Relikte und Endemiten in Pflanzengesellschaften Bayerns- eine vorlaufige Ubersicht. Ber. Bayer. Bot. Ges. 61: 303-323.

SILVESTRE, S. -1987-Salix L., in: Flora Vascular de Andalucía Occidental I. Ed. Ketres. Barcelona.

VELASCO NEGUERUELA, A. - 1980- Notas sobre la vegetación de los enclaves hidroturbosos de los Montes de Toledo (España). Anales Jard. Bot. Madrid 37 (1): 125-128.

WOJTERSKI, T. W. -1985- Guide de l'excursion internationale de phytosociologie. Algerie du Nord. Ed. Institut National Agronomique. El Harrach.

WOJTERSKI, T. W. - 1990- Degradation stages of the oak forests in the area of Algiers. Vegetatio 87: 135-143.
ZERAIA, L. -1981- Essai d'interpretation comparative des donnees ecologiques phenologiques et de production subero-ligneuse dans les forets de chene-liege de Provence cristalline (France meridionale) et d'Algerie. Tesis doctoral. Universidad de Aix-Marseille.

Aceptado para su publicación en Septiembre de 1999

Dirección de los autores: A. V. PÉREZ LATORRE, P. NAVAS, D. NAVAS, Y. GIL y B. CABEZUDO: Departamento de Biología Vegetal (Botánica). Universidad de Málaga. Apdo. 59. E-29080 Málaga. E-mail: avperez@uma.es. A. GALÁN DE MERA: Laboratorio de Botánica. Universidad San PabloCEU. Apdo. 67. E-28660 Boadilla del Monte. Madrid. E-mail: agalmer@ceu.es. 